\title{
Equations for the estimation of strong ground motions from shallow crustal earthquakes using data from Europe and the Middle East: Horizontal peak ground acceleration and spectral acceleration
}

\author{
N. N. Ambraseys, J. Douglas, S. K. Sarma \\ Department of Civil and Environmental Engineering, \\ Imperial College London, \\ South Kensington Campus, \\ London, \\ SW7 2AZ, \\ United Kingdom. \\ Tel: +44 (0)20 75946059 \\ Fax: +44 (0)20 72252716 \\ Email:n.ambraseys@imperial.ac.uk
}

and

P. M. Smit currently at:

National Emergency Operations Centre,

CH-8044 Zürich,

Switzerland.

November 9, 2004

Running title: Equations for estimation of horizontal ground motions

Keywords: Strong ground motion estimation, attenuation relations, Europe, Middle East

Article type: General paper

*Now at: ARN/RIS; BRGM; 3 avenue C. Guillemin; BP 6009; 45060 Orléans Cedex 2; France. 


\begin{abstract}
This article presents equations for the estimation of horizontal strong ground motions caused by shallow crustal earthquakes with magnitudes $M_{w} \geq 5$ and distance to the surface projection of the fault less than $100 \mathrm{~km}$. These equations were derived by weighted regression analysis, used to remove observed magnitude-dependent variance, on a set of 595 strong-motion records recorded in Europe and the Middle East. Coefficients are included to model the effect of local site effects and faulting mechanism on the observed ground motions. The equations include coefficients to model the observed magnitudedependent decay rate. The main findings of this study are that: short-period ground motions from small and moderate magnitude earthquakes decay faster than the commonly assumed $1 / r$, the average effect of differing faulting mechanisms is not large and corresponds to factors between 0.8 (normal and odd) and 1.3 (thrust) with respect to strike-slip motions and that the average long-period amplification caused by soft soil deposits is about 2.6 over those on rock sites. Disappointingly the standard deviations associated with the derived equations are not significantly lower than those found in previous studies.
\end{abstract}

\title{
1 Introduction
}

This paper is the latest in a series of studies on the estimation of strong ground motions for engineering design using the strong-motion archive at Imperial College London. Previous studies include: Ambraseys \& Bommer (1991), Ambraseys et al. (1996), Ambraseys \& Simpson (1996) and Ambraseys \& Douglas (2003). There are a number of reasons for this new study. Firstly, the amount of strong-motion data available for this study is much greater than was available for previous studies; this enables more robust estimation of the regression coefficients. This new data has been collected in the framework of three projects by Imperial College and European partners which sought to improve the dissemination of highquality strong-motion data (Ambraseys et al., 2000, 2002, 2004a), see Ambraseys et al. (2004c) and Ambraseys et al. (2004b) for details. Also during these projects many of the associated parameters of the strong-motion data contained within the databank were reassessed. This reassessment should lead to an improvement in the reliability of the obtained equations. Previous equations have been derived using a limited quantity of data from the near source of large earthquakes. There is evidence that this has lead to equations that overpredict near-source ground motions for large earthquakes (Ambraseys \& Douglas, 2003). In addition previous equations did not consider the effect of source mechanism on ground motions although this has been shown to be an important factor (e.g. Bommer et al., 2003).

Only data from Europe and the Middle East has been used because it is felt that the data in the Imperial College London strong-motion archive is reasonably complete for moderate and large earthquakes 
that occurred in this region. Also this data has been carefully reviewed and the associated parameters appraised and reassessed during the three recent projects mentioned above. In addition, Douglas (2004b) has shown, using a method based on analysis of variance, that there seems to be a significant difference in ground motions between California and Europe; those in California seem to be slightly higher than those in Europe for the same magnitude and distance. Consequently, it has been decided to exclude data from California and elsewhere although it would increase the quantity of high-quality near-source data available. Chen \& Atkinson (2002) investigate the apparent source spectra in a number of regions, including California and Turkey, and conclude that they are similar. In view of this, data from different parts of the world could be used to validate the equations by examining residuals but this has not been attempted here.

It is not expected that the standard deviations of the equations presented here will be significantly less than those derived in previous studies because not many new independent variables are introduced but the median ground motions given a particular magnitude and distance are likely to be better defined because the equations are based on more and higher quality data than previous equations.

\section{Data used}

The choice of which records to include and which to exclude from the regression analysis is one of the most important decisions in deriving ground motion estimation equations. There is a balance to be struck between being not restrictive enough in the data used leading to unreliable coefficients and hence predictions due to errors and uncertainties in the independent and dependent parameters and too restrictive, which leads to a too small set of data and hence non-robust coefficients. An example of this is the problem of a lack of local site information. Ideally all stations would have a published local shear-wave velocity profile so the shear-wave velocity could be used directly in the equations. However, to restrict data selection to only stations with shear-wave velocity profiles would lead to a small, poorly distributed set of data and consequently the equations could be unreliable.

As mentioned above, data from all seismically active parts of Europe and the Middle East has been considered whereas data from outside this region has been excluded from consideration. One justification for combining data from different regions of Europe and the Middle East is that Douglas (2004a) has shown, through a method based on analysis of variance, that recorded strong ground motion in the Caucasus region, central Italy, Friuli, Greece and south Iceland shows little evidence for regional differences although this is based on a limited amount of data with low engineering significance. Whereas Douglas (2004b) does find some evidence for regional differences in ground motions between Europe and California. 


\subsection{Magnitude}

The magnitude scale used here is moment magnitude $\left(M_{w}\right)$, defined by Kanamori (1977) as: $M_{w}=$ $2 / 3 \log M_{0}-6$ where $M_{0}$ is the seismic moment in $\mathrm{Nm}$. Only earthquakes with available estimates of $M_{0}$ were used. Empirical conversion formulae from other magnitude scales, e.g. $M_{s}$ or $M_{L}$, to $M_{w}$ were not used because this conversion can increase the uncertainty in the magnitude estimates. The choice of $M_{w}$ means that only strong-motion records from moderate and large earthquakes can be used because $M_{w}$ is not routinely calculated for small earthquakes. Therefore, in order to have a good distribution of records at all magnitudes, only records from earthquakes with $M_{w} \geq 5$ were chosen. This also excludes records from small earthquakes that are unlikely to be of engineering significance.

\subsection{Source-to-site distance}

The distance to the surface projection of the fault (Joyner \& Boore, 1981), $d_{f}$, (also known as fault distance or Joyner-Boore distance) is used as the distance metric for this study. For earthquakes where the location of the causative fault has not been reported, mainly earthquakes with $M_{w} \leq 6$, epicentral distance, $d_{e}$ is used instead. For small earthquakes $d_{e}$ and $d_{f}$ are similar because of the small rupture planes of such earthquakes. Distance to the surface projection of the fault is used because it does not require an estimate of the depth of the earthquake, which can be associated with large error, unlike distance to the rupture or seismogenic distance (e.g. Campbell \& Bozorgnia, 2003). Also it has been found (Douglas, 2001) that distance to the rupture does not lead to a reduction in the standard deviation associated with ground motion prediction equations. Records from distances greater than $100 \mathrm{~km}$ have been excluded for a number of reasons. Firstly, this excludes records that are likely to be of low engineering significance due to their large source-to-site distances. Secondly, it reduces the bias that could be introduced by including records from distances greater than the distance to the first non-triggering station. Thirdly, it reduces the effect of differences in the anelastic decay in different regions of Europe and the Middle East. Lastly it means that the distribution of records with respect to magnitude and distance is reasonably uniform and reduces the correlation between magnitude and distance, which can cause problems in the regression stage.

\subsection{Faulting mechanism}

Only earthquakes with a published focal mechanism solution in terms of the trends and plunges of the $\mathrm{T}, \mathrm{B}$ and $\mathrm{P}$ axes have been included. In some previous studies, earthquakes have been classified using knowledge of regional tectonics or by assuming that aftershocks have the same mechanism as the mainshock. These assumptions will sometimes lead to incorrectly classifying earthquakes. For example, 
Ouyed et al. (1983) compute well-constrained focal mechanisms for 81 aftershocks of the thrust faulting 10th October $1980 \mathrm{El}$ Asnam (Algeria) earthquake using an array of 28 portable seismic stations. They find that aftershocks mainly displayed thrust mechanisms but a significant proportion showed strikeslip mechanisms and two aftershocks even had normal faulting. Lyon-Caen et al. (1988) compute focal mechanisms of 133 aftershocks of the normal faulting 13th September 1986 Kalamata (Greece) earthquake using records from 16 temporary stations. They find that although most aftershocks displayed normal mechanisms, some showed strike-slip faulting and some aftershocks in the footwall had reverse mechanisms. Consequently, if records from aftershocks with no published focal mechanisms, but which are assumed to have the same mechanism as the main shock, are used, this can increase the uncertainty in the computation of style-of-faulting coefficients (Bommer et al., 2003).

The method of Frohlich \& Apperson (1992) has been used to classify earthquakes by style of faulting. In this scheme, earthquakes with plunges of their $\mathrm{T}$ axis greater than $50^{\circ}$ are classified as thrust, those with plunges of their $\mathrm{B}$ axis or $\mathrm{P}$ axis greater than $60^{\circ}$ are classified as strike-slip or normal and all other earthquakes are classified as odd. Bommer et al. (2003) have investigated the different published schemes for classifying earthquakes with respect to mechanism and have found that the method proposed by Frohlich \& Apperson (1992) does not suffer from the ambiguities of methods based on the rake angle because it does not require knowledge of which plane is the main plane and which the auxiliary. Bommer et al. (2003) also show that the method of Frohlich \& Apperson (1992) classifies earthquakes similarly to that adopted by Boore et al. (1997), i.e. classifying earthquakes with rake angles within $30^{\circ}$ of the horizontal as strike-slip and other earthquakes into the correct dip-slip category.

Note that in this article the classification 'thrust' is used, following its use by Frohlich \& Apperson (1992), rather than the more commonly-used word 'reverse'.

\subsection{Building type}

In parts of Europe and the Middle East (e.g. Greece) it is common to install strong-motion instruments in the ground floors or basements of relatively large buildings. There is evidence that such buildings can influence the measured ground motions and therefore in other parts of the world with much strongmotion data, such as California, records from such buildings are excluded from analysis. Since goodquality data, with all the required independent variables, from Europe and the Middle East is already limited it was decided not to reject records from stations within the ground floors or basements of large buildings. 


\subsection{Local site conditions}

Only records from stations with known site classification in terms of categories proposed by Boore et al. (1993) have been used. Therefore four site classes have been used: very soft soil (L) $V_{s, 30} \leq$ $180 \mathrm{~ms}^{-1}$, soft soil (S) $180<V_{s, 30} \leq 360 \mathrm{~ms}^{-1}$, stiff soil (A) $360<V_{s, 30} \leq 750 \mathrm{~ms}^{-1}$ and rock (R) $V_{s, 30}>750 \mathrm{~ms}^{-1}$. For only 89 of the stations (out of 338), contributing 161 records (out of 595), do measured shear-wave velocity profiles exist and therefore the rest of the stations have been classified using descriptions of the local site conditions. Douglas (2003b) showed that the three-step regression method used by Ambraseys et al. (1996), which can handle stations without a site classification, can yield incorrect coefficients. Therefore sites with unknown site classifications had to be removed because they could not be handled by the regression method.

\subsection{Time-history quality}

All records from instruments that triggered late and hence missed the start of the motion are rejected, although Douglas (2003d) showed that they could give good spectral acceleration estimates for a limited period range if the duration recorded was sufficiently long. There is sufficient better quality data available not to require their use. Records with poor digitisation were also rejected.

\subsection{Processing technique}

The correction technique implemented in the Basic Strong-Motion Accelerogram Processing Software (BAP) software (Converse \& Brady, 1992) was used for the correction of all time-histories used in this study. This method consists of a correction for the instrument response and high-cut filtering, with a cosine transition from the roll-off frequency to the cut-off frequency, followed by low-cut bidirectional Butterworth filtering of the acceleration after padding the time-histories with zeros. The main problem with filtering strong-motion records is the selection of appropriate cut-off frequencies for the high-cut and, particularly, low-cut frequencies. For this study a method based on the estimated signal-to-noise ratio of each record was used.

Time-histories from digital instruments often include long enough pre-event portions to use as an estimate of the noise. Therefore for those records with pre-event portions the Fourier amplitude spectrum of this noise estimate was computed as was the Fourier amplitude spectrum of the rest of the signal and the ratio was calculated. The low cut-off frequency was chosen from this spectrum as the frequency at which the signal-to-noise ratio became less than two. The instrument corrected and filtered displacement time-history was then plotted and the cut-off frequency altered if the displacement trace did not look realistic, although often it did not need changing. 
It is more difficult to choose cut-offs for records from analogue instruments because estimates of the noise do not usually exist. Most films from analogue instruments feature a fixed trace, which record the position of light beams reflected from mirrors attached to the instrument case (Hudson, 1979). Since these traces do not record the ground motions, if they were digitised in the same way as the ground motion traces they would provide the best estimate of the recording and digitisation noise. Unfortunately, however, they are not often digitised or disseminated; only 123 records in the Imperial College strongmotion archive have an associated digitised fixed trace. For those time-histories that have such a digitised fixed trace they were used to select the low cut-off frequencies in the same way as was done with the records with pre-event portions.

For those records from analogue instruments and with no fixed traces the Fourier amplitude spectrum was examined following the suggestion of Zaré \& Bard (2002) that Fourier amplitudes that do not tend to zero at low- and high-frequencies are evidence for noise. The estimated cut-off frequencies were often varied if it was found that the displacement traces were not realistic or if it was found a less strict cut-off frequency could be used and still obtain a realistic displacement trace. Even with the technique adopted here for the selection of cut-off frequencies for records from analogue instruments with no digitised fixed traces there is still some subjectivity in the process.

After choosing the appropriate cut-off frequency for each component (two horizontal and one vertical) of a strong-motion record a single cut-off frequency was chosen for all three components for consistency. The choice of this single cut-off was difficult for some records because the generally lower amplitude vertical ground motions means that often the appropriate low frequency cut-off for vertical components is higher than for the corresponding horizontal components.

The high frequency filtering was accomplished using the commonly-chosen roll-off frequency of $23 \mathrm{~Hz}$ and a cut-off of $25 \mathrm{~Hz}$ for records from analogue instruments and a roll-off of $50 \mathrm{~Hz}$ and a cutoff of $100 \mathrm{~Hz}$ for records from digital instruments (e.g. Converse \& Brady, 1992). Since most digital instruments have natural frequencies of about $50 \mathrm{~Hz}$, and some of those with lower natural frequencies correct for the instrument response automatically, the effect of instrument correction is not large and therefore the requirement to apply a high-cut filter is less than for records from analogue instruments.

A number of the strong-motion records used by Ambraseys et al. (1996) for spectral accelerations up to $2 \mathrm{~s}$ do not seem to be of high enough quality to yield accurate SA estimates. Therefore it is likely that long period (>1s) estimates from the equations of Ambraseys et al. (1996) are affected by noise.

A few records from the strong-motion network of former Yugoslavia were only available in already corrected form and hence these corrected records were used for the periods within their passbands.

Only records within the passband of the filters (i.e. $1.25 f_{l}$ to $f_{h}$, where $f_{l}$ is the low cut-off frequency 
and $f_{h}$ is the high roll-off frequency) used were included in the regression analysis at period of interest. For example, a record with a low cut-off frequency, $f_{l}$, of $1 \mathrm{~Hz}$ is not used for frequencies less than $1.25 \mathrm{~Hz}$, i.e. for periods greater than $0.8 \mathrm{~s}$. Consequently the number of records used for the derivation of equations decreases as the period increases.

\subsection{Combination of horizontal components}

In this article, equations are derived for the prediction of the larger horizontal component of ground motions. So that these values are unbiased only records with both horizontal components are used. Also so that the same set of records can be used for deriving mutually consistent equations for the estimation of vertical ground motions only records with a vertical component are used.

\subsection{Summary of data selected}

In total, 595 triaxial strong-motion records from Europe and the Middle East were selected. These records come from 135 earthquakes and 338 different stations. Table 5 lists the strong-motion records used for this study. Table 1 shows the distribution of records selected in terms of local site class and mechanism. It shows that the distribution of records with respect to mechanism is reasonable uniform with between 15 and $32 \%$ of records in each category. The distribution with respect to site class is similarly uniform except for very soft soil for which there are only 11 records. Consequently records from this site class were incorporated into the soft soil category for the regression analysis.

Figure 1 shows the distribution of all selected records with respect to magnitude, distance, local site class and mechanism. It shows that, as expected, there is a lack of data from large $\left(M_{w}>6.5\right)$ earthquakes particularly from normal (due to fault segmentation) and strike-slip earthquakes. All distances ranges are well represented.

Figure 2 shows the number of records available for regression at each period. It shows that at long periods there are fewer records available. The number of records available starts decreasing rapidly at about $0.8 \mathrm{~s}$ and for periods greater than $4 \mathrm{~s}$ there are few records available. It was decided to only conduct regression analysis for periods up to $2.5 \mathrm{~s}$, where the number of records available is 207 ( $35 \%$ of the total number of records), because for longer periods there are too few records to obtain stable results. Figure 3 shows the distribution of records with respect to the independent variables (magnitude, distance, local site categories and style-of-faulting) at $2.5 \mathrm{~s}$, which can be compared to Figure 1 . The noise present in strong-motion records, particularly those from analogue instruments, means that larger amplitude ground motions (i.e. those from close to the source or from large earthquakes) are better represented in the set in the long period range $(T>1 \mathrm{~s})$. 
The majority of records come from four countries: Italy, 174 (29\%); Turkey, 128 (22\%); Greece, $112(19 \%)$ and Iceland, 69 (12\%). Other countries providing records are: Albania (1 record), Algeria (3), Armenia (7), Bosnia \& Herzegovina (4), Croatia (1), Cyprus (4), Georgia (14), Iran (17), Israel (5), Macedonia (1), Portugal (4), Serbia \& Montenegro (24), Slovenia (15), Spain (6), Syria (5) and Uzbekistan (1). For some of these countries (e.g. Iran) there is much strong-motion data but unfortunately information on the local site conditions at the strong-motion station is missing and therefore it was not used here.

The relatively strict criteria adopted here mean that the number of selected records (595) is only about $50 \%$ larger than used by Ambraseys et al. (1996) although the total number of recordings from earthquakes with $M_{s}>4$ from Europe and the Middle East has more than doubled in the last ten years (Ambraseys et al., 2004c).

\section{Regression technique}

The algorithm for the one-stage maximum-likelihood method proposed by Joyner \& Boore (1993) was used to derive the equations because it accounts for the correlation between ground motion from the same earthquake whereas the ordinary one-stage method does not. The two-stage maximum-likelihood method was not used because it underestimates $\sigma$ for sets with many singly-recorded earthquakes (Spudich et al., 1999). This set has 39 singly-recorded earthquakes out of 135.

A method that accounts for the correlation between ground motions from the same site (e.g. Chen \& Tsai, 2002) was not tried since there are records from 338 different stations and consequently it is likely that the method would not give an accurate estimate of the site-to-site variability since there are too few sites that have recorded multiple earthquakes. In fact, 196 stations only contribute a single record. Chen $\&$ Tsai (2002) validated their method using a set of 424 records from only 45 different stations therefore there were enough stations that have recorded multiple earthquakes.

The method introduced by Rhoades (1997), which allows for uncertainty in the magnitude determinations, was not used because all the magnitude determinations are thought to be associated with similar uncertainties since they are all $M_{w}$ estimates from published $M_{0}$ values. Rhoades (1997) shows that even when the uncertainties in magnitude estimates varies the derived coefficients are similar to those derived assuming the magnitudes are determined to the same accuracy.

In fact, since there is little correlation (correlation coefficient of 0.23 between $M_{w}$ and distance for the PGA data and 0.22 for the data for $2.5 \mathrm{~s}$ ) between magnitude and distance in the set of records used the ordinary one-stage method yields similar coefficients as the one-stage maximum-likelihood method. 


\subsection{Pure error analysis}

To choose the correct regression method it is important to know the variability in the ground motions used to derive the equations. To obtain a true estimate of this variability the concept of pure error (Draper \& Smith, 1981, pp. 33-42) is used here, as was previously used by Douglas \& Smit (2001). This technique was used to investigate whether the standard logarithmic transformation is justified; the magnitude-dependence of the scatter; and to assess the lower limit on the equations' standard deviations using only magnitude and distance.

\subsubsection{Logarithmic transformation}

All previously published attenuation relations, except those presented by Bolt \& Abrahamson (1982) and Brillinger \& Preisler (1984), have assumed the errors are proportional to the size of the ground motion even if this is not explicitly stated and hence have taken the logarithm of the recorded ground motion, see for example Draper \& Smith (1981, pp. 237-238). Donovan \& Bornstein (1978), Campbell (1997) and others have found evidence, once the regression analysis has been preformed, that the uncertainty depends on the size of the ground motion even after taking the logarithm. If this dependence of uncertainty on the amplitude of the ground motion is significant then it means that logarithmic transformation is not correct (Draper \& Smith, 1981, pp. 237-238).

As was done by Douglas \& Smit (2001), the dataspace was divided into intervals of 0.2 magnitude units [this analysis uses $M_{w}$ unlike Douglas \& Smit (2001) who used $M_{s}$ ] by $2 \mathrm{~km}$ within which the mean, $\eta$, and unbiased standard deviation, $\sigma$, of the untransformed ground motion (PGA and SA) were calculated using the maximum-likelihood method (Spudich et al., 1999, p. 1170). For PGA and each period of SA, the coefficient of variation, $V=100 \sigma / \eta$, was plotted against $\eta$. If $\sigma$ was proportional to $\eta$ then these graphs should show no trend with increasing ground motion. A linear equation $V=\alpha+\beta \eta$ was fitted to each of these graphs. The $95 \%$ confidence intervals of $\alpha$ and $\beta$ were computed along with the standard deviation of the equation as were the computed and critical $t$ value for $\beta=0$ for the $5 \%$ significance level. It was found that $\beta$ is not significantly different than zero for PGA and for almost all of the periods investigated because computed $t$ is not bigger than critical $t$. Thus the null hypothesis that the scatter associated with measured ground motion is proportional to the amplitude of the ground motion cannot be rejected, so the logarithmic transformation is justified. For nine periods ( $0.26,0.28$ and $0.44-0.65 \mathrm{~s}) \beta$ was found to be significantly different than zero therefore suggesting that the logarithmic transformation is not justified for those periods. However, since for neighbouring periods the logarithmic transformation is justified it was decided to apply the logarithmic transformation for the entire period range. 


\subsubsection{Dependence of scatter on magnitude}

Next the dependence of the coefficient of variation on magnitude was investigated. Unlike in the study of Douglas \& Smit (2001), this hypothesis was tested by plotting $\sigma$ computed using the logarithms of the ground motions [rather than $V$ as was done by Douglas \& Smit (2001)] against mean $M_{w}$ of the interval. The fitted line coefficients for PGA and for almost all short periods show that there is a decrease in error with increasing $M_{w}$ and the $t$ test shows that the hypothesis that $\sigma$ is independent of $M_{w}$ can be rejected at the $5 \%$ significance level. An example of the observed dependence of $\sigma$ on $M_{w}$ and the fitted line is shown in Figure 4. For all periods greater than $0.95 \mathrm{~s}$ the hypothesis that $\sigma$ is independent of $M_{w}$ cannot be rejected at the $5 \%$ significance level. The magnitude dependence of the scatter of short-period ground motions suggests that the characteristic of the earthquakes causing the magnitude-dependence does not hold for longer-periods. However, the distribution of data begins to change at about $0.95 \mathrm{~s}$ due to the filter cut-offs used for the strong-motion records. There are less records in the set for long periods and there are more records from large magnitude earthquakes as a proportion of the total. Therefore the lack of magnitude dependence in $\sigma$ for longer periods may be due to this and not a characteristic of the earthquakes. The reader is referred to Youngs et al. (1995) for a discussion of possible reasons for an observed magnitude-dependent scatter.

\subsubsection{Lower limit on standard deviations possible using only magnitude and distance}

Pure error analysis can be used to assess the lower limit of the standard deviation achievable by using only magnitude and distance in the ground motion estimation equation. For each period, the mean standard deviation of the interval standard deviations was computed. These provide an estimate of this lower limit. For this study they vary between 0.23 and 0.32 , therefore the derived equations cannot be expected to yield overall standard deviations less than these values.

\subsection{Weighting}

When there is a variation in the variability of the dependent variable Draper \& Smith (1981, pp. 108-116) describe how weighted regression should be performed. As has been demonstrated there is a dependence of $\sigma$ on $M_{w}$ and consequently this should be incorporated into the regression analysis.

For simplicity, weighting was based on a linear function relating $\sigma$ and $M_{w}$ for periods shorter than $0.95 \mathrm{~s}$. For longer periods no weighting was performed because the gradient of the best-fit line relating $\sigma$ and $M_{w}$ was not significantly different than zero at the $5 \%$ level. These weighting functions were the reciprocals of the $\sigma$ s derived using the best-fit lines found above. This is slightly different than the models of the dependence of $\sigma$ on $M_{w}$ proposed by Youngs et al. (1995), who use a constant $\sigma$ for 
$M_{w} \leq 5$ and for $M_{w} \geq 7$ and a linear dependence for $M_{w}$ in between, and Campbell \& Bozorgnia (2003) who propose a constant $\sigma$ for $M_{w}>7.4$. Since there is no data from $M_{w}<5$ and little from $M_{w}>7$ it is not possible to adopt a more complex form for the dependence of $\sigma$ on $M_{w}$.

The effect of this weighting is to give more emphasis to records from large magnitude earthquakes since ground motions from large earthquakes are less variable than those from small earthquakes.

After the regression analysis is performed the computed standard deviations have to be multiplied by the reciprocal of the weighting function applied (i.e. the linear relation between $\sigma$ and $M_{w}$ derived using the pure error analysis) in order to produce standard deviations applicable for the estimation of different percentiles of ground motion .

\section{Functional form}

There is evidence that the decay rate of ground motions is dependent on the magnitude of the causative earthquake. Ground motions from large earthquakes decay slower than those from small earthquakes and the decay rate of small earthquakes is faster than the commonly assumed -1 (e.g. Douglas, 2003c). For example, Atkinson \& Boore (2003) adopt a magnitude-dependent far-field decay rate for their equations for subduction zone regions. Possible causes for geometrical decay rates lower than -1 are discussed by Frankel et al. (1990, pp. 17455-17456). They compute synthetic SH seismograms for a typical eastern North American crust and find a decay rate of -1.5 for hypocentral distances between 15 and $90 \mathrm{~km}$. They note that this steep decay is caused by the reflection of the upgoing direct $S$ wave off the underside of the layer interfaces above the source. As hypocentral distance increases, the upgoing ray impinges at a more shallow angle on the interfaces, reflecting increasing amounts of energy downwards and reducing the energy transmitted to the surface. For crustal structures without interfaces above the source they find $1 / r$ decay. For moderate and large earthquakes the source can no longer be considered a point source and therefore the size of the fault will mean the decay rate will be less than for earthquakes with small fault planes and this will compensate for the faster than -1 decay rate.

To investigate the dependence of decay rate on magnitude, records from the ten best-recorded earthquakes within the selected set were used. The best-recorded of these earthquakes has 26 records and the least-well recorded has 13 records. The PGA data from each of these earthquakes were fitted individually assuming a functional form: $\log y=a_{1}+a_{2} \log \sqrt{d^{2}+a_{3}^{2}}$, i.e. geometric decay with a far-field decay rate of $a_{2}$. Figure 5 shows the far-field decay rates plotted against magnitude for these ten earthquakes and also the best-fit line assuming a linear dependence of decay rate on $M_{w}$. This figure shows that the data used for this study supports a decay rate that varies with magnitude, where ground motions from small earthquakes decay more rapidly than ground motions from large earthquakes. Since there is limited 
data a linear dependence between decay rate and $M_{w}$ was assumed.

There is growing evidence that the scaling of ground motions with magnitude changes for earthquakes that rupture the entire seismogenic zone, both theoretical (Fukushima, 1996; Douglas, 2002) and observational (e.g. Sadigh et al., 1997). This is commonly included within ground motion estimation equations through the use of a term with a quadratic dependence on magnitude (e.g. Boore et al., 1997). The inclusion of such a term was tried in this study, however, it was found that the coefficient was not significant at the $5 \%$ significance level and so it was dropped.

The data used is not adequate to simultaneously determine negative geometric and anelastic decay coefficients. Therefore it was assumed that the decay attributable to anelastic decay is incorporated into the geometric decay coefficient. It was possible to determine a negative anelastic coefficient by constraining the geometric decay coefficient to -1 but, as is shown above, there is evidence that the decay of ground motions from small earthquakes is faster than that from large earthquakes which would not be modelled by constraining the geometric decay to -1 .

The functional form adopted was:

$$
\log y=a_{1}+a_{2} M_{w}+\left(a_{3}+a_{4} M_{w}\right) \log \sqrt{d^{2}+a_{5}^{2}}+a_{6} S_{S}+a_{7} S_{A}+a_{8} F_{N}+a_{9} F_{T}+a_{10} F_{O}
$$

where $S_{S}=1$ for soft soil sites and 0 otherwise, $S_{A}=1$ for stiff soil sites and 0 otherwise, $F_{N}=1$ for normal faulting earthquakes and 0 otherwise, $F_{T}=1$ for thrust faulting earthquakes and 0 otherwise and $F_{O}=1$ for odd faulting earthquakes and 0 otherwise.

Firstly the regression analysis was performed with all terms. At certain periods different coefficients were significantly different than zero. In order to improve the accuracy of those terms that are significant the analysis was repeated constraining the non-significant terms to zero. This process has a minor impact on the computed standard deviations. When the results from this second analysis were graphed it was noticed that the estimated response spectral accelerations, particularly those for large magnitudes, showed considerable variation between neighbouring periods since the functional form changed because of the dropping of non-significant coefficients. In view of this, it was decided to report the coefficients derived by including all of terms in the equation even if some were not significant.

There is evidence that the effect of faulting mechanism on ground motions is dependent on sourceto-site distance (Bommer et al., 2003, Figure 9) and also that nonlinear effects should cause local site amplifications to be dependent on magnitude and distance (e.g. Abrahamson \& Silva, 1997). To model both of these possible effects would require the inclusion of additional coefficients within the equation. Due to the limited data it was felt that it would be unlikely that realistic values of these additional coefficients could be obtained due to trade-offs between the terms and therefore these effects are not 
modelled.

\section{Results}

Equations were derived for the estimation of peak ground acceleration and spectral acceleration for $5 \%$ critical damping ratio and for 61 periods between $0.05 \mathrm{~s}(20 \mathrm{~Hz})$ and $2.5 \mathrm{~s}(0.4 \mathrm{~Hz})$ using the Caltech spacing (Brady et al., 1973). The coefficients, associated standard deviations and the number of records, earthquakes and stations used to derive each equation are reported in Table 2. The non-significant coefficients are highlighted in Table 2 although these coefficients should not be dropped when computing ground motion estimates.

Smoothing of the derived coefficients may reduce the period-to-period variability caused by the different distributions of records with respect to the independent variables. Therefore its use may help improve the reliability of the long-period estimates, which are based on less data than the short period estimates. However, since for periods longer than $0.90 \mathrm{~s}$ unweighted regression was performed the derived coefficients show a large change between 0.90 and $0.95 \mathrm{~s}$, smoothing was not attempted since it would be difficult to fit a simple function through the short and long period coefficients.

Figure 6 shows the decay of estimated peak ground acceleration and spectral acceleration at $1 \mathrm{~s}$ natural period with distance for $M_{w}=5,6$ and 7 strike-slip earthquakes at a rock site. This figure shows the effect of the magnitude dependent decay rate for short period ground motions (e.g. peak ground acceleration) and magnitude independent decay rate for long period ground motions (e.g. spectral acceleration at $1 \mathrm{~s})$.

Figure 7 shows the estimated response spectra for $M_{w}=5,6$ and 7 strike-slip earthquakes at 10 and at $100 \mathrm{~km}$ at a rock site. This figure shows the effect of the magnitude-dependent decay rate because at near-source distances the effect of magnitude on the spectral accelerations is much less than at large source-to-site distances.

\subsection{Effect of faulting mechanism}

Figure 8 shows a comparison of the ratio of spectral accelerations from thrust/reverse faulting earthquakes to those from strike-slip faulting earthquakes, $F_{\mathrm{R}: \mathrm{SS}}$, derived in this study to those in the literature. $F_{\mathrm{R}: S S}$ derived here is only significantly different than one at the $5 \%$ level for the period range $0.28-0.60 \mathrm{~s}$ and at $0.75 \mathrm{~s}$. Figure 8 shows that the factor derived here matches closely to those derived previously particularly that of Boore et al. (1997) and corresponds to a maximum factor of about 1.3. The match with the factor derived by Boore et al. (1997) could be due to the close match between a style-of-faulting classification using the criteria of Frohlich \& Apperson (1992) and that used by Boore 
et al. (1997) who use $30^{\circ}$ as their critical rake angle. Similarly the higher factor derived by Campbell \& Bozorgnia (2003) could be due to their use of $22.5^{\circ}$ as the critical rake angle. For a discussion of the effect of the mechanism classification scheme on the derived style-of-faulting factors see Bommer et al. (2003).

Figure 9 shows the derived ratios of spectral accelerations caused by normal faulting earthquakes and from earthquakes whose mechanism is defined as odd to those from strike-slip earthquakes, $F_{\mathrm{N}: \mathrm{SS}}$ and $F_{\mathrm{O}: \mathrm{SS}}$ respectively. $F_{\mathrm{N}: \mathrm{SS}}$ is only significantly different than one at the $5 \%$ level for periods shorter than $0.12 \mathrm{~s}$ and $F_{\mathrm{O}: \mathrm{SS}}$ is only significantly different than one at the $5 \%$ level for periods $0.95 \mathrm{~s}$ and $1.5-2.2 \mathrm{~s}$. Figure 9 shows that there is evidence for slightly smaller short period ground motions from normal faulting earthquakes than strike-slip earthquakes (factor of about 0.80 ) but that for most periods the amplitudes of ground motions from normal and strike-slip earthquakes are similar. These findings are in agreement with the factors derived by and the discussion in Bommer et al. (2003), who assess evidence given in the literature on the difference between normal faulting ground motions and strikeslip motions and conclude that $F_{\mathrm{N}: \mathrm{SS}}$ is between 0.90 and one. Figure 9 also shows that long period spectral accelerations from earthquakes classified as odd are lower (factor of about 0.75 ) than those from strike-slip earthquakes.

\subsection{Effect of local site conditions}

Figure 10 shows a comparison between the local site amplification factors for soft soil sites and stiff soil sites derived in this study and those derived in some previous studies. $F_{\text {softsoil:rock }}$ is significant for almost all periods and gives peak amplification over rock motions of about 2.6 at about $2 \mathrm{~s}$, which is similar to the amplifications found by Campbell \& Bozorgnia (2003) but is much higher than the amplifications derived by other studies. $F_{\text {stiffsoil:rock }}$ is significant for periods longer than $0.19 \mathrm{~s}$ and reaches a maximum amplification of about 1.7 at $1.5 \mathrm{~s}$, which is similar to the amplifications found by Boore et al. (1997) but is lower than those by Campbell \& Bozorgnia (2003) and higher than those by Ambraseys et al. (1996) and Lussou et al. (2001).

\subsection{Comparisons to previous equations}

The estimated ground motions from the equations derived in this study were compared with Ambraseys et al. (1996), Boore et al. (1997), Spudich et al. (1999) and Campbell \& Bozorgnia (2003). Boore et al. (1997) and Spudich et al. (1999) are derived using the same magnitude scale and distance metric as used here and consequently no conversions needed to be applied. Ambraseys et al. (1996) used $M_{s}$ rather than $M_{w}$, hence a conversion needs to be undertaken; this was done using the equations of Ekström \& 
Dziewonski (1988). Campbell \& Bozorgnia (2003) use seismogenic distance rather than distance to the surface projection of the fault and consequently a conversion needs to be applied. The comparison was made for a vertical strike-slip fault with a non-seismogenic layer of $3 \mathrm{~km}$ thickness at the top of the crust.

Figure 11 shows that the estimated response spectra from the equations derived here match the estimated response spectra given by the equations of Ambraseys et al. (1996) for moderate and large magnitudes at all distances covered by the equations. Whereas the estimated response spectra given by the new equations for small magnitudes are below the spectra given by Ambraseys et al. (1996) for short distances and above for long distances. This is because the equations of Ambraseys et al. (1996) assumed a magnitude-independent decay rate that, due to the distribution of data (most records from long distances are from moderate and large magnitude earthquakes), corresponds to the decay rate of large earthquakes. The equations presented here predict a much faster decay rate for small earthquakes $(-1.615$ compared to -0.922 for PGA from a $M_{w}=5$ earthquake) and consequently the estimated ground motions from small earthquakes at large distances are much lower than those predicted by Ambraseys et al. (1996). This suggests that small earthquakes at large distances are less important than would be assumed by using the equations of Ambraseys et al. (1996).

A comparison with the estimated ground motions from the equations of Boore et al. (1997) shows similar features to those shown in Figure 11 for similar reasons. In particular, Boore et al. (1997) use little data from earthquakes with $M_{w}<6$ for deriving their response spectral ordinate equations and consequently their equations may not be valid for small magnitude earthquakes.

A comparison with the predictions using the equations of Spudich et al. (1999) again show similar features to the comparison with predictions using the equations of Ambraseys et al. (1996). The ground motions from Spudich et al. (1999) are usually slightly below those given by the equations derived here since Spudich et al. (1999) derive their equations for extensional regimes, which they show to have significantly lower ground motions than other regions, whereas in this study data from compressional and extensional regimes have been combined.

Figure 12 shows that the ground motion estimates from the equations presented here match those given by the equations of Campbell \& Bozorgnia (2003) for the magnitudes and distances considered here except at large distances from small earthquakes, again since Campbell \& Bozorgnia (2003) had little data from such magnitudes and distances in their construction set.

\section{Residuals}

Table 3 gives the median amplification factor (computed by taking the anti-logarithm of the mean residuals for that station) over the median ground motion estimates for the strong-motion stations that have 
recorded five or more earthquakes. It shows that for some stations there is a considerable local site amplification. For example, the stations at Nocera Umbra show an amplification factor of up to 4.23 at a natural period of $0.2 \mathrm{~s}$. This has been comprehensively studied recently and it has been shown to be due to the sub-vertical fault and to highly fractured rocks that amplify high frequency motions (e.g. Marra et al., 2000). Another station that shows considerable amplification is Gubbio-Piana, which has a median amplification of 8.16 at a natural period of $2 \mathrm{~s}$. This station is in a sedimentary basin, which generates surface waves that cause high long-period ground motions. One station that shows considerably lower than expected short period spectral accelerations is Yarimca-Petkim. The reason for this is currently unknown.

Table 4 gives the median amplification factor for the ten best recorded earthquakes. It shows that most earthquakes do not show a significant deviation from the median (most factors are about one). There is evidence that the ground motions from the Umbria Marche sequence are higher than would be expected for such sized earthquakes. Also this analysis suggests that ground motions recorded during the Düzce (12th November 1999) earthquake are lower than would be expected from such an earthquake. The fault length of this earthquake was much shorter than would be expected for a earthquake of $M_{w}=7.2$. Utkucu et al. (2003) estimate the rupture plane of this earthquake was $40 \times 20 \mathrm{~km}$ and that the rupture was bilateral. The equation of Wells \& Coppersmith (1994) for subsurface rupture length for all earthquakes gives an estimated median rupture length for an $M_{w}=7.2$ earthquake of $64 \mathrm{~km}$ and a 16 th percentile length of $44 \mathrm{~km}$. The combination of a bilateral rupture and a short rupture estimate may be the cause of lower than expected ground motions. Somerville (2003) suggests that buried ruptures may generate larger ground motions to those that ruptured the surface, such as the Kocaeli and Düzce earthquakes, which may explain the lower ground motions observed.

The residuals have been normalised by dividing by the computed standard deviation. This has been done to aid understanding of the graphs due to the use of weighted regression, which requires that the residuals and the independent variables are multiplied by the square-root of their weights.

Figure 13 shows graphs of the normalised weighted residuals against $M_{w}$ and distance for PGA and spectral acceleration at $1 \mathrm{~s}$ natural period. Figure 13(a) shows that the magnitude-dependent weighting introduced into the regression analysis removes the normally observed magnitude-dependence of the residuals. All the residual plots examined show no obvious dependence of the scatter on magnitude or distance. The apparent constant bias in the residual plot for spectral acceleration at $1 \mathrm{~s}$ natural period is common to all graphs of residuals for long period motions. It is caused by the use of the maximum-likelihood regression method since it splits the error into intra- and inter-earthquake portions and therefore within the regression analysis records from well-recorded earthquakes are weighted differ- 
ently than those from less well recorded earthquakes because ground motions from the same earthquake are assumed to be correlated. Therefore the observation of a zero mean residual when ordinary regression is used no longer holds for maximum-likelihood regression.

\section{Discussion and conclusions}

For moderate and large earthquakes $\left(M_{w}>6\right)$ predicted PGA and SA from the equations presented here are not much different than those predicted by other recent ground motion estimation equations for shallow crustal earthquakes, such as Ambraseys et al. (1996), Boore et al. (1997), Spudich et al. (1999) and Campbell \& Bozorgnia (2003). This shows that estimates of ground motions for such earthquakes are well-defined and estimates are stable when different sets of data are used. Previous equations have usually been derived using sets of records with a lack of data from the intermediate and far-field of small earthquakes $\left(M_{w}<6\right)$ therefore the equations have not been well-constrained for such magnitudes and distances. The equations presented here, are constrained by data from such magnitudes and distances and the differing decay rates from small and large earthquakes are modelled through a magnitude-dependent decay rate. A comparison of the estimated ground motions from small earthquakes at large distances shows that previous equations predict significantly higher motions than those predicted by the equations presented here. This could have an impact on seismic hazard assessments that may have over-estimated the amplitude of ground motions from small earthquakes at large distances.

The amplification of long period ground motions at soft soil sites over the ground motions at rock sites predicted by the equations presented here are much larger than many previous studies have found. One possible reason for this is that the set of data used here has more records from the intermediateand far-field of small and moderate earthquakes than previous studies had in their sets. This means that possible non-linear site effects at soft soil sites are less common than in previous equations. However, estimated short period amplifications, which are more likely to be affected by non-linear soil response, from this study closely match those found in previous studies and therefore it is unlikely that non-linear effects are significantly lowering the long period amplifications obtained in previous studies.

In Europe and the Middle East, earthquakes showing different styles of faulting (thrust, strike-slip, normal and odd) can occur within reasonably short distances. For example, in western Greece earthquakes of all four mechanisms occur within a region of only a couple of degrees square (e.g. Pondrelli et al., 2002). Therefore, the effect of these four different mechanisms on recorded ground motions was investigated here as has been done previously in western America for the differences between ground motions from strike-slip and reverse earthquakes (e.g. Abrahamson \& Silva, 1997; Boore et al., 1997; Campbell \& Bozorgnia, 2003; Sadigh et al., 1997) and in Europe and the Middle East for the differences 
between ground motions from strike-slip, normal and reverse earthquakes (Bommer et al., 2003). It is found that the ratio of ground motions from thrust/reverse faulting earthquakes to ground motions from strike-slip faulting earthquakes closely matches previous estimates, particularly those from Boore et al. (1997) and corresponds to a maximum factor of about 1.3 at a period of $0.5 \mathrm{~s}$. This study has found that short-period ground motions from normal faulting earthquakes are slightly less than those from strikeslip earthquakes (factor of about 0.75 at $0.1 \mathrm{~s}$ ), which confirms previous suggestions (Bommer et al., 2003) on the ratio of normal to strike-slip ground motions. Also it is found that long-period ground motions from odd faulting earthquakes are slightly less than those from strike-slip earthquakes (factor of about 0.7 at $2 \mathrm{~s}$ ). Therefore, there is an observed effect of faulting mechanism on ground motions but this effect is not as large as the effect of local site conditions. However, in the near-source region it is likely that the effect of mechanism is greater, due to the proximity to the source, and that of local site conditions is less, due to non-linear soil response.

This study has confirmed the observation of a number of studies (e.g. Youngs et al., 1995; Campbell \& Bozorgnia, 2003) that ground motions from small earthquakes are more variable (in relative terms) than those from large earthquakes. This magnitude-dependence of the scatter has been shown to be significant at the $5 \%$ level for short periods (up to $0.90 \mathrm{~s}$ ) but not significant for longer periods. This suggests that the physical characteristic of earthquakes causing this magnitude-dependence is a shortperiod phenomenon.

The investigation of pure error reported here shows that the standard deviations associated with the derived equations is about the lowest that can be obtained without using more additional variables. A more complex functional form will not lead to a reduction in the associated standard deviation although it may provide a better estimate of the median ground motions.

One interesting and disappointing finding is that the associated standard deviations of the equations presented here do not show lower standard deviations than the equations presented by Ambraseys et al. (1996), which use a similar set of data. For example, for PGA the equation presented by Ambraseys et al. (1996) has an associated standard deviation of 0.25 whereas the equation presented here has a intra-earthquake standard deviation of $0.665-0.065 M_{w}$ and an inter-earthquake standard deviation of $0.222-0.022 M_{w}$, which corresponds to an overall standard deviation varying from 0.36 for an $M_{w}=5$ earthquake to 0.19 for an $M_{w}=7.5$ earthquake. This lack of improvement is surprising because the effect of different faulting mechanisms has been included into the equations and because the independent parameters of many of the records used by Ambraseys et al. (1996) have been reassessed following recent investigations. There are a few reasons why there is a lack of improvement in the accuracy of an individual estimate of ground motion by using these new equations over the equations published by 
Ambraseys et al. (1996). Firstly Ambraseys et al. (1996) adopted magnitude-independent standard deviations whereas this study adopted a magnitude-dependent error. Consequently the standard deviations reported by Ambraseys et al. (1996) correspond to the overall scatter, probably for a magnitude in the middle of their set of data, e.g. about $M_{w}=6.5$. Examining the standard deviations for the equations reported here for $M_{w}=6.5$ gives comparable standard deviations to those reported by Ambraseys et al. (1996). Secondly, the set of data used by Ambraseys et al. (1996) shows the commonly-observed distribution of records with respect to magnitude and distance, i.e. records from small earthquakes only are recorded at short distances whereas those from larger magnitudes are recorded at all distances. This is due to the triggering of analogue instruments. The set of records used here show a much more uniform distribution with respect to magnitude and distance, with records from all distances from small and large earthquakes. Consequently there is a higher proportion of data from large distances, where regional differences in crustal structure and attenuation become important, used in this study and therefore the large variability in these far-field records contribute to the scatter. Thirdly, although extra coefficients were included in the equation to model the differences between ground motions from earthquakes with different styles of faulting many of the derived coefficients are not significant (particularly those for normal and odd faulting earthquakes) and consequently they could probably be removed without increasing the standard deviation.

Analysis of the residuals from stations and earthquakes with a large number of associated records shows that for some stations (e.g. Gubbio Piana) and earthquakes (e.g. Düzce) there is consistent large under- or over-prediction of the ground motions. An investigation into the causes of these consistent features should lead to highlighting the characteristics of the stations and the earthquakes that need to be included in future ground motion estimation equations.

\section{Acknowledgements}

This study was funded by EPSRC grant no. GR/52114/01(P); we thank them for their support. We would also like to thank the European Commission for providing financial support for the original CD ROM and Internet site projects through the $4^{\text {th }}$ Framework Programme (contract ENV4-CT97-0397) and the $5^{\text {th }}$ Framework Programme (contract EVR1-CT-1999-40008). We are indebted to numerous individuals, organizations and agencies that generously contributed strong-motion records. Please see the Acknowledgements page of ISESD for details. In addition, we are thank Atilla Ansal and two anonymous reviewers whose valuable suggestions lead to significant improvements to this article. 


\section{Addendum}

The decision not to use data from western North America for the derivation of the equations presented in this article was, in part, based on the finding of Douglas (2004b) that ground motions in Europe and California seem to be significantly different. A recent earthquake that provides a further test of this hypothesis is the Parkfield (28th September 2004) earthquake that was well recorded at all distances from the source. In Figure 14 the recorded PGAs from all 79 free-field strong-motion stations reported in the Internet Quick Report of the California Integrated Seismic Network for this earthquake are compared with the predicted median PGAs from the equation presented in this article and also those predicted by the equation of Boore et al. (1997). This figure shows that the observed Parkfield PGA values are well predicted by the equation presented here for all distances, even when the presented equation is extrapolated to greater distances than its strict applicability. The figure also shows that the equation of Boore et al. (1997) overpredicts the observed PGAs at large distances for this earthquake, as is also noted on the website of California Integrated Seismic Network. Therefore, although this is a limited test using data from one earthquake, the differences in ground motions between western North America and Europe perhaps are not as significant as would be thought given the analysis of Douglas (2004b).

\section{References}

Abrahamson, N. A., \& Litehiser, J. J. 1989. Attenuation of vertical peak acceleration. Bulletin of the Seismological Society of America, 79(3), 549-580.

Abrahamson, N. A., \& Silva, W. J. 1997. Empirical response spectral attenuation relations for shallow crustal earthquakes. Seismological Research Letters, 68(1), 94-127.

Ambraseys, N., Smit, P., Berardi, R., Rinaldis, D., Cotton, F., \& Berge, C. 2000. Dissemination of European Strong-Motion Data. CD-ROM collection. European Commission, Directorate-General XII, Environmental and Climate Programme, ENV4-CT97-0397, Brussels, Belgium.

Ambraseys, N., Smit, P., Sigbjörnsson, R., Suhadolc, P., \& Margaris, B. 2002. Internet-Site for European Strong-Motion Data. http: //www. isesd.cv.ic.ac.uk. European Commission, DirectorateGeneral XII, Environmental and Climate Programme, Brussels, Belgium.

Ambraseys, N. N., \& Bommer, J. J. 1991. The attenuation of ground accelerations in Europe. Earthquake Engineering and Structural Dynamics, 20(12), 1179-1202.

Ambraseys, N. N., \& Douglas, J. 2003. Near-field horizontal and vertical earthquake ground motions. Soil Dynamics and Earthquake Engineering, 23(1), 1-18. 
Ambraseys, N. N., \& Simpson, K. A. 1996. Prediction of vertical response spectra in Europe. Earthquake Engineering and Structural Dynamics, 25(4), 401-412.

Ambraseys, N. N., Bommer, J. J., \& Sarma, S. K. 1992 (Nov). A review of seismic ground motions for UK design. ESEE Report 92-8. Department of Civil Engineering, Imperial College, London.

Ambraseys, N. N., Simpson, K. A., \& Bommer, J. J. 1996. Prediction of horizontal response spectra in Europe. Earthquake Engineering and Structural Dynamics, 25(4), 371-400.

Ambraseys, N. N., Douglas, J., Sigbjörnsson, R., Berge-Thierry, C., Suhadolc, P., Costa, G., \& Smit, P. M. 2004a (Feb). Dissemination of European Strong-Motion Data, vol. 2 using Strong-Motion Datascape Navigator. CD-ROM collection. Engineering and Physical Sciences Research Council, United Kingdom.

Ambraseys, N. N., Douglas, J., Sigbjörnsson, R., Berge-Thierry, C., Suhadolc, P., Costa, G., \& Smit, P. M. 2004b. Dissemination of European Strong-Motion Data, volume 2. In: Proceedings of Thirteenth World Conference on Earthquake Engineering. Paper no. 32.

Ambraseys, N. N., Smit, P., Douglas, J., Margaris, B., Sigbjörnsson, R., Ólafsson, S., Suhadolc, P., \& Costa, G. 2004c. Internet site for European strong-motion data. Bollettino di Geofisica Teorica ed Applicata, 45(3), 113-129.

Aptikaev, F., \& Kopnichev, J. 1980. Correlation between seismic vibration parameters and type of faulting. Pages 107-110 of: Proceedings of Seventh World Conference on Earthquake Engineering, vol. 1.

Atkinson, G. M., \& Boore, D. M. 2003. Empirical ground-motion relations for subduction zone earthquakes and their application to Cascadia and other regions. Bulletin of the Seismological Society of America, 93(4), 1703-1729.

Bolt, B. A., \& Abrahamson, N. A. 1982. New attenuation relations for peak and expected accelerations of strong ground motion. Bulletin of the Seismological Society of America, 72(6), 2307-2321.

Bommer, J. J., Douglas, J., \& Strasser, F. O. 2003. Style-of-faulting in ground-motion prediction equations. Bulletin of Earthquake Engineering, 1(2), 171-203.

Boore, D. M., Joyner, W. B., \& Fumal, T. E. 1993. Estimation of response spectra and peak accelerations from western North American earthquakes: An interim report. Open-File Report 93-509. U.S. Geological Survey. 70 pages. 
Boore, D. M., Joyner, W. B., \& Fumal, T. E. 1997. Equations for estimating horizontal response spectra and peak acceleration from western North American earthquakes: A summary of recent work. Seismological Research Letters, 68(1), 128-153.

Brady, A. G., Trifunac, M. D., \& Hudson, D. E. 1973 (Feb). Analyses of strong motion earthquake accelerograms - response spectra. Tech. rept. Earthquake Engineering Research Laboratory - California Institute of Technology.

Brillinger, D. R., \& Preisler, H. K. 1984. An exploratory analysis of the Joyner-Boore attenuation data. Bulletin of the Seismological Society of America, 74(4), 1441-1450.

Campbell, K. W. 1997. Empirical near-source attenuation relationships for horizontal and vertical components of peak ground acceleration, peak ground velocity, and pseudo-absolute acceleration response spectra. Seismological Research Letters, 68(1), 154-179.

Campbell, K. W., \& Bozorgnia, Y. 2003. Updated near-source ground-motion (attenuation) relations for the horizontal and vertical components of peak ground acceleration and acceleration response spectra. Bulletin of the Seismological Society of America, 93(1), 314-331.

Chen, S.-Z., \& Atkinson, G. M. 2002. Global comparison of earthquake source spectra. Bulletin of the Seismological Society of America, 92(3), 885-895.

Chen, Y.-H., \& Tsai, C.-C. P. 2002. A new method for estimation of the attenuation relationship with variance components. Bulletin of the Seismological Society of America, 92(5), 1984-1991.

Converse, A. M., \& Brady, A. G. 1992 (Mar). BAP basic strong-motion accelerogram processing software, version 1.0. Open-File Report 92-296A. US Geological Survey.

Cousins, W. J., Zhao, J. X., \& Perrin, N. D. 1999. A model for the attenuation of peak ground acceleration in New Zealand earthquakes based on seismograph and accelerograph data. Bulletin of the New Zealand Society for Earthquake Engineering, 32(4), 193-220.

Crouse, C. B., \& McGuire, J. W. 1996. Site response studies for purpose of revising NEHRP seismic provisions. Earthquake Spectra, 12(3), 407-439.

Donovan, N. C., \& Bornstein, A. E. 1978. Uncertainties in seismic risk analysis. Journal of the Geotechnical Engineering Division, ASCE, 104(GT7), 869-887.

Douglas, J. 2001 (Oct). A critical reappraisal of some problems in engineering seismology. Ph.D. thesis, University of London. 
Douglas, J. 2002. Note on scaling of peak ground acceleration and peak ground velocity with magnitude. Geophysical Journal International, 148(2), 336-339.

Douglas, J. 2003a. Earthquake ground motion estimation using strong-motion records: A review of equations for the estimation of peak ground acceleration and response spectral ordinates. EarthScience Reviews, 61(1-2), 43-104.

Douglas, J. 2003b. Note on the inclusion of site classification information in equations to estimate strong ground motions. Journal of Earthquake Engineering, 7(3), 373-380.

Douglas, J. 2003c (Aug). A note on the use of strong-motion data from small magnitude earthquakes for empirical ground motion estimation. In: Skopje Earthquake 40 Years of European Earthquake Engineering (SE-4OEEE).

Douglas, J. 2003d. What is a poor quality strong-motion record? Bulletin of Earthquake Engineering, 1(1), 141-156.

Douglas, J. 2004a. An investigation of analysis of variance as a tool for exploring regional differences in strong ground motions. Journal of Seismology. In press.

Douglas, J. 2004b. Use of analysis of variance for the investigation of regional dependence of strong ground motions. In: Proceedings of Thirteenth World Conference on Earthquake Engineering. Paper no. 29.

Douglas, J., \& Smit, P. M. 2001. How accurate can strong ground motion attenuation relations be? Bulletin of the Seismological Society of America, 91(6), 1917-1923.

Draper, N. R., \& Smith, H. 1981. Applied Regression Analysis. 2nd edn. John Wiley \& Sons.

Ekström, G., \& Dziewonski, A. M. 1988. Evidence of bias in estimations of earthquake size. Nature, 332(Mar), 319-323.

Frankel, A., McGarr, A., Bicknell, J., Mori, J., Seeber, L., \& Cranswick, E. 1990. Attenuation of highfrequency shear waves in the crust: Measurements from New York State, South Africa, and southern California. Journal of Geophysical Research, 95(B11), 17441-17457.

Frohlich, C., \& Apperson, K. D. 1992. Earthquake focal mechanisms, moment tensors, and the consistency of seismic activity near plate boundaries. Tectonics, 11(2), 279-296.

Fukushima, Y. 1996. Scaling relations for strong ground motion prediction models with $M^{2}$ terms. Bulletin of the Seismological Society of America, 86(2), 329-336. 
Hudson, D. E. 1979. Reading and Interpreting Strong Motion Accelerograms. Berkeley, USA: Earthquake Engineering Research Institute. 112 pages.

Joyner, W. B., \& Boore, D. M. 1981. Peak horizontal acceleration and velocity from strong-motion records including records from the 1979 Imperial Valley, California, earthquake. Bulletin of the Seismological Society of America, 71(6), 2011-2038.

Joyner, W. B., \& Boore, D. M. 1993. Methods for regression analysis of strong-motion data. Bulletin of the Seismological Society of America, 83(2), 469-487.

Kanamori, H. 1977. The energy release in great earthquakes. Journal of Geophysical Research, 82(20), 2981-2987.

Lussou, P., Bard, P. Y., Cotton, F., \& Fukushima, Y. 2001. Seismic design regulation codes: Contribution of K-Net data to site effect evaluation. Journal of Earthquake Engineering, 5(1), 13-33.

Lyon-Caen, H., Armijo, R., Drakopoulos, J., Baskoutass, J., Delibassis, N., Gaulon, R., Kouskouna, V., Latoussakis, J., Makropoulos, K., Papadimitriou, P., Papanastassiou, D., \& Pedotti, G. 1988. The 1986 Kalamata (south Peloponnesus) earthquake: Detailed study of a normal fault, evidences for east-west extension in the Hellenic Arc. Journal of Geophysical Research, 93(B12), 14967-15000.

Marra, F., Azzara, R., Bellucci, F., Caserta, A., Cultrera, G., Mele, G., Palombo, B., Rovelli, A., \& Boschi, E. 2000. Large amplification of ground motion at rock sites within a fault zone in Nocera Umbra (central Italy). Journal of Seismology, 4(4), 543-554.

Ouyed, M., Yielding, G., Hatzfeld, D., \& King, G. C. P. 1983. An aftershock study of the El Asnam (Algeria) earthquake of 1980 October 10. Geophysical Journal of the Royal Astronomical Society, 73, $605-639$.

PML. 1985. Seismological studies for UK hazard analysis. Tech. rept. 346/85. Principia Mechanica Ltd., London. Not seen. Reported in Ambraseys et al. (1992).

Pondrelli, S., Morelli, A., Ekstrom, G., Mazza, S., Boschi, E., \& Dziewonski, A. M. 2002. EuropeanMediterranean regional centroid-moment tensors: 1997-2000. Physics of the Earth and Planetary Interiors, 130, 71-101.

Rhoades, D. A. 1997. Estimation of attenuation relations for strong-motion data allowing for individual earthquake magnitude uncertainties. Bulletin of the Seismological Society of America, 87(6), 16741678 . 
Sadigh, K., Chang, C.-Y., Egan, J. A., Makdisi, F., \& Youngs, R. R. 1997. Attenuation relationships for shallow crustal earthquakes based on California strong motion data. Seismological Research Letters, 68(1), 180-189.

Sen, M. K. 1990 (May). Deep structural complexity and site response in Los Angeles basin. Pages 545-553 of: Proceedings of the Fourth U.S. National Conference on Earthquake Engineering, vol. 1.

Somerville, P. G. 2003. Magnitude scaling of the near fault rupture directivity pulse. Physics of the Earth and Planetary Interiors, 137, 201-212.

Spudich, P., Joyner, W. B., Lindh, A. G., Boore, D. M., Margaris, B. M., \& Fletcher, J. B. 1999. SEA99: A revised ground motion prediction relation for use in extensional tectonic regimes. Bulletin of the Seismological Society of America, 89(5), 1156-1170.

Utkucu, M., Nalbant, S. S., McCloskey, J., Steacy, S., \& Alptekin, Ö. 2003. Slip distribution and stress changes associated with the 1999 November 12, Düzce (Turkey). Geophysical Journal International, 153(1), 229-241.

Wells, D. L., \& Coppersmith, K. J. 1994. New empirical relationships among magnitude, rupture length, rupture width, rupture area, and surface displacement. Bulletin of the Seismological Society of America, 84(4), 974-1002.

Youngs, R. R., Abrahamson, N., Makdisi, F. I., \& Sadigh, K. 1995. Magnitude-dependent variance of peak ground acceleration. Bulletin of the Seismological Society of America, 85(4), 1161-1176.

Zaré, M., \& Bard, P.-Y. 2002. Strong motion dataset of Turkey: Data processing and site classification. Soil Dynamics and Earthquake Engineering, 22, 703-718. 
Table 1: Distribution of data used with respect to local site class (L: very soft soil, S: soft soil, A: stiff soil and R: rock) and faulting mechanism.

\begin{tabular}{l|rrrr|r} 
& $\mathrm{L}$ & $\mathrm{S}$ & $\mathrm{A}$ & $\mathrm{R}$ & Total \\
\hline Normal & 6 & 40 & 79 & 66 & $191(32 \%)$ \\
Strike-slip & 1 & 35 & 53 & 71 & $160(27 \%)$ \\
Thrust & 1 & 17 & 49 & 24 & $91(15 \%)$ \\
Odd & 3 & 51 & 57 & 42 & $153(26 \%)$ \\
\hline Total & 11 & 143 & 238 & 203 & 595 \\
& $(2 \%)$ & $(24 \%)$ & $(40 \%)$ & $(34 \%)$ & \\
\hline
\end{tabular}

Table 2: Derived coefficients for the estimation of horizontal peak ground acceleration and response spectral acceleration for $5 \%$ damping. $a_{1}-a_{10}$ are the derived coefficients (italics signify a non-significant coefficient at the $5 \%$ level), $\sigma_{1}$ is the intra-earthquake standard deviation, $\sigma_{2}$ is the inter-earthquake standard deviations, $N_{\text {rec }}$ is the number of records used, $N_{\text {eq }}$ is the number of earthquakes used and $N_{\mathrm{st}}$ is the number of stations used.

\begin{tabular}{|c|c|c|c|c|c|c|c|c|c|c|c|c|c|c|c|}
\hline Period & $a_{1}$ & $a_{2}$ & $a_{3}$ & $a_{4}$ & $a_{5}$ & $a_{6}$ & $a_{7}$ & $a_{8}$ & $a_{9}$ & $a_{10}$ & $\sigma_{1}$ & $\sigma_{2}$ & $N_{\text {rec }}$ & $N_{\text {eq }}$ & $N_{\mathrm{st}}$ \\
\hline PGA & 2.522 & -0.142 & -3.184 & 0.314 & 7.6 & 0.137 & 0.050 & -0.084 & 0.062 & -0.044 & $0.665-0.065 M_{w}$ & $0.222-0.022 M_{w}$ & 595 & 135 & 338 \\
\hline 0.050 & 3.247 & -0.225 & -3.525 & 0.359 & 7.4 & 0.098 & 0.005 & -0.096 & 0.078 & -0.048 & $0.708-0.069 M_{w}$ & $0.249-0.024 M_{w}$ & 595 & 135 & 338 \\
\hline 0.055 & 3.125 & -0.206 & -3.418 & 0.345 & 7.1 & 0.085 & 0.004 & -0.096 & 0.072 & -0.050 & $0.672-0.063 M_{w}$ & $0.235-0.022 M_{w}$ & 595 & 135 & 338 \\
\hline 0.060 & 3.202 & -0.212 & -3.444 & 0.347 & 7.4 & 0.079 & 0.002 & -0.103 & 0.073 & -0.047 & $0.687-0.065 M_{w}$ & $0.237-0.023 M_{w}$ & 595 & 135 & 338 \\
\hline 0.065 & 3.442 & -0.242 & -3.571 & 0.365 & 7.7 & 0.069 & 0.001 & -0.104 & 0.076 & -0.035 & $0.693-0.067 M_{w}$ & $0.241-0.023 M_{w}$ & 595 & 135 & 338 \\
\hline 0.070 & 3.504 & -0.249 & -3.576 & 0.367 & 7.9 & 0.064 & -0.002 & -0.114 & 0.068 & -0.043 & $0.647-0.059 M_{w}$ & $0.225-0.021 M_{w}$ & 595 & 135 & 338 \\
\hline 0.075 & 3.472 & -0.240 & -3.521 & 0.358 & 8.0 & 0.064 & -0.003 & -0.121 & 0.063 & -0.046 & $0.674-0.063 M_{w}$ & $0.227-0.021 M_{w}$ & 595 & 135 & 338 \\
\hline 0.080 & 3.526 & -0.248 & -3.520 & 0.358 & 8.1 & 0.069 & -0.002 & -0.116 & 0.074 & -0.040 & $0.756-0.076 M_{w}$ & $0.252-0.025 M_{w}$ & 595 & 135 & 338 \\
\hline 0.085 & 3.320 & -0.215 & -3.381 & 0.336 & 8.0 & 0.067 & 0.010 & -0.116 & 0.075 & -0.039 & $0.750-0.076 M_{w}$ & $0.258-0.026 M_{w}$ & 595 & 135 & 338 \\
\hline 0.090 & 3.309 & -0.211 & -3.353 & 0.332 & 7.9 & 0.064 & 0.014 & -0.119 & 0.065 & -0.048 & $0.727-0.072 M_{w}$ & $0.249-0.025 M_{w}$ & 595 & 135 & 338 \\
\hline 0.095 & 3.479 & -0.240 & -3.420 & 0.345 & 7.8 & 0.062 & 0.014 & -0.107 & 0.073 & -0.051 & $0.772-0.079 M_{w}$ & $0.262-0.027 M_{w}$ & 595 & 135 & 338 \\
\hline 0.100 & 3.596 & -0.258 & -3.511 & 0.360 & 7.9 & 0.065 & 0.025 & -0.095 & 0.076 & -0.047 & $0.747-0.075 M_{w}$ & $0.249-0.025 M_{w}$ & 595 & 135 & 338 \\
\hline 0.110 & 3.453 & -0.239 & -3.398 & 0.345 & 7.9 & 0.077 & 0.041 & -0.082 & 0.072 & -0.052 & $0.810-0.084 M_{w}$ & $0.256-0.027 M_{w}$ & 595 & 135 & 338 \\
\hline 0.120 & 3.330 & -0.214 & -3.300 & 0.329 & 8.0 & 0.070 & 0.045 & -0.081 & 0.065 & -0.046 & $0.753-0.075 M_{w}$ & $0.240-0.024 M_{w}$ & 595 & 135 & 338 \\
\hline 0.130 & 3.249 & -0.195 & -3.254 & 0.321 & 8.2 & 0.069 & 0.043 & -0.084 & 0.056 & -0.059 & $0.712-0.068 M_{w}$ & $0.236-0.023 M_{w}$ & 595 & 135 & 338 \\
\hline 0.140 & 2.993 & -0.154 & -3.088 & 0.297 & 8.2 & 0.065 & 0.042 & -0.074 & 0.053 & -0.067 & $0.650-0.059 M_{w}$ & $0.218-0.020 M_{w}$ & 595 & 135 & 338 \\
\hline 0.150 & 2.725 & -0.111 & -2.909 & 0.270 & 8.3 & 0.067 & 0.044 & -0.074 & 0.067 & -0.060 & $0.634-0.057 M_{w}$ & $0.223-0.020 M_{w}$ & 595 & 135 & 338 \\
\hline 0.160 & 2.738 & -0.120 & -2.912 & 0.274 & 8.2 & 0.085 & 0.049 & -0.069 & 0.090 & -0.061 & $0.734-0.072 M_{w}$ & $0.251-0.025 M_{w}$ & 595 & 135 & 338 \\
\hline 0.170 & 2.692 & -0.114 & -2.907 & 0.275 & 8.2 & 0.091 & 0.053 & -0.059 & 0.087 & -0.055 & $0.760-0.077 M_{w}$ & $0.257-0.026 M_{w}$ & 595 & 135 & 338 \\
\hline 0.180 & 2.665 & -0.110 & -2.907 & 0.276 & 8.1 & 0.098 & 0.049 & -0.057 & 0.087 & -0.054 & $0.736-0.073 M_{w}$ & $0.251-0.025 M_{w}$ & 595 & 135 & 338 \\
\hline 0.190 & 2.713 & -0.118 & -2.989 & 0.288 & 8.1 & 0.112 & 0.059 & -0.050 & 0.090 & -0.054 & $0.752-0.076 M_{w}$ & $0.250-0.025 M_{w}$ & 595 & 135 & 338 \\
\hline 0.200 & 2.632 & -0.109 & -2.990 & 0.289 & 8.1 & 0.124 & 0.070 & -0.033 & 0.090 & -0.039 & $0.784-0.080 M_{w}$ & $0.251-0.026 M_{w}$ & 595 & 135 & 338 \\
\hline 0.220 & 2.483 & -0.088 & -2.941 & 0.281 & 7.9 & 0.136 & 0.078 & -0.033 & 0.086 & -0.024 & $0.778-0.079 M_{w}$ & $0.244-0.025 M_{w}$ & 595 & 135 & 338 \\
\hline 0.240 & 2.212 & -0.051 & -2.823 & 0.265 & 7.6 & 0.156 & 0.087 & -0.037 & 0.090 & -0.020 & $0.770-0.077 M_{w}$ & $0.235-0.024 M_{w}$ & 595 & 135 & 338 \\
\hline 0.260 & 2.058 & -0.036 & -2.787 & 0.263 & 7.3 & 0.179 & 0.077 & -0.024 & 0.120 & 0.010 & $0.917-0.101 M_{w}$ & $0.278-0.030 M_{w}$ & 595 & 135 & 338 \\
\hline 0.280 & 1.896 & -0.010 & -2.732 & 0.251 & 7.5 & 0.193 & 0.074 & -0.023 & 0.112 & 0.027 & $0.947-0.104 M_{w}$ & $0.285-0.031 M_{w}$ & 595 & 135 & 338 \\
\hline 0.300 & 1.739 & 0.009 & -2.667 & 0.244 & 7.1 & 0.192 & 0.069 & -0.034 & 0.104 & 0.012 & $0.890-0.095 M_{w}$ & $0.267-0.028 M_{w}$ & 595 & 135 & 338 \\
\hline 0.320 & 1.728 & 0.001 & -2.688 & 0.251 & 7.1 & 0.207 & 0.073 & -0.021 & 0.118 & 0.008 & $0.917-0.098 M_{w}$ & $0.273-0.029 M_{w}$ & 595 & 135 & 338 \\
\hline 0.340 & 1.598 & 0.020 & -2.667 & 0.246 & 7.2 & 0.216 & 0.078 & -0.010 & 0.118 & 0.005 & $0.896-0.095 M_{w}$ & $0.261-0.028 M_{w}$ & 595 & 135 & 338 \\
\hline 0.360 & 1.477 & 0.034 & -2.641 & 0.244 & 6.9 & 0.230 & 0.091 & -0.013 & 0.107 & -0.011 & $0.846-0.087 M_{w}$ & $0.254-0.026 M_{w}$ & 595 & 135 & 338 \\
\hline 0.380 & 1.236 & 0.071 & -2.534 & 0.227 & 6.7 & 0.247 & 0.100 & -0.010 & 0.106 & -0.018 & $0.803-0.080 M_{w}$ & $0.250-0.025 M_{w}$ & 595 & 135 & 338 \\
\hline 0.400 & 1.070 & 0.091 & -2.474 & 0.219 & 6.3 & 0.256 & 0.097 & -0.013 & 0.115 & -0.020 & $0.793-0.078 M_{w}$ & $0.244-0.024 M_{w}$ & 594 & 134 & 338 \\
\hline 0.420 & 0.998 & 0.096 & -2.469 & 0.220 & 5.9 & 0.259 & 0.100 & -0.021 & 0.116 & -0.024 & $0.757-0.072 M_{w}$ & $0.233-0.022 M_{w}$ & 594 & 134 & 338 \\
\hline
\end{tabular}


Table 2: continued

\begin{tabular}{|c|c|c|c|c|c|c|c|c|c|c|c|c|c|c|c|}
\hline Period & $a_{1}$ & $a_{2}$ & $a_{3}$ & $a_{4}$ & $a_{5}$ & $a_{6}$ & $a_{7}$ & $a_{8}$ & $a_{9}$ & $a_{10}$ & $\sigma_{1}$ & $\sigma_{2}$ & $N_{\text {rec }}$ & $N_{\text {eq }}$ & $N_{\mathrm{st}}$ \\
\hline 0.440 & 1.045 & 0.085 & -2.540 & 0.231 & 6.3 & 0.269 & 0.114 & -0.016 & 0.114 & -0.028 & $0.787-0.077 M_{w}$ & $0.241-0.024 M_{w}$ & 594 & 134 & 338 \\
\hline 0.460 & 0.980 & 0.093 & -2.564 & 0.234 & 6.3 & 0.278 & 0.122 & -0.011 & 0.108 & -0.029 & $0.766-0.074 M_{w}$ & $0.238-0.023 M_{w}$ & 594 & 134 & 338 \\
\hline 0.480 & 0.874 & 0.103 & -2.530 & 0.231 & 6.2 & 0.286 & 0.130 & 0.001 & 0.118 & -0.024 & $0.778-0.076 M_{w}$ & $0.240-0.023 M_{w}$ & 594 & 134 & 338 \\
\hline 0.500 & 0.624 & 0.139 & -2.410 & 0.212 & 6.1 & 0.289 & 0.133 & 0.004 & 0.126 & -0.026 & $0.798-0.079 M_{w}$ & $0.246-0.024 M_{w}$ & 592 & 134 & 338 \\
\hline 0.550 & 0.377 & 0.174 & -2.317 & 0.196 & 6.1 & 0.293 & 0.137 & -0.004 & 0.118 & -0.035 & $0.841-0.085 M_{w}$ & $0.268-0.027 M_{w}$ & 591 & 134 & 338 \\
\hline 0.600 & 0.359 & 0.158 & -2.343 & 0.206 & 5.4 & 0.311 & 0.136 & 0.008 & 0.118 & -0.028 & $0.919-0.099 M_{w}$ & $0.308-0.033 M_{w}$ & 590 & 134 & 337 \\
\hline 0.650 & 0.130 & 0.182 & -2.294 & 0.202 & 5.0 & 0.318 & 0.149 & 0.005 & 0.107 & -0.031 & $0.867-0.090 M_{w}$ & $0.301-0.031 M_{w}$ & 588 & 134 & 336 \\
\hline 0.700 & -0.014 & 0.198 & -2.305 & 0.205 & 4.8 & 0.327 & 0.154 & -0.011 & 0.105 & -0.032 & $0.803-0.080 M_{w}$ & $0.298-0.030 M_{w}$ & 579 & 132 & 333 \\
\hline 0.750 & -0.307 & 0.236 & -2.201 & 0.191 & 4.7 & 0.318 & 0.148 & -0.001 & 0.114 & -0.032 & $0.774-0.076 M_{w}$ & $0.278-0.027 M_{w}$ & 569 & 132 & 329 \\
\hline 0.800 & -0.567 & 0.279 & -2.083 & 0.170 & 5.2 & 0.332 & 0.178 & -0.003 & 0.083 & -0.062 & $0.661-0.059 M_{w}$ & $0.240-0.021 M_{w}$ & 550 & 128 & 324 \\
\hline 0.850 & -0.519 & 0.262 & -2.177 & 0.186 & 4.9 & 0.341 & 0.183 & 0.005 & 0.085 & -0.070 & $0.694-0.064 M_{w}$ & $0.253-0.023 M_{w}$ & 546 & 127 & 321 \\
\hline 0.900 & -0.485 & 0.249 & -2.246 & 0.199 & 4.5 & 0.354 & 0.191 & -0.003 & 0.072 & -0.082 & $0.714-0.067 M_{w}$ & $0.263-0.025 M_{w}$ & 533 & 125 & 314 \\
\hline 0.950 & -1.133 & 0.369 & -1.957 & 0.143 & 5.5 & 0.353 & 0.204 & -0.025 & 0.024 & -0.109 & 0.309 & 0.121 & 514 & 122 & 305 \\
\hline 1.000 & -1.359 & 0.403 & -1.848 & 0.124 & 6.0 & 0.357 & 0.211 & -0.013 & 0.024 & -0.101 & 0.305 & 0.120 & 490 & 116 & 295 \\
\hline 1.100 & -1.675 & 0.437 & -1.711 & 0.108 & 5.5 & 0.373 & 0.213 & -0.029 & -0.007 & -0.108 & 0.306 & 0.118 & 475 & 112 & 290 \\
\hline 1.200 & -1.982 & 0.477 & -1.636 & 0.095 & 5.4 & 0.389 & 0.226 & -0.014 & -0.017 & -0.095 & 0.297 & 0.120 & 459 & 107 & 284 \\
\hline 1.300 & -2.226 & 0.511 & -1.605 & 0.089 & 5.5 & 0.395 & 0.215 & -0.004 & -0.025 & -0.085 & 0.296 & 0.119 & 442 & 102 & 275 \\
\hline 1.400 & -2.419 & 0.533 & -1.541 & 0.080 & 6.0 & 0.408 & 0.237 & 0.028 & -0.040 & -0.091 & 0.290 & 0.115 & 408 & 96 & 263 \\
\hline 1.500 & -2.639 & 0.550 & -1.443 & 0.074 & 4.9 & 0.405 & 0.229 & 0.020 & -0.053 & -0.133 & 0.292 & 0.111 & 379 & 90 & 246 \\
\hline 1.600 & -2.900 & 0.587 & -1.351 & 0.060 & 5.2 & 0.387 & 0.216 & 0.019 & -0.056 & -0.131 & 0.296 & 0.114 & 358 & 87 & 239 \\
\hline 1.700 & -2.695 & 0.564 & -1.564 & 0.086 & 6.5 & 0.380 & 0.212 & 0.001 & -0.081 & -0.141 & 0.302 & 0.117 & 358 & 87 & 239 \\
\hline 1.800 & -3.209 & 0.630 & -1.410 & 0.069 & 5.4 & 0.391 & 0.174 & 0.012 & -0.035 & -0.154 & 0.291 & 0.128 & 319 & 81 & 217 \\
\hline 1.900 & -3.313 & 0.647 & -1.424 & 0.067 & 5.9 & 0.386 & 0.175 & 0.030 & -0.033 & -0.145 & 0.290 & 0.133 & 319 & 81 & 217 \\
\hline 2.000 & -3.063 & 0.586 & -1.372 & 0.070 & 4.2 & 0.421 & 0.177 & 0.008 & -0.019 & -0.174 & 0.282 & 0.134 & 260 & 72 & 185 \\
\hline 2.100 & -3.043 & 0.578 & -1.435 & 0.080 & 4.3 & 0.404 & 0.171 & 0.002 & -0.026 & -0.164 & 0.281 & 0.134 & 260 & 72 & 185 \\
\hline 2.200 & -3.068 & 0.575 & -1.448 & 0.083 & 4.2 & 0.394 & 0.160 & -0.007 & -0.034 & -0.169 & 0.283 & 0.136 & 260 & 72 & 185 \\
\hline 2.300 & -3.996 & 0.740 & -0.829 & -0.025 & 5.1 & 0.349 & 0.135 & -0.010 & -0.031 & -0.125 & 0.282 & 0.137 & 208 & 59 & 146 \\
\hline 2.400 & -4.108 & 0.758 & -0.755 & -0.038 & 5.3 & 0.338 & 0.119 & -0.024 & -0.050 & -0.147 & 0.284 & 0.137 & 208 & 59 & 146 \\
\hline 2.500 & -4.203 & 0.768 & -0.714 & -0.044 & 5.1 & 0.325 & 0.103 & -0.026 & -0.063 & -0.155 & 0.285 & 0.137 & 207 & 59 & 145 \\
\hline
\end{tabular}


Table 3: Average bias for the stations that have recorded five or more earthquakes.

\begin{tabular}{llllllll}
\hline \multirow{2}{*}{ Name } & Site & \multicolumn{6}{c}{ Average factor } \\
& class & PGA & $0.1 \mathrm{~s}$ & $0.2 \mathrm{~s}$ & $0.5 \mathrm{~s}$ & $1.0 \mathrm{~s}$ & $2.0 \mathrm{~s}$ \\
\hline Assisi-Stallone & $\mathrm{R}$ & 1.85 & 1.31 & 2.94 & 2.18 & 1.25 & - \\
Bevagna & $\mathrm{A}$ & 1.02 & 1.08 & 1.08 & 3.70 & - & - \\
Colfiorito & $\mathrm{A}$ & 0.78 & 0.76 & 0.85 & 1.26 & - & - \\
Düzce-Meteoroloji Mudurlugu & $\mathrm{S}$ & 1.16 & 0.95 & 1.35 & 1.42 & - & - \\
Forgaria-Cornio & $\mathrm{A}$ & 1.19 & 1.16 & 1.65 & 2.11 & - & - \\
Gubbio-Piana & $\mathrm{S}$ & 1.39 & 1.67 & 2.44 & 2.90 & 4.66 & 8.16 \\
Hella & $\mathrm{A}$ & 0.92 & 0.89 & 1.12 & 1.09 & - & - \\
Kobarid-Osn.Skola & $\mathrm{A}$ & 1.35 & 1.45 & 2.02 & - & - & - \\
Kyparrisia-Agriculture Bank & $\mathrm{R}$ & 0.98 & 1.19 & 0.91 & 0.88 & - & - \\
Lefkada-OTE Building & $\mathrm{S}$ & 1.83 & 1.14 & 1.73 & 3.84 & - & - \\
Nocera Umbra & $\mathrm{R}$ & 3.27 & 3.16 & 4.23 & 1.79 & 1.75 & - \\
Nocera Umbra 2 & $\mathrm{R}$ & 2.64 & 3.12 & 2.65 & 0.79 & 0.70 & - \\
Nocera Umbra-Biscontini & $\mathrm{R}$ & 1.73 & 2.19 & 1.18 & 0.62 & - & - \\
Rieti & $\mathrm{L}$ & 0.88 & 0.88 & 1.52 & 1.35 & 3.19 & 2.63 \\
Yarimca-Petkim & $\mathrm{S}$ & 0.50 & 0.45 & 0.49 & 1.03 & 1.14 & - \\
Zakynthos-OTE Building & $\mathrm{A}$ & 1.30 & 1.33 & 1.86 & 2.62 & - & - \\
\hline
\end{tabular}

Table 4: Average bias for the ten best recorded earthquakes (13 records or more).

\begin{tabular}{lccccccccc}
\hline Name & $M_{w}$ & Mech. & \multicolumn{7}{c}{ Average factor } \\
& & & PGA & $0.1 \mathrm{~s}$ & $0.2 \mathrm{~s}$ & $0.5 \mathrm{~s}$ & $1.0 \mathrm{~s}$ & $2.0 \mathrm{~s}$ \\
\hline Campano Lucano (23/11/1980) & 6.9 & $\mathrm{~N}$ & 0.87 & 1.00 & 1.14 & 1.38 & 1.47 & - \\
Umbria Marche (26/9/1997 09:40) & 6.0 & $\mathrm{~N}$ & 1.31 & 1.34 & 1.56 & 1.85 & - & - \\
Umbria Marche (6/10/1997) & 5.5 & $\mathrm{~N}$ & 1.86 & 1.78 & 2.45 & 2.16 & - & - \\
Umbria Marche (3/4/1998) & 5.1 & $\mathrm{~N}$ & 1.50 & 1.45 & 1.75 & 1.70 & - & - \\
Kocaeli (17/8/1999) & 7.6 & $\mathrm{~S}$ & 0.86 & 0.82 & 0.98 & 1.04 & 0.96 & 0.62 \\
Kocaeli aftershock (13/9/1999) & 5.8 & $\mathrm{O}$ & 1.24 & 1.26 & 1.51 & 1.95 & 1.48 & 2.20 \\
Kocaeli (31/8/1999) & 5.1 & $\mathrm{O}$ & 0.74 & 0.78 & 0.75 & 1.29 & 1.76 & - \\
Düzce (12/11/1999) & 7.2 & $\mathrm{O}$ & 0.58 & 0.60 & 0.66 & 0.69 & 0.62 & - \\
South Iceland (17/6/2000) & 6.5 & $\mathrm{~S}$ & 1.10 & 1.34 & 1.07 & 1.15 & 1.29 & 1.52 \\
South Iceland (21/6/2000) & 6.4 & $\mathrm{~S}$ & 0.71 & 0.72 & 0.66 & 0.86 & 1.11 & 1.99 \\
\hline
\end{tabular}


Figure captions

1. Distribution of the data used in terms of magnitude, distance, local site class and mechanism. $\circ$ denotes record from very soft soil site, $\diamond$ denotes record from soft soil site, $\triangle$ denotes record from stiff soil site and $\nabla$ denotes record from rock site.

2. Number of records, earthquakes and stations available for regression for each period.

3. Distribution of the data used to derive the equations for spectral acceleration for $2.5 \mathrm{~s}$ natural period in terms of magnitude, distance, local site class and mechanism. $\circ$ denotes record from very soft soil site, $\diamond$ denotes record from soft soil site, $\triangle$ denotes record from stiff soil site and $\nabla$ denotes record from rock site.

4. Observed dependence of $\sigma$ on $M_{w}$ using the binned data for PGA. The fitted line has the equation: $\sigma=0.5774-0.0561 M_{w}$.

5. Far-field decay rates against magnitude $\left(M_{w}\right)$ of the ten best-recorded earthquakes in the set. Also shown is the best-fit line assuming a linear dependence of decay rate on $M_{w}$.

6. Decay of peak ground acceleration and spectral acceleration at $1 \mathrm{~s}$ natural period from magnitude $M_{w}=5,6$ and 7 strike-slip earthquakes at rock sites.

a. PGA.

b. SA at $1 \mathrm{~s}$ natural period.

7. Estimated spectral acceleration for $M_{w}=5,6$ and 7 strike-slip earthquakes at 10 and $100 \mathrm{~km}$ at a rock site.
a. $10 \mathrm{~km}$.
b. $100 \mathrm{~km}$.

8. Comparison of the ratio of spectral accelerations from thrust/reverse faulting earthquakes to those from strike-slip faulting earthquakes derived in this study to those in the literature. Modified from Bommer et al. (2003).

9. Ratios of peak ground accelerations and spectral accelerations from normal faulting earthquakes and earthquakes whose mechanism is defined as odd to those from strike-slip faulting earthquakes. Also shown are the ratios of ground motions from normal faulting earthquakes to those from strike-slip faulting earthquakes derived by Bommer et al. (2003). 
10. Comparison of estimated ratio of horizontal peak ground acceleration and response spectral amplitudes for ground motions on: a) soft soil sites and hard rock sites and on: b) stiff soil sites and hard rock sites, for four recent equations to estimate strong ground motions. Soft soil sites were assumed to have an average shear-wave velocity in the top $30 \mathrm{~m}$ of $310 \mathrm{~ms}^{-1}$ and hence be within category $\mathrm{S}\left(180<V_{s, 30} \leq 360 \mathrm{~ms}^{-1}\right)$ of Ambraseys et al. (1996) and category $\mathrm{C}$ $\left(200<V_{s, 30} \leq 400 \mathrm{~ms}^{-1}\right)$ of Lussou et al. (2001); for the equations of Boore et al. (1997) the actual shear-wave velocity was used and for the equations of Campbell \& Bozorgnia (2003) $S_{V F S}=0.25, S_{S R}=0$ and $S_{F R}=0$ as suggested by Table 5 of Campbell \& Bozorgnia (2003). Stiff soil sites were assumed to have an average shear-wave velocity in the top $30 \mathrm{~m}$ of $420 \mathrm{~ms}^{-1}$ and hence be within category A $\left(360<V_{s, 30} \leq 750 \mathrm{~ms}^{-1}\right)$ of Ambraseys et al. (1996) and category B $\left(400<V_{s, 30} \leq 800 \mathrm{~ms}^{-1}\right)$ of Lussou et al. (2001); for the equations of Boore et al. (1997) the actual shear-wave velocity was used and for the equations of Campbell \& Bozorgnia (2003) $S_{V F S}=0, S_{S R}=1$ and $S_{F R}=0$ as suggested by Table 5 of Campbell \& Bozorgnia (2003). Hard rock sites were assumed to have an average shear-wave velocity in the top $30 \mathrm{~m}$ of $800 \mathrm{~ms}^{-1}$ and hence be within category $\mathrm{R}\left(V_{s, 30}>750 \mathrm{~ms}^{-1}\right)$ of Ambraseys et al. (1996) and category A $\left(V_{s, 30}>800 \mathrm{~ms}^{-1}\right)$ of Lussou et al. (2001); for the equations of Boore et al. (1997) the actual shear-wave velocity was used and for the equations of Campbell \& Bozorgnia (2003) $S_{V F S}=0, S_{S R}=0$ and $S_{F R}=1$ as suggested by Table 5 of Campbell \& Bozorgnia (2003). A seismogenic distance of $10.4 \mathrm{~km}$ and a magnitude of $M_{w}=6.5$ was used to compute the ratios for the equations of Campbell \& Bozorgnia (2003); all the other ratios are independent of distance and magnitude. Modified from Douglas (2003a).

a. Soft soil.

b. Stiff soil.

11. Comparison of the estimated median response spectra given by the equations presented here for strike-slip faulting (thick lines)and those presented by Ambraseys et al. (1996) (thin lines), which are independent of faulting mechanism.
a. $M_{w}=5.0\left(M_{s}=4.3\right), d_{f}=10 \mathrm{~km}$.
b. $M_{w}=5.0\left(M_{s}=4.3\right), d_{f}=100 \mathrm{~km}$.
c. $M_{w}=7.0\left(M_{s}=6.9\right), d_{f}=10 \mathrm{~km}$.
d. $M_{w}=7.0\left(M_{s}=6.9\right), d_{f}=100 \mathrm{~km}$.

12. Comparison of the estimated median response spectra given by the equations presented here (thick lines) and those presented by Campbell \& Bozorgnia (2003) (thin lines) for strike-slip faulting. 
a. $M_{w}=5.0, d_{f}=10 \mathrm{~km}\left(d_{s}=10.4 \mathrm{~km}\right)$.

b. $M_{w}=5.0, d_{f}=100 \mathrm{~km}\left(d_{s}=100 \mathrm{~km}\right)$.

c. $M_{w}=7.0, d_{f}=10 \mathrm{~km}\left(d_{s}=10.4 \mathrm{~km}\right)$.

d. $M_{w}=7.0, d_{f}=100 \mathrm{~km}\left(d_{s}=100 \mathrm{~km}\right)$.

13. Residuals against $M_{w}$ and distance for PGA and SA at $1 \mathrm{~s}$. At the right-hand end of each residual plot there is a histogram using the residuals binned into 0.1 unit intervals.
a. PGA.
b. PGA.
c. SA at $1 \mathrm{~s}$ natural period.
d. SA at $1 \mathrm{~s}$ natural period.

14. Comparison of the observed free-field peak ground acceleration values measured during the Parkfield (28th September 2004) earthquake as reported in the Internet Quick Report of the California Integrated Seismic Network to the median peak ground accelerations predicted using the equation presented here (thick line), for an $M_{w}=6.0$ strike-slip earthquake and stiff soil site class, and those predicted using the equation of Boore et al. (1997) (thin line), for an $M_{w}=6.0$ strike-slip earthquake and $V_{s, 30}=420 \mathrm{~ms}^{-1}$. The dotted portions are for the extension of the predictions outside their distance range of strict applicability. 

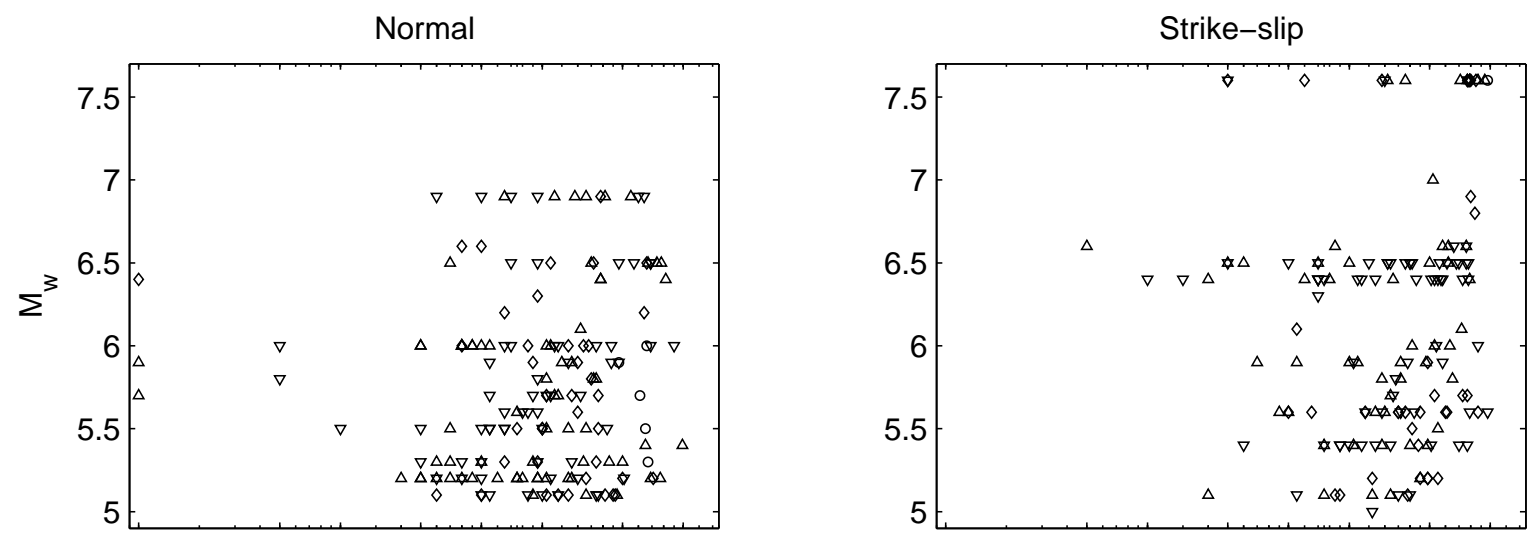

Thrust
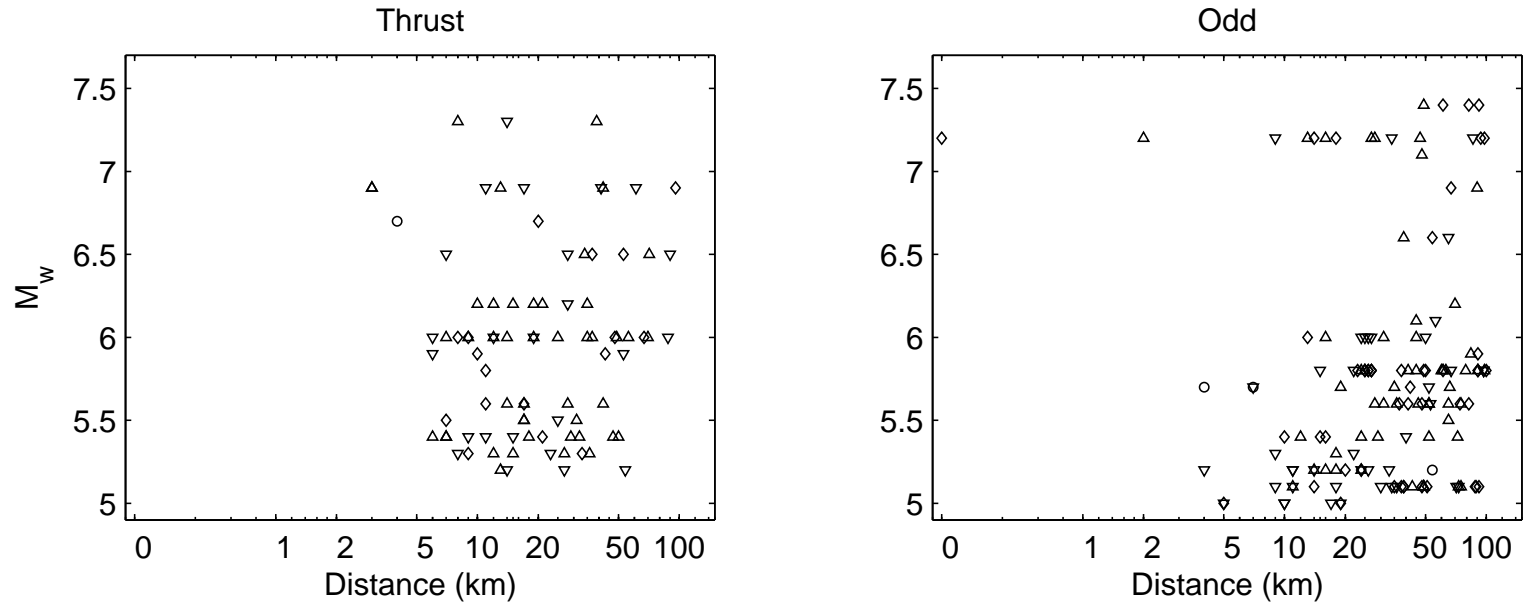

Figure 1:

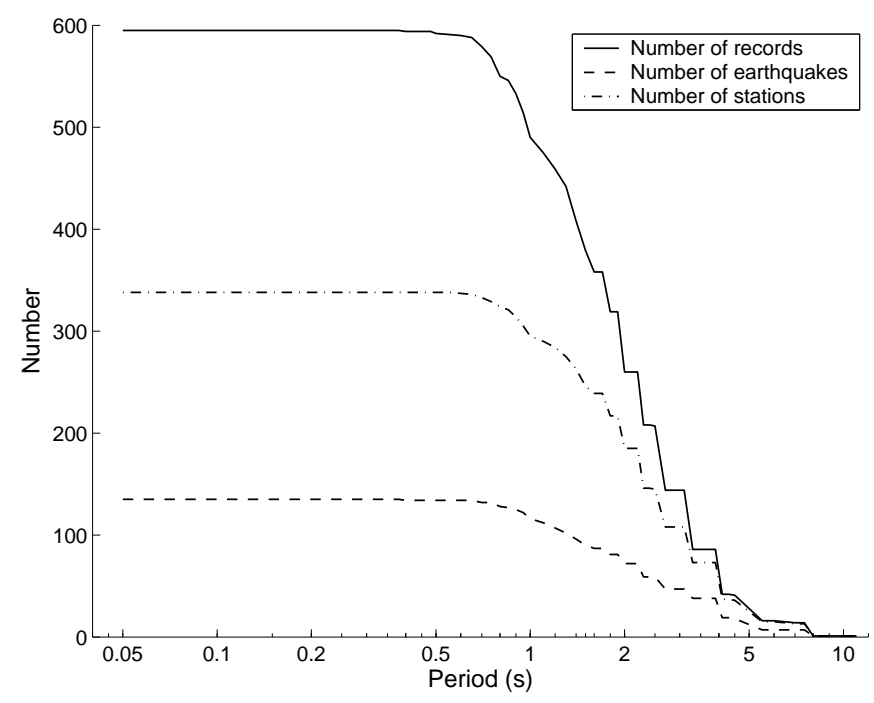

Figure 2: 

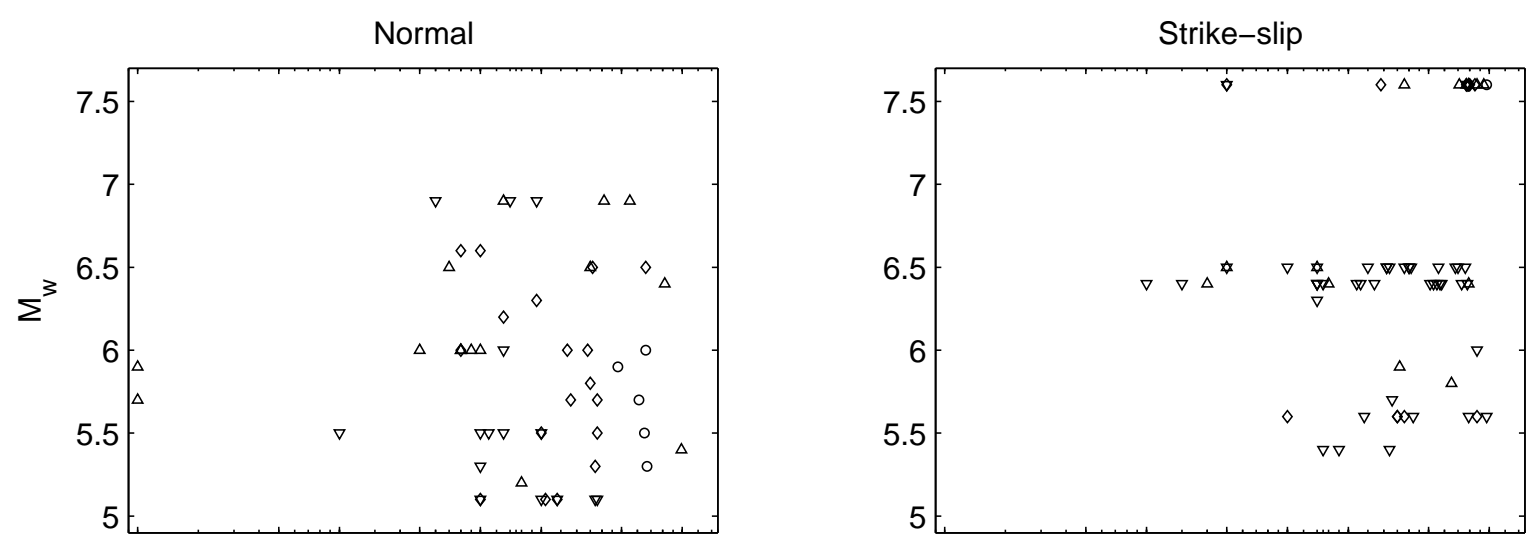

Thrust

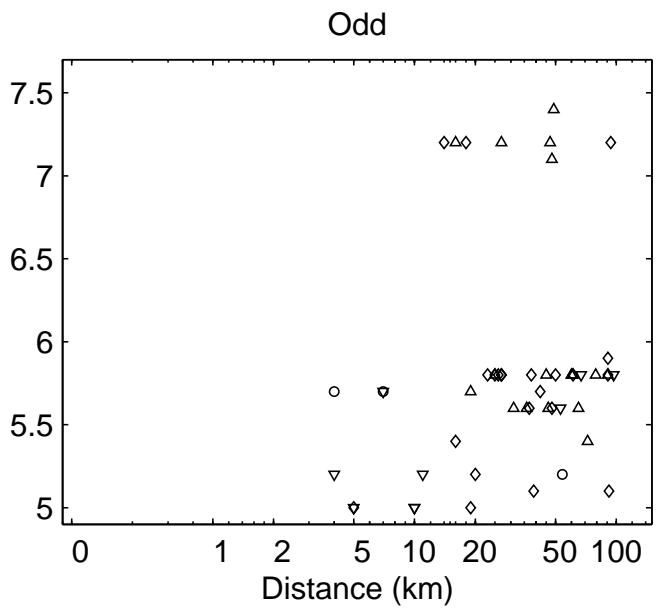

Figure 3:

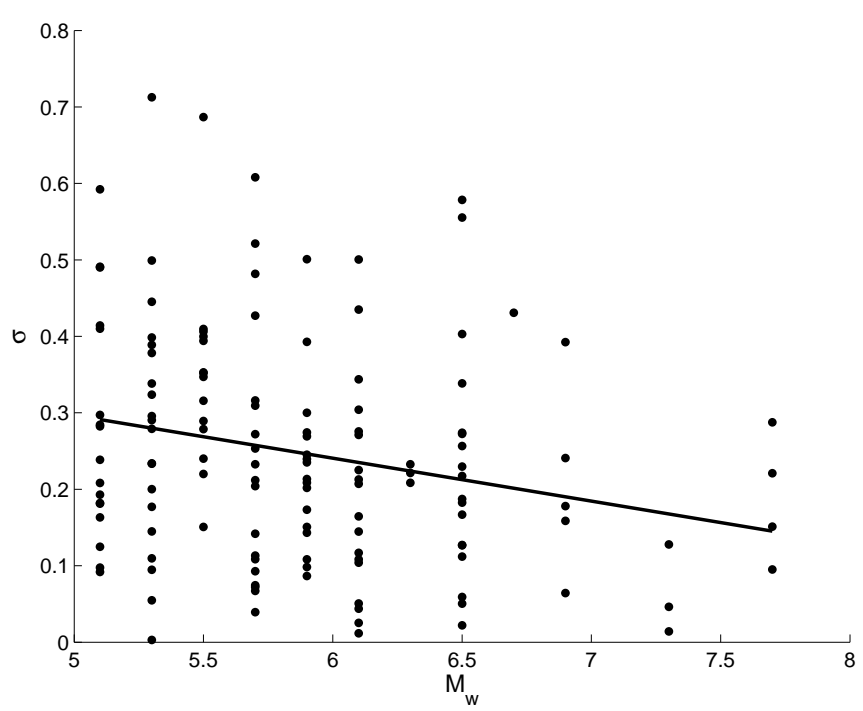

Figure 4: 


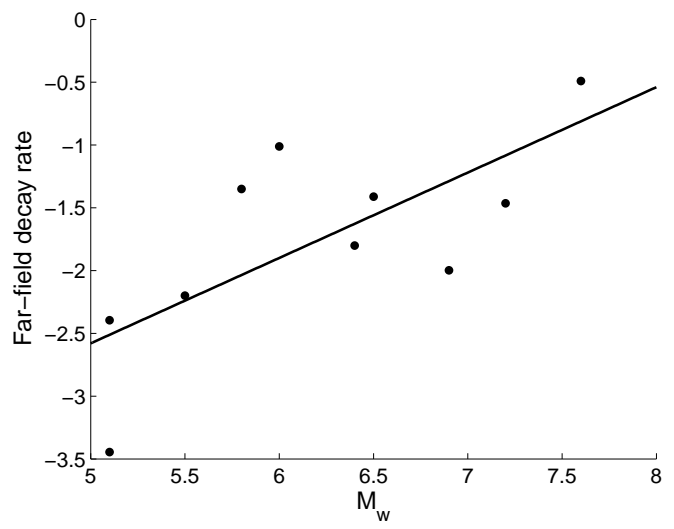

Figure 5: 


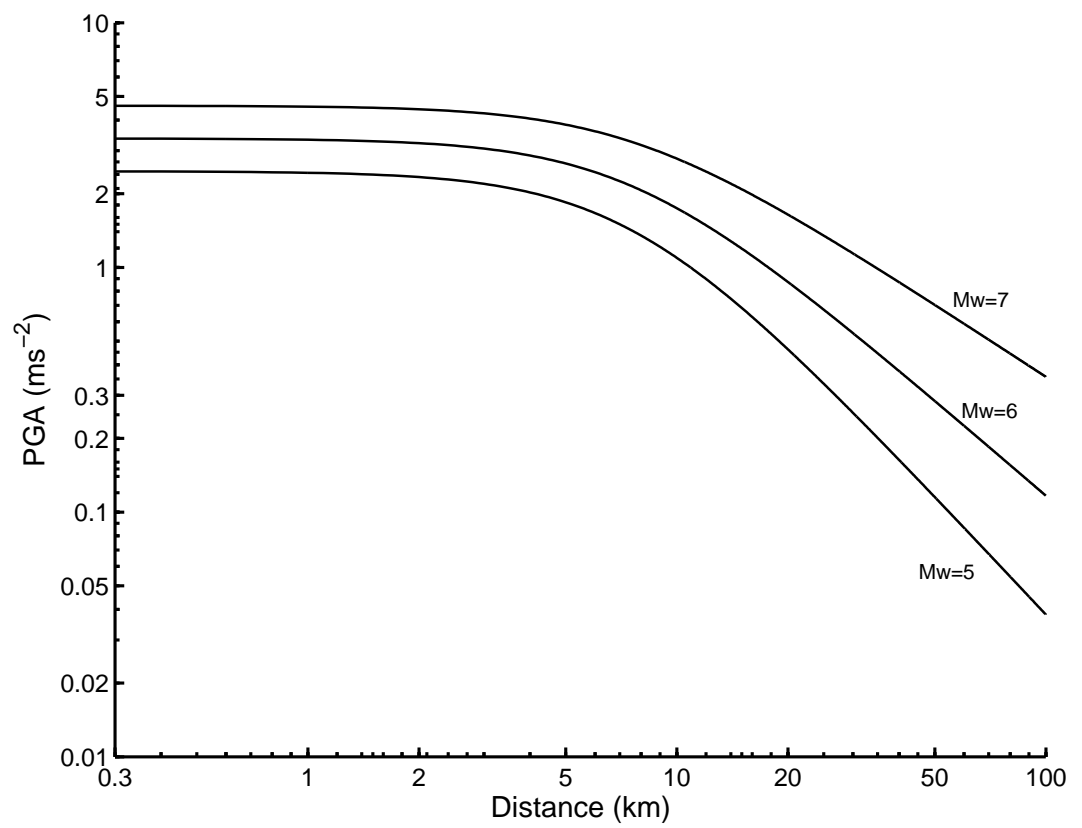

(a)

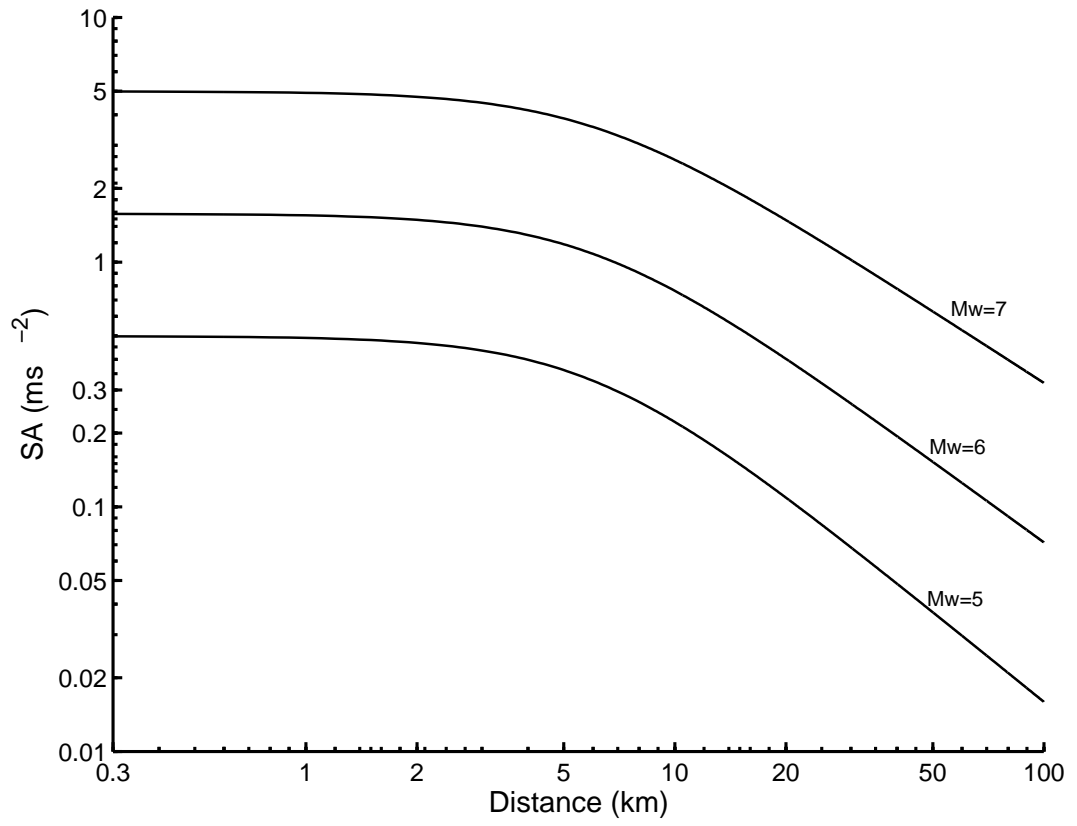

(b)

Figure 6: 


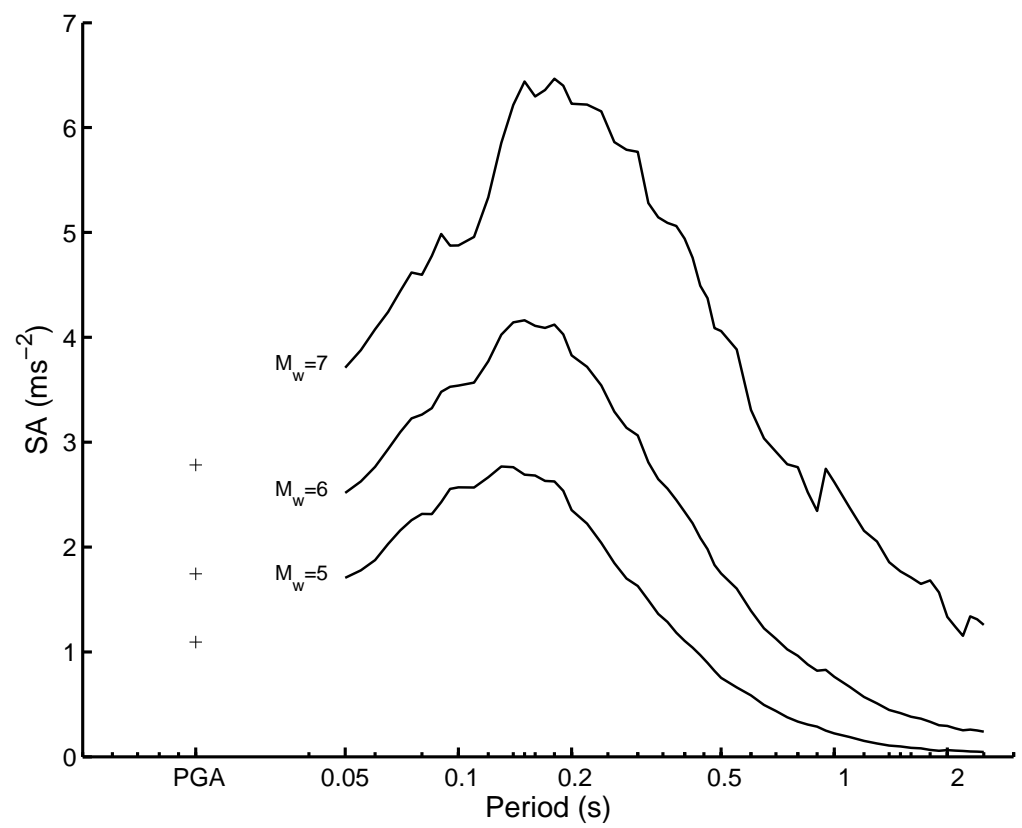

(a)

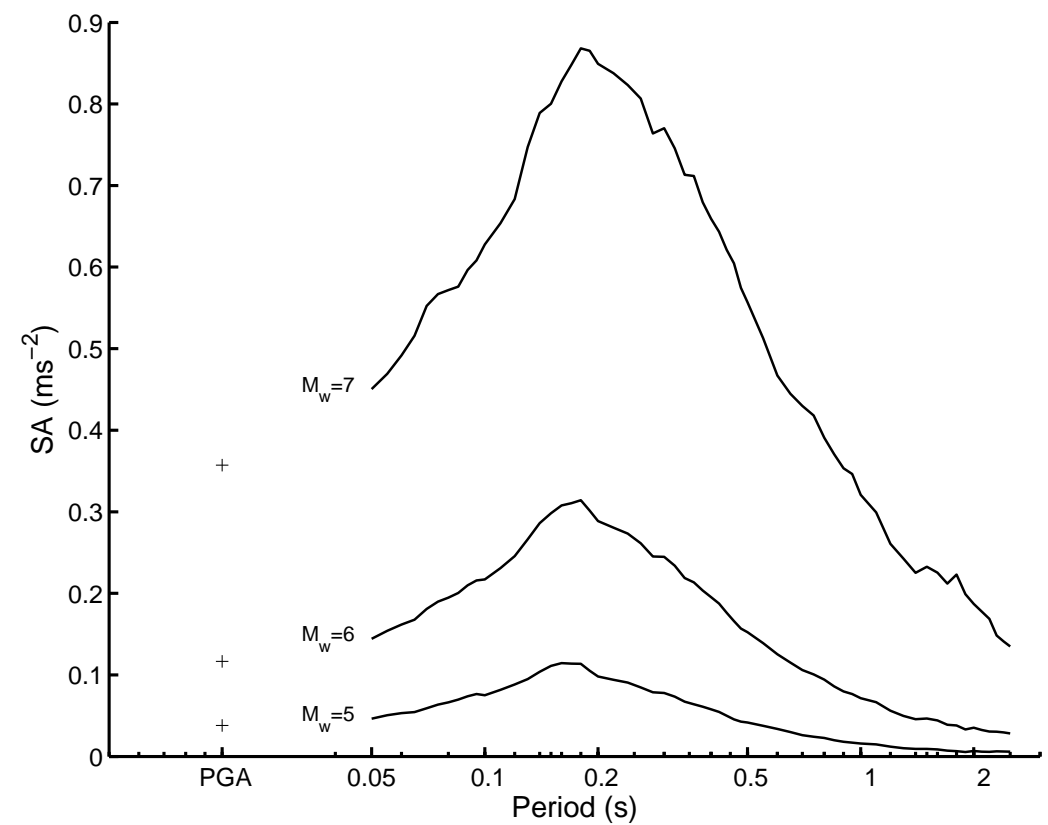

(b)

Figure 7: 


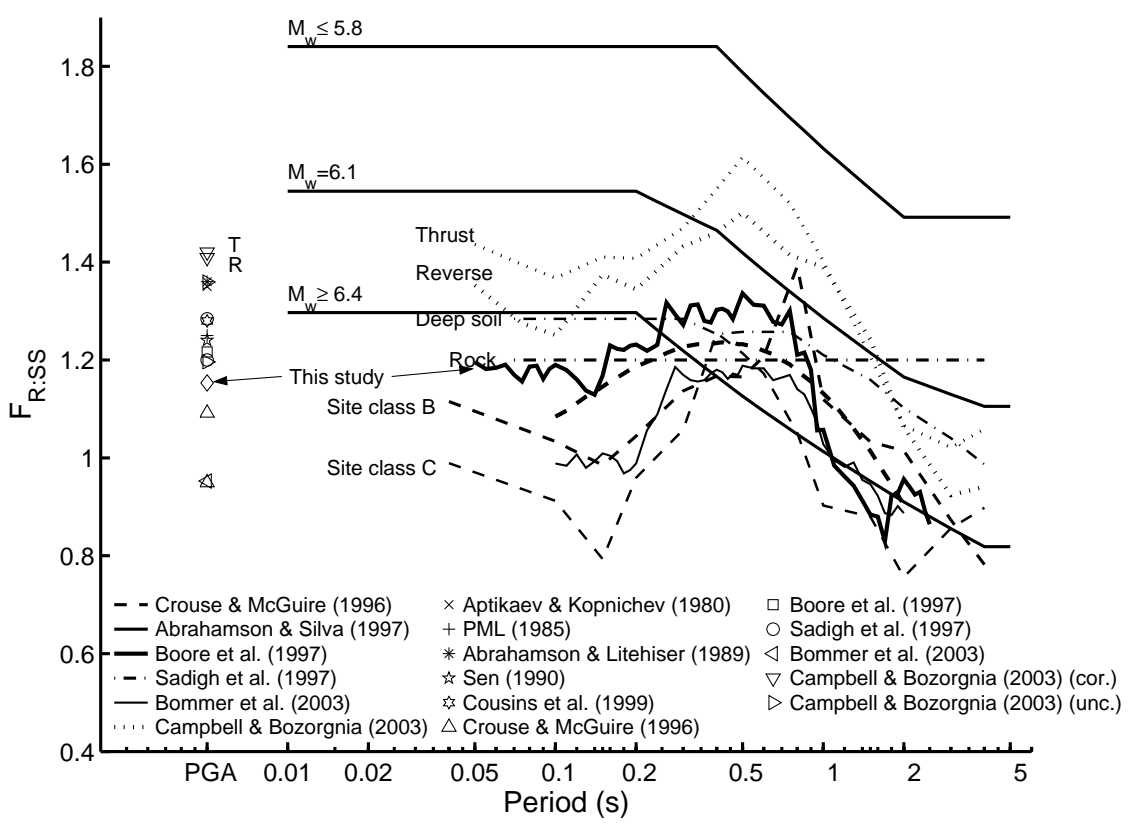

Figure 8:

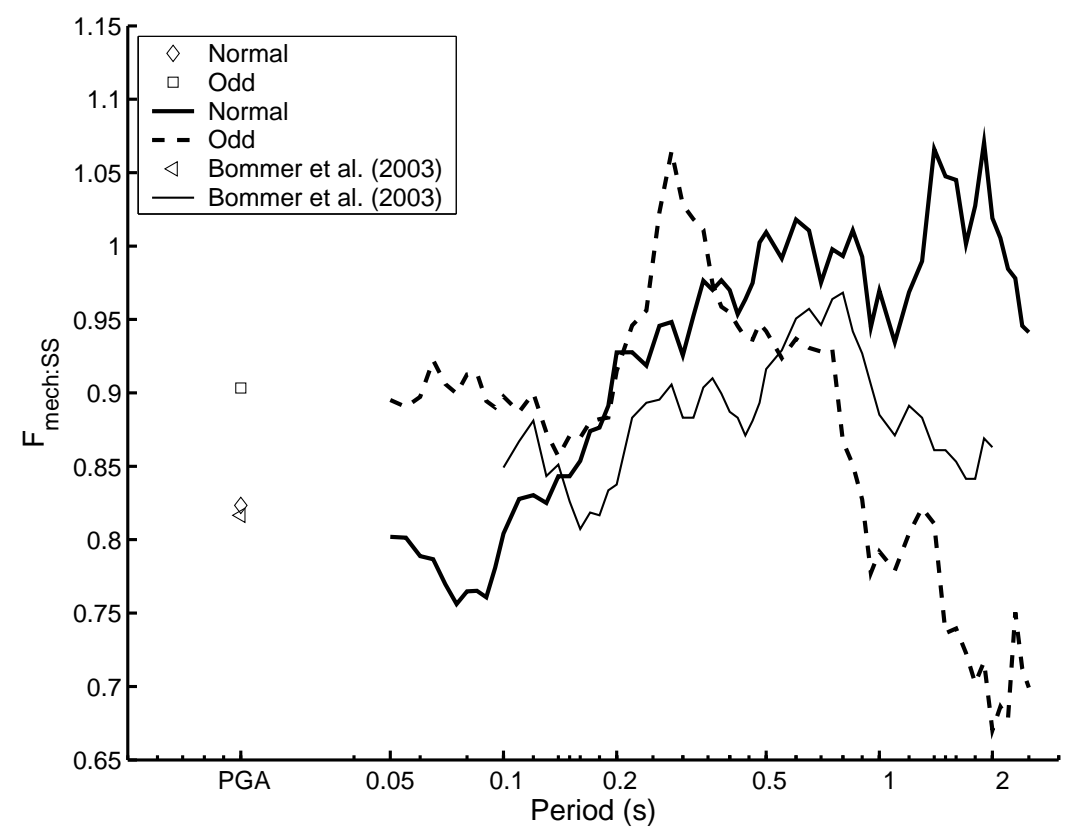

Figure 9: 


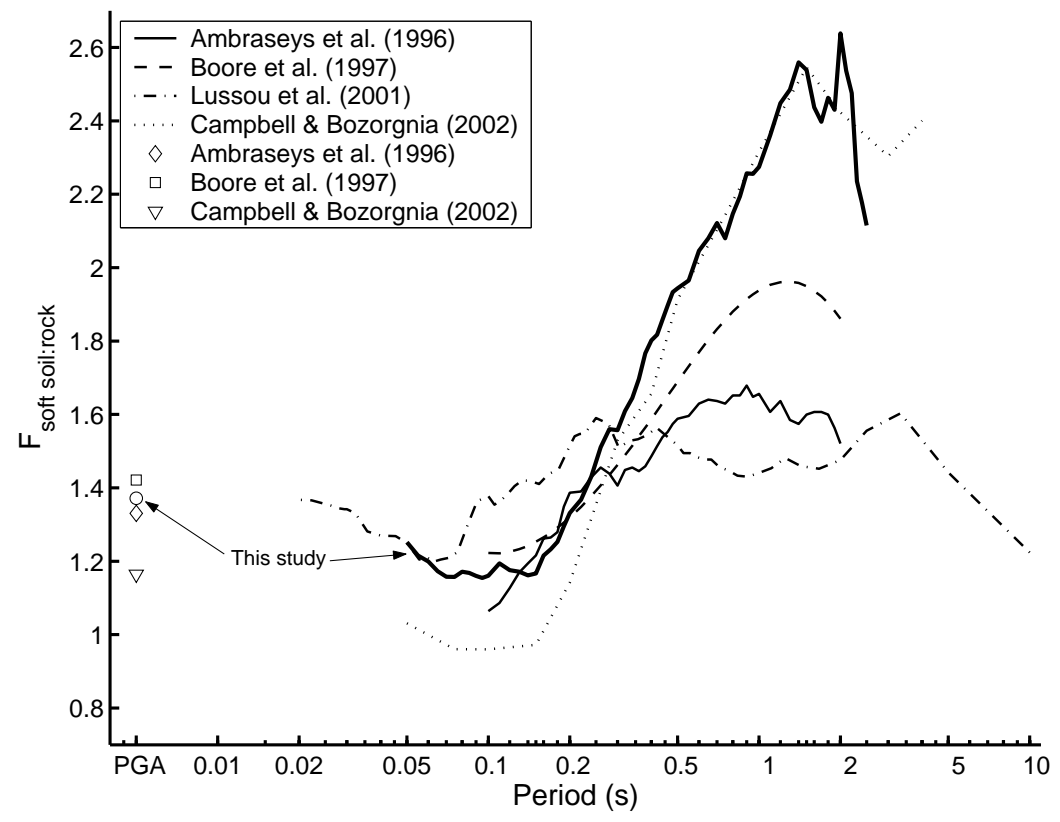

(a)

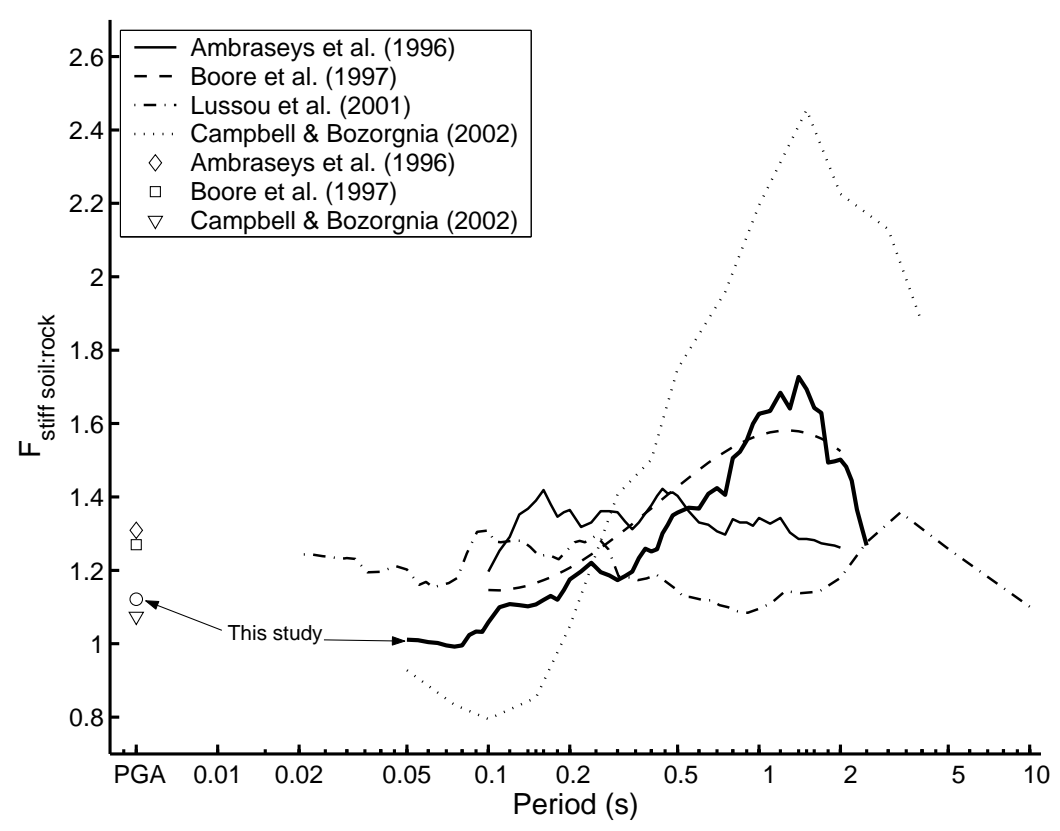

(b)

Figure 10: 


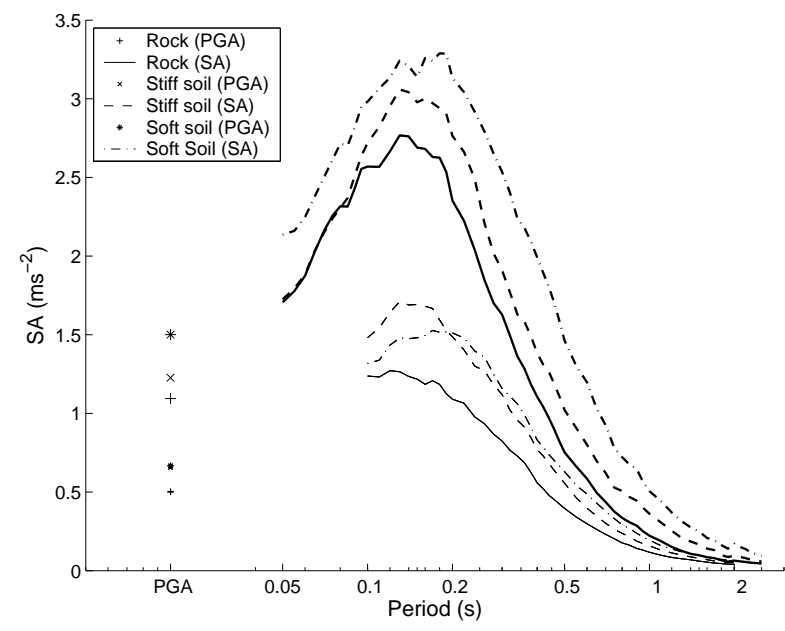

(a)

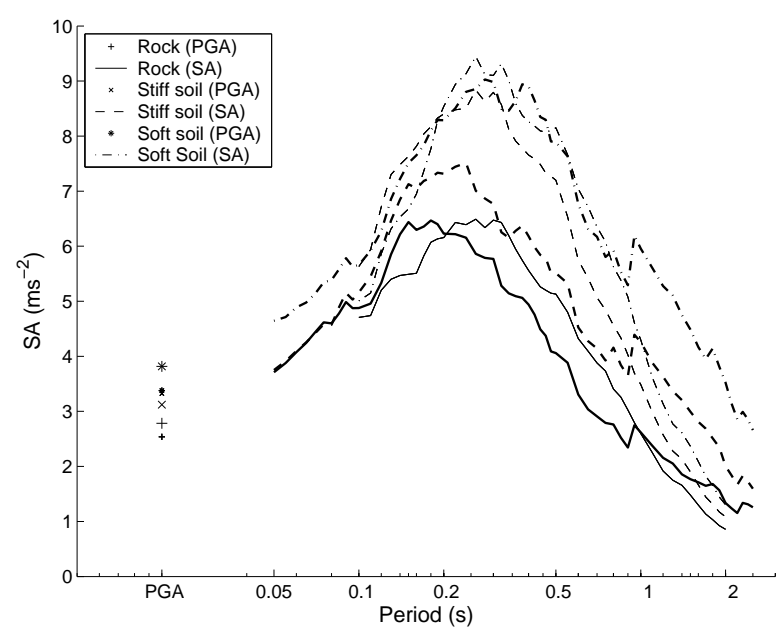

(c)

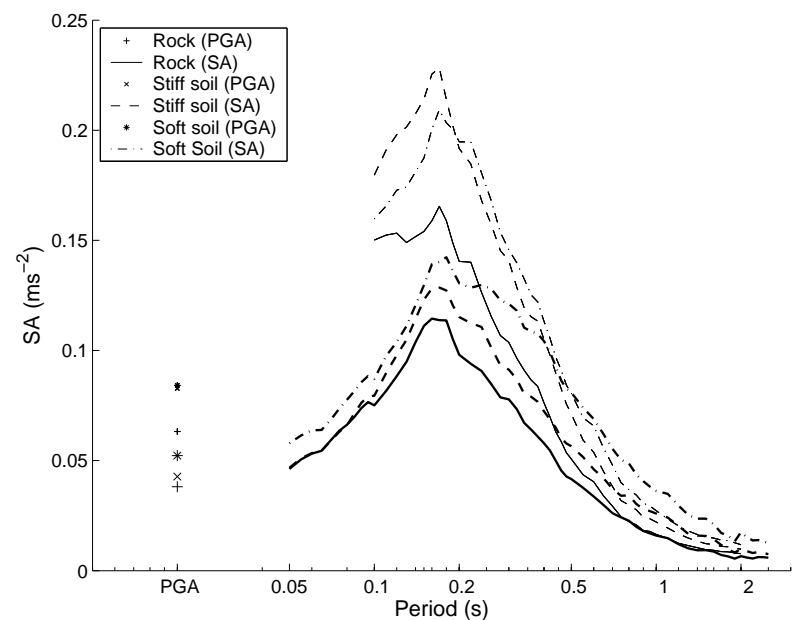

(b)

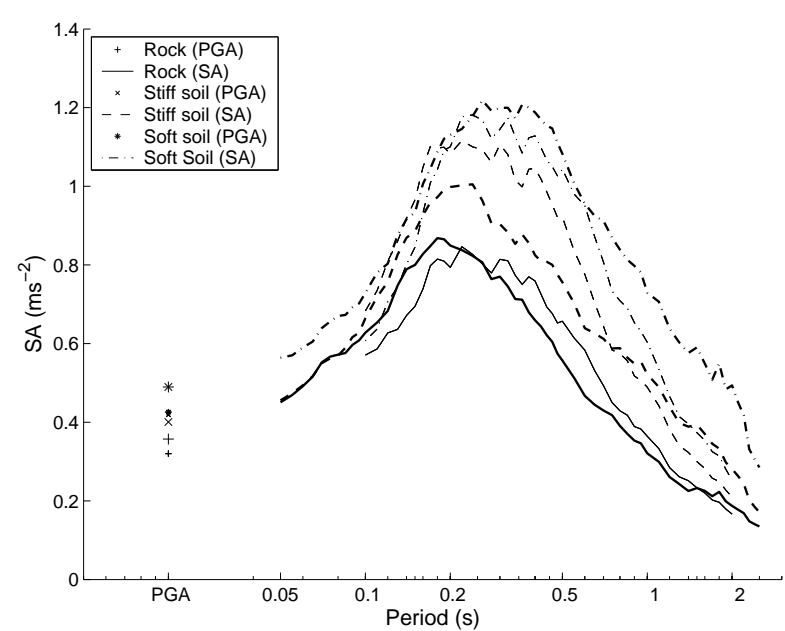

(d)

Figure 11: 


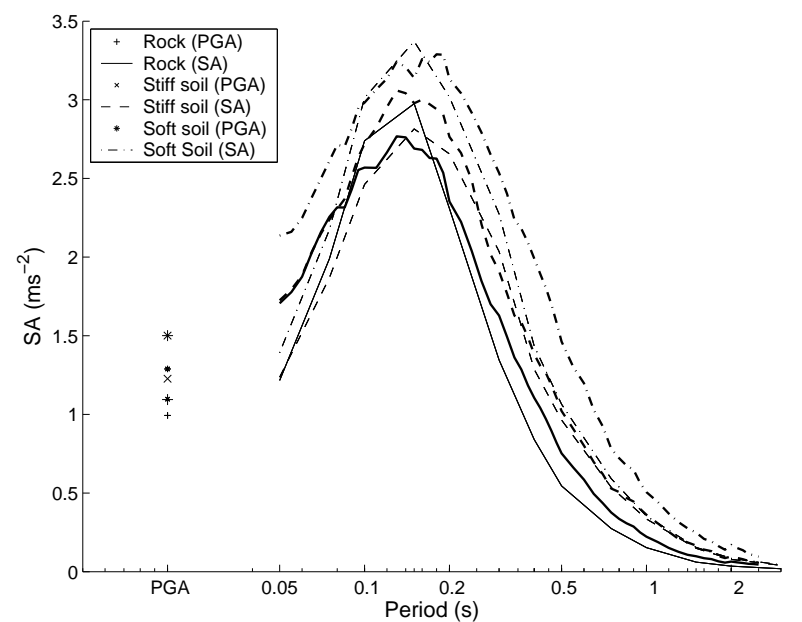

(a)

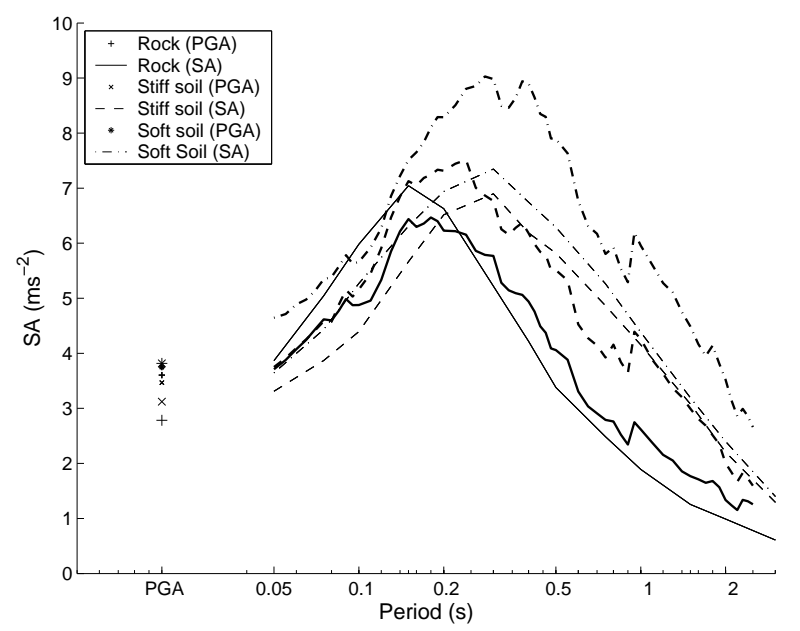

(c)

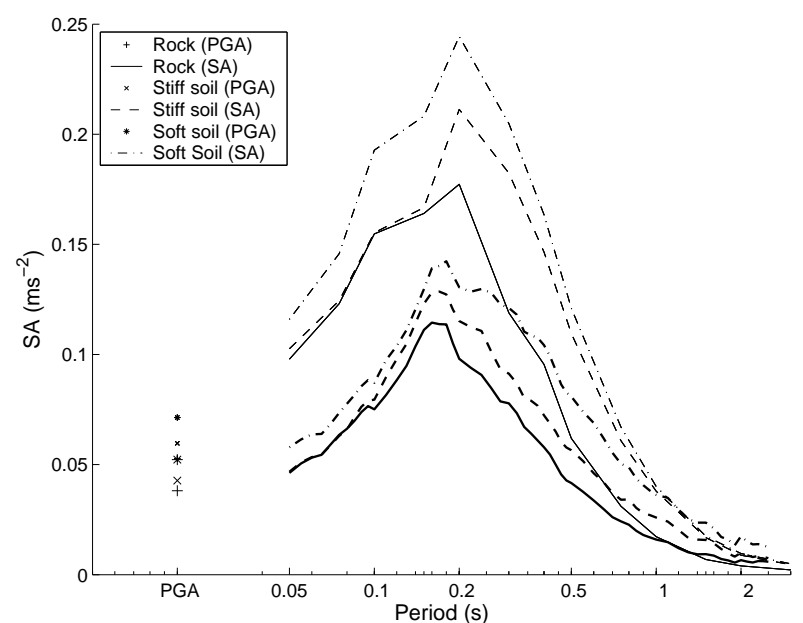

(b)

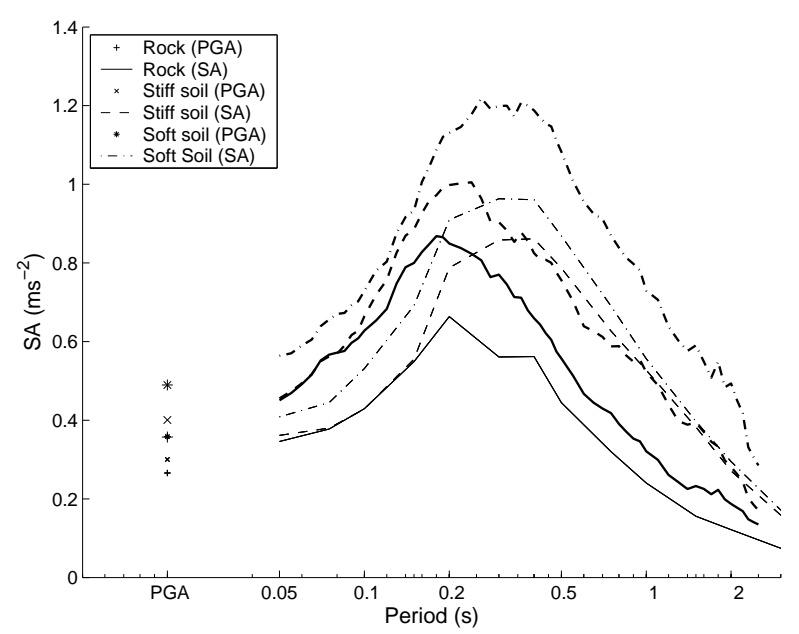

(d)

Figure 12: 


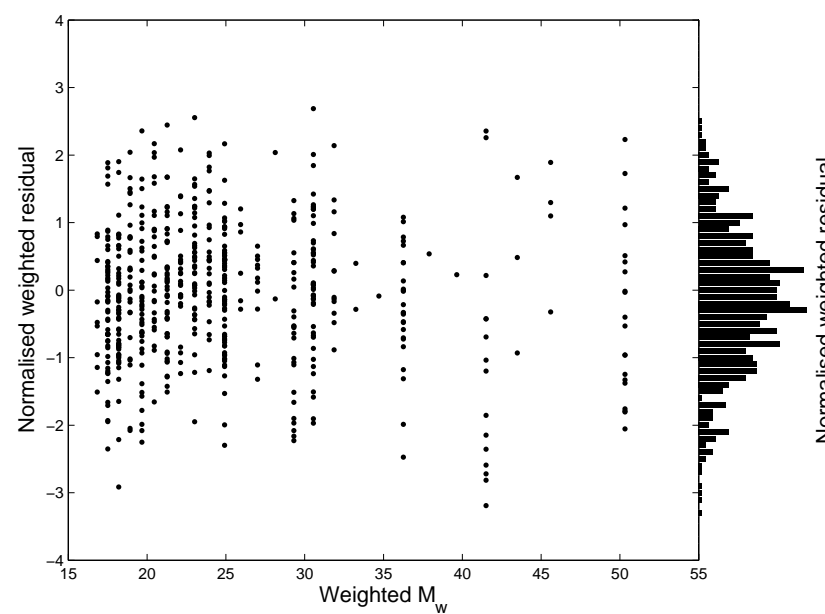

(a)

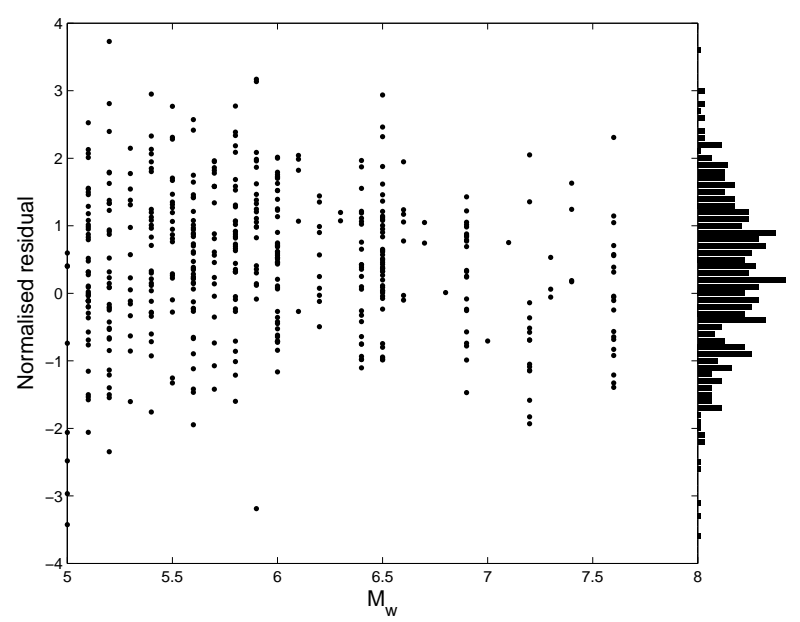

(c)

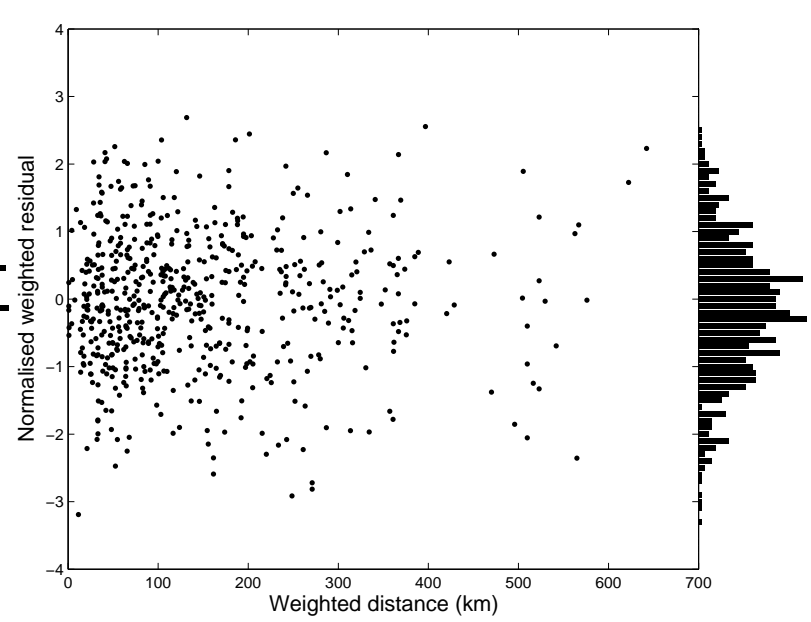

(b)

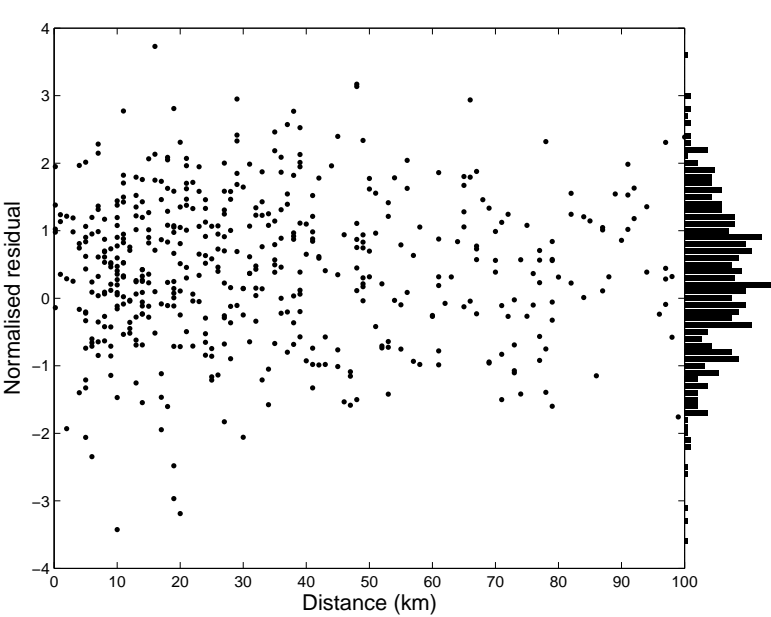

(d)

Figure 13: 


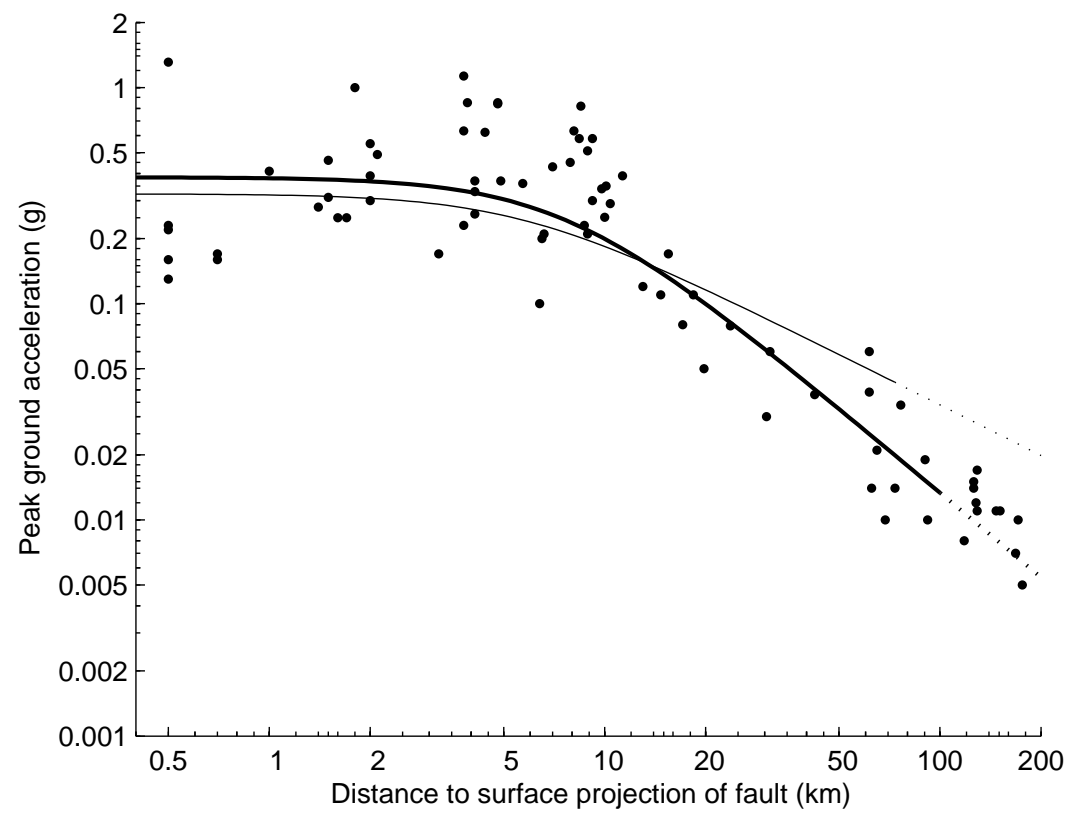

Figure 14: 
Table 5: Strong-motion records used for this study, where Co. is two letter country abbreviation, $h$ is focal depth, Mech. is faulting mechanism ( $\mathrm{N}$ is normal, $\mathrm{O}$ is odd, $\mathrm{S}$ is strike-slip, $\mathrm{T}$ is thrust), Site is local site class ( $\mathrm{L}$ is very soft soil, $\mathrm{S}$ is soft soil, $\mathrm{A}$ is stiff soil and $\mathrm{R}$ is rock) and $d$ is source-to-site distance. Abbreviations used for country names are: AB (Albania), AL (Algeria), AR (Armenia), BH (Bosnia and Herzegovina), CR (Croatia), CY (Cyprus), EG (Egypt), GE (Georgia), GR (Greece), IC (Iceland), IR (Iran), IS (Israel), IT (Italy), LE (Lebanon), MA (Macedonia), PO (Portugal), SM (Serbia \& Montenegro), SL (Slovenia), SP (Spain), SY (Syria), TU (Turkey) and UZ (Uzbekistan).

\begin{tabular}{|c|c|c|c|c|c|c|c|c|c|}
\hline Date & Time (UTC) & Co. & $\begin{array}{r}h \\
(\mathrm{~km})\end{array}$ & $M_{w}$ & Mech. & Station & Co. & Site & $\begin{array}{r}d \\
(\mathrm{~km})\end{array}$ \\
\hline $04 / 11 / 1973$ & $15: 52: 12$ & GR & 7 & 5.8 & $\mathrm{~T}$ & Lefkada-OTE Building & GR & $\mathrm{S}$ & 11 \\
\hline $06 / 05 / 1976$ & $20: 00: 13$ & IT & 7 & 6.5 & $\mathrm{~T}$ & Tolmezzo-Diga Ambiesta & IT & $\mathrm{R}$ & 7 \\
\hline $06 / 05 / 1976$ & $20: 00: 13$ & IT & 7 & 6.5 & $\mathrm{~T}$ & Codroipo & IT & A & 34 \\
\hline $06 / 05 / 1976$ & $20: 00: 13$ & IT & 7 & 6.5 & $\mathrm{~T}$ & Barcis & IT & $\mathrm{s}$ & 37 \\
\hline $06 / 05 / 1976$ & $20: 00: 13$ & IT & 7 & 6.5 & $\mathrm{~T}$ & Conegliano-Veneto & IT & A & 71 \\
\hline $06 / 05 / 1976$ & $20: 00: 13$ & IT & 7 & 6.5 & $\mathrm{~T}$ & Feltre & IT & $\mathrm{R}$ & 90 \\
\hline $07 / 05 / 1976$ & $00: 23: 49$ & IT & 9 & 5.2 & $\mathrm{~T}$ & Tolmezzo-Diga Ambiesta & IT & $\mathrm{R}$ & 14 \\
\hline $17 / 05 / 1976$ & $02: 58: 42$ & $\mathrm{UZ}$ & 30 & 6.7 & $\mathrm{~T}$ & Karakyr Point & $\mathrm{UZ}$ & $\mathrm{L}$ & 4 \\
\hline $17 / 06 / 1976$ & $14: 28: 51$ & IT & 15 & 5.2 & $\mathrm{O}$ & Forgaria-Cornio & IT & A & 16 \\
\hline $11 / 09 / 1976$ & $16: 31: 11$ & IT & 3 & 5.3 & $\mathrm{~T}$ & Tarcento & IT & $\mathrm{R}$ & 8 \\
\hline $11 / 09 / 1976$ & $16: 31: 11$ & IT & 3 & 5.3 & $\mathrm{~T}$ & Buia & IT & $\mathrm{s}$ & 9 \\
\hline $11 / 09 / 1976$ & $16: 31: 11$ & IT & 3 & 5.3 & $\mathrm{~T}$ & Breginj-Fabrika IGLI & SL & A & 15 \\
\hline $11 / 09 / 1976$ & $16: 31: 11$ & IT & 3 & 5.3 & $\mathrm{~T}$ & Forgaria-Cornio & IT & A & 15 \\
\hline $11 / 09 / 1976$ & $16: 31: 11$ & IT & 3 & 5.3 & $\mathrm{~T}$ & Kobarid-Osn.Skola & SL & A & 27 \\
\hline $11 / 09 / 1976$ & $16: 35: 03$ & IT & 12 & 5.5 & $\mathrm{~T}$ & Buia & IT & $\mathrm{s}$ & 7 \\
\hline $11 / 09 / 1976$ & $16: 35: 03$ & IT & 12 & 5.5 & $\mathrm{~T}$ & San Rocco & IT & A & 17 \\
\hline $11 / 09 / 1976$ & $16: 35: 03$ & IT & 12 & 5.5 & $\mathrm{~T}$ & Forgaria-Cornio & IT & A & 17 \\
\hline $11 / 09 / 1976$ & $16: 35: 03$ & IT & 12 & 5.5 & $\mathrm{~T}$ & Robic & SL & $\mathrm{R}$ & 25 \\
\hline $11 / 09 / 1976$ & $16: 35: 03$ & IT & 12 & 5.5 & $\mathrm{~T}$ & Kobarid-Osn.Skola & SL & A & 31 \\
\hline $15 / 09 / 1976$ & 03:15:19 & IT & 5 & 6.0 & $\mathrm{~T}$ & Buia & IT & $\mathrm{s}$ & 9 \\
\hline $15 / 09 / 1976$ & $03: 15: 19$ & IT & 5 & 6.0 & $\mathrm{~T}$ & San Rocco & IT & A & 12 \\
\hline $15 / 09 / 1976$ & 03:15:19 & IT & 5 & 6.0 & $\mathrm{~T}$ & Forgaria-Cornio & IT & A & 12 \\
\hline $15 / 09 / 1976$ & 03:15:19 & IT & 5 & 6.0 & $\mathrm{~T}$ & Breginj-Fabrika IGLI & SL & A & 14 \\
\hline $15 / 09 / 1976$ & 03:15:19 & IT & 5 & 6.0 & $\mathrm{~T}$ & Robic & SL & $\mathrm{R}$ & 19 \\
\hline $15 / 09 / 1976$ & 03:15:19 & IT & 5 & 6.0 & $\mathrm{~T}$ & Kobarid-Osn.Skola & SL & A & 25 \\
\hline $15 / 09 / 1976$ & 03:15:19 & IT & 5 & 6.0 & $\mathrm{~T}$ & Codroipo & IT & A & 35 \\
\hline $15 / 09 / 1976$ & 09:21:19 & IT & 8 & 6.0 & $\mathrm{~T}$ & Tarcento & IT & $\mathrm{R}$ & 6 \\
\hline $15 / 09 / 1976$ & 09:21:19 & IT & 8 & 6.0 & $\mathrm{~T}$ & Breginj-Fabrika IGLI & SL & A & 7 \\
\hline $15 / 09 / 1976$ & 09:21:19 & IT & 8 & 6.0 & $\mathrm{~T}$ & Buia & IT & $\mathrm{s}$ & 8 \\
\hline $15 / 09 / 1976$ & 09:21:19 & IT & 8 & 6.0 & $\mathrm{~T}$ & Forgaria-Cornio & IT & A & 9 \\
\hline $15 / 09 / 1976$ & $09: 21: 19$ & IT & 8 & 6.0 & $\mathrm{~T}$ & San Rocco & IT & A & 9 \\
\hline $15 / 09 / 1976$ & $09: 21: 19$ & IT & 8 & 6.0 & $\mathrm{~T}$ & Robic & SL & $\mathrm{R}$ & 12 \\
\hline $15 / 09 / 1976$ & 09:21:19 & IT & 8 & 6.0 & $\mathrm{~T}$ & Kobarid-Osn.Skola & SL & A & 19 \\
\hline $15 / 09 / 1976$ & 09:21:19 & IT & 8 & 6.0 & $\mathrm{~T}$ & Conegliano-Veneto & IT & A & 70 \\
\hline $15 / 09 / 1976$ & 09:21:19 & IT & 8 & 6.0 & $\mathrm{~T}$ & Feltre & IT & $\mathrm{R}$ & 88 \\
\hline $24 / 11 / 1976$ & $12: 22: 16$ & $\mathrm{TU}$ & 10 & 7.0 & $\mathrm{~s}$ & Maku & IR & A & 52 \\
\hline $16 / 09 / 1977$ & $23: 48: 08$ & IT & 8 & 5.4 & $\mathrm{~T}$ & Forgaria-Cornio & IT & A & 6 \\
\hline $16 / 09 / 1977$ & $23: 48: 08$ & IT & 8 & 5.4 & $\mathrm{~T}$ & San Rocco & IT & A & 7 \\
\hline $16 / 09 / 1977$ & $23: 48: 08$ & IT & 8 & 5.4 & $\mathrm{~T}$ & Somplago Centrale-Uscita Galleria & IT & $\mathrm{R}$ & 9 \\
\hline $16 / 09 / 1977$ & 23:48:08 & IT & 8 & 5.4 & $\mathrm{~T}$ & Tolmezzo-Base Diga & IT & $\mathrm{R}$ & 11 \\
\hline $16 / 09 / 1977$ & 23:48:08 & IT & 8 & 5.4 & $\mathrm{~T}$ & Breginj-Fabrika IGLI & SL & A & 32 \\
\hline $16 / 09 / 1977$ & 23:48:08 & IT & 8 & 5.4 & $\mathrm{~T}$ & Kobarid-Osn.Skola & SL & A & 47 \\
\hline $11 / 03 / 1978$ & $19: 20: 48$ & IT & 15 & 5.2 & $\mathrm{~N}$ & Ferruzzano & IT & $\mathrm{R}$ & 10 \\
\hline $11 / 03 / 1978$ & $19: 20: 48$ & IT & 15 & 5.2 & $\mathrm{~N}$ & Pellaro & IT & $\mathrm{s}$ & 33 \\
\hline $15 / 04 / 1978$ & $23: 33: 48$ & IT & 15 & 6.0 & $\mathrm{O}$ & Patti-Cabina Prima & IT & $\mathrm{s}$ & 13 \\
\hline $15 / 04 / 1978$ & 23:33:48 & IT & 15 & 6.0 & $\mathrm{O}$ & Naso & IT & A & 16 \\
\hline $15 / 04 / 1978$ & 23:33:48 & IT & 15 & 6.0 & $\mathrm{O}$ & Milazzo & IT & $\mathrm{R}$ & 26 \\
\hline $15 / 04 / 1978$ & $23: 33: 48$ & IT & 15 & 6.0 & $\mathrm{O}$ & Messina 1 & IT & $\mathrm{R}$ & 50 \\
\hline $20 / 06 / 1978$ & $20: 03: 22$ & GR & 6 & 6.2 & $\mathrm{~N}$ & Thessaloniki-City Hotel & GR & $\mathrm{s}$ & 13 \\
\hline $20 / 06 / 1978$ & $20: 03: 22$ & GR & 6 & 6.2 & $\mathrm{~N}$ & Gevgelija-Fabrika Keramike & MA & $\mathrm{s}$ & 64 \\
\hline $16 / 09 / 1978$ & $15: 35: 57$ & IR & 4 & 7.3 & $\mathrm{~T}$ & Tabas & IR & A & 8 \\
\hline $16 / 09 / 1978$ & $15: 35: 57$ & IR & 4 & 7.3 & $\mathrm{~T}$ & Dayhook & IR & $\mathrm{R}$ & 14 \\
\hline $16 / 09 / 1978$ & $15: 35: 57$ & IR & 4 & 7.3 & $\mathrm{~T}$ & Boshroyeh & IR & A & 39 \\
\hline 09/04/1979 & $02: 10: 21$ & SM & 13 & 5.4 & $\mathrm{~T}$ & Ulcinj-Hotel Albatros & SM & $\mathrm{R}$ & 15 \\
\hline 09/04/1979 & $02: 10: 21$ & SM & 13 & 5.4 & $\mathrm{~T}$ & Ulcinj-Hotel Olimpic & SM & A & 18 \\
\hline 09/04/1979 & $02: 10: 21$ & SM & 13 & 5.4 & $\mathrm{~T}$ & Petrovac-Hotel Oliva & SM & A & 29 \\
\hline $15 / 04 / 1979$ & $06: 19: 41$ & SM & 12 & 6.9 & $\mathrm{~T}$ & Bar-Skupstina Opstine & SM & A & 3 \\
\hline $15 / 04 / 1979$ & $06: 19: 41$ & SM & 12 & 6.9 & $\mathrm{~T}$ & Petrovac-Hotel Oliva & SM & A & 3 \\
\hline $15 / 04 / 1979$ & $06: 19: 41$ & SM & 12 & 6.9 & $\mathrm{~T}$ & Ulcinj-Hotel Albatros & SM & $\mathrm{R}$ & 11 \\
\hline $15 / 04 / 1979$ & 06:19:41 & SM & 12 & 6.9 & $\mathrm{~T}$ & Ulcinj-Hotel Olimpic & SM & A & 13 \\
\hline $15 / 04 / 1979$ & 06:19:41 & SM & 12 & 6.9 & $\mathrm{~T}$ & Hercegnovi Novi-O.S.D. Pavicic School & SM & $\mathrm{R}$ & 17 \\
\hline $15 / 04 / 1979$ & $06: 19: 41$ & SM & 12 & 6.9 & $\mathrm{~T}$ & Titograd-Seismoloska Stanica & SM & $\mathrm{R}$ & 41 \\
\hline $15 / 04 / 1979$ & $06: 19: 41$ & SM & 12 & 6.9 & $\mathrm{~T}$ & Titograd-Geoloski Zavod & SM & A & 42 \\
\hline $15 / 04 / 1979$ & $06: 19: 41$ & SM & 12 & 6.9 & $\mathrm{~T}$ & Dubrovnik-Pomorska Skola & $\mathrm{CR}$ & $\mathrm{R}$ & 61 \\
\hline $15 / 04 / 1979$ & $06: 19: 41$ & SM & 12 & 6.9 & $\mathrm{~T}$ & Gacko-Zemlj. Zadruga & BH & $\mathrm{s}$ & 96 \\
\hline $15 / 04 / 1979$ & 14:43:06 & SM & 7 & 5.8 & $\mathrm{O}$ & Hercegnovi Novi-O.S.D. Pavicic School & SM & $\mathrm{R}$ & 22 \\
\hline $15 / 04 / 1979$ & 14:43:06 & SM & 7 & 5.8 & $\mathrm{O}$ & Petrovac-Hotel Oliva & SM & A & 24 \\
\hline $15 / 04 / 1979$ & 14:43:06 & SM & 7 & 5.8 & $\mathrm{O}$ & Bar-Skupstina Opstine & SM & A & 41 \\
\hline $15 / 04 / 1979$ & 14:43:06 & SM & 7 & 5.8 & $\mathrm{O}$ & Ulcinj-Hotel Olimpic & SM & A & 63 \\
\hline $24 / 05 / 1979$ & $17: 23: 18$ & SM & 5 & 6.2 & $\mathrm{~T}$ & Budva-PTT & SM & A & 10 \\
\hline $24 / 05 / 1979$ & $17: 23: 18$ & SM & 5 & 6.2 & $\mathrm{~T}$ & Petrovac-Hotel Rivijera & SM & A & 12 \\
\hline $24 / 05 / 1979$ & $17: 23: 18$ & SM & 5 & 6.2 & $\mathrm{~T}$ & Bar-Skupstina Opstine & SM & A & 15 \\
\hline $24 / 05 / 1979$ & $17: 23: 18$ & SM & 5 & 6.2 & $\mathrm{~T}$ & Kotor-Naselje Rakite & SM & A & 19 \\
\hline $24 / 05 / 1979$ & $17: 23: 18$ & SM & 5 & 6.2 & $\mathrm{~T}$ & Tivat-Aerodrom & SM & A & 19 \\
\hline $24 / 05 / 1979$ & $17: 23: 18$ & SM & 5 & 6.2 & $\mathrm{~T}$ & Kotor-Zovod za Biologiju Mora & SM & A & 21 \\
\hline $24 / 05 / 1979$ & $17: 23: 18$ & SM & 5 & 6.2 & $\mathrm{~T}$ & Hercegnovi Novi-O.S.D. Pavicic School & SM & $\mathrm{R}$ & 28 \\
\hline $24 / 05 / 1979$ & $17: 23: 18$ & SM & 5 & 6.2 & $\mathrm{~T}$ & Ulcinj-Hotel Olimpic & SM & A & 35 \\
\hline $18 / 07 / 1979$ & 13:12:02 & $\mathrm{TU}$ & 5 & 5.3 & $\mathrm{~N}$ & Dursunbey-Kandilli Gozlem Istasyonu & $\mathrm{TU}$ & A & 6 \\
\hline $19 / 09 / 1979$ & $21: 35: 37$ & IT & 4 & 5.8 & $\mathrm{~N}$ & Cascia & IT & $\mathrm{R}$ & 1 \\
\hline
\end{tabular}


Table 5: continued

\begin{tabular}{|c|c|c|c|c|}
\hline Date & Time (UTC) & Co. & $\begin{array}{r}h \\
(\mathrm{~km})\end{array}$ & $M_{w}$ \\
\hline $19 / 09 / 1979$ & $21: 35: 37$ & IT & 4 & 5.8 \\
\hline $19 / 09 / 1979$ & $21: 35: 37$ & IT & 4 & 5.8 \\
\hline 19/09/1979 & $21: 35: 37$ & IT & 4 & 5.8 \\
\hline $19 / 09 / 1979$ & $21: 35: 37$ & IT & 4 & 5.8 \\
\hline $01 / 01 / 1980$ & $16: 42: 39$ & $\mathrm{PO}$ & 5 & 6.9 \\
\hline $18 / 05 / 1980$ & $20: 02: 57$ & SM & 4 & 5.9 \\
\hline $18 / 05 / 1980$ & 20:02:57 & SM & 4 & 5.9 \\
\hline $11 / 08 / 1980$ & 09:15:59 & GR & 5 & 5.2 \\
\hline $23 / 11 / 1980$ & $18: 34: 52$ & IT & 16 & 6.9 \\
\hline $23 / 11 / 1980$ & $18: 34: 52$ & IT & 16 & 6.9 \\
\hline $23 / 11 / 1980$ & $18: 34: 52$ & IT & 16 & 6.9 \\
\hline $23 / 11 / 1980$ & $18: 34: 52$ & IT & 16 & 6.9 \\
\hline $23 / 11 / 1980$ & $18: 34: 52$ & IT & 16 & 6.9 \\
\hline $23 / 11 / 1980$ & $18: 34: 52$ & IT & 16 & 6.9 \\
\hline $23 / 11 / 1980$ & $18: 34: 52$ & IT & 16 & 6.9 \\
\hline $23 / 11 / 1980$ & $18: 34: 52$ & IT & 16 & 6.9 \\
\hline $23 / 11 / 1980$ & $18: 34: 52$ & IT & 16 & 6.9 \\
\hline $23 / 11 / 1980$ & $18: 34: 52$ & IT & 16 & 6.9 \\
\hline $23 / 11 / 1980$ & $18: 34: 52$ & IT & 16 & 6.9 \\
\hline $23 / 11 / 1980$ & $18: 34: 52$ & IT & 16 & 6.9 \\
\hline $23 / 11 / 1980$ & $18: 34: 52$ & IT & 16 & 6.9 \\
\hline $16 / 01 / 1981$ & $00: 37: 47$ & IT & 5 & 5.2 \\
\hline $16 / 01 / 1981$ & $00: 37: 47$ & IT & 5 & 5.2 \\
\hline $16 / 01 / 1981$ & $00: 37: 47$ & IT & 5 & 5.2 \\
\hline $16 / 01 / 1981$ & $00: 37: 47$ & IT & 5 & 5.2 \\
\hline $16 / 01 / 1981$ & $00: 37: 47$ & IT & 5 & 5.2 \\
\hline $16 / 01 / 1981$ & $00: 37: 47$ & IT & 5 & 5.2 \\
\hline $16 / 01 / 1981$ & $00: 37: 47$ & IT & 5 & 5.2 \\
\hline $16 / 01 / 1981$ & $00: 37: 47$ & IT & 5 & 5.2 \\
\hline $16 / 01 / 1981$ & $00: 37: 47$ & IT & 5 & 5.2 \\
\hline $16 / 01 / 1981$ & $00: 37: 47$ & IT & 5 & 5.2 \\
\hline $24 / 02 / 1981$ & 20:53:39 & GR & 10 & 6.6 \\
\hline $24 / 02 / 1981$ & $20: 53: 39$ & GR & 10 & 6.6 \\
\hline $25 / 02 / 1981$ & $02: 35: 53$ & GR & 8 & 6.3 \\
\hline $10 / 03 / 1981$ & $15: 16: 20$ & GR & 10 & 5.4 \\
\hline $10 / 03 / 1981$ & $15: 16: 20$ & GR & 10 & 5.4 \\
\hline $13 / 08 / 1981$ & $02: 58: 12$ & BH & 10 & 5.7 \\
\hline $13 / 08 / 1981$ & $02: 58: 12$ & BH & 10 & 5.7 \\
\hline $13 / 08 / 1981$ & $02: 58: 12$ & BH & 10 & 5.7 \\
\hline $17 / 01 / 1983$ & $12: 41: 31$ & GR & 5 & 6.9 \\
\hline $17 / 01 / 1983$ & $12: 41: 31$ & GR & 5 & 6.9 \\
\hline $31 / 01 / 1983$ & $15: 27: 02$ & GR & 4 & 5.4 \\
\hline $23 / 03 / 1983$ & 23:51:08 & GR & 3 & 6.2 \\
\hline $05 / 07 / 1983$ & $12: 01: 27$ & $\mathrm{TU}$ & 7 & 6.1 \\
\hline 05/07/1983 & $12: 01: 27$ & $\mathrm{TU}$ & 7 & 6.1 \\
\hline 06/08/1983 & $15: 43: 53$ & GR & 22 & 6.6 \\
\hline 06/08/1983 & $15: 43: 53$ & GR & 22 & 6.6 \\
\hline $26 / 08 / 1983$ & 12:52:09 & GR & 12 & 5.1 \\
\hline $26 / 08 / 1983$ & $12: 52: 09$ & GR & 12 & 5.1 \\
\hline $26 / 08 / 1983$ & 12:52:09 & GR & 12 & 5.1 \\
\hline $30 / 10 / 1983$ & $04: 12: 28$ & $\mathrm{TU}$ & 16 & 6.6 \\
\hline $30 / 10 / 1983$ & $04: 12: 28$ & $\mathrm{TU}$ & 16 & 6.6 \\
\hline $29 / 04 / 1984$ & 05:02:59 & IT & 9 & 5.6 \\
\hline $29 / 04 / 1984$ & 05:02:59 & IT & 9 & 5.6 \\
\hline $29 / 04 / 1984$ & 05:02:59 & IT & 9 & 5.6 \\
\hline $29 / 04 / 1984$ & 05:02:59 & IT & 9 & 5.6 \\
\hline $29 / 04 / 1984$ & 05:02:59 & IT & 9 & 5.6 \\
\hline $07 / 05 / 1984$ & $17: 49: 42$ & IT & 11 & 5.9 \\
\hline $07 / 05 / 1984$ & $17: 49: 42$ & IT & 11 & 5.9 \\
\hline $07 / 05 / 1984$ & $17: 49: 42$ & IT & 11 & 5.9 \\
\hline $07 / 05 / 1984$ & $17: 49: 42$ & IT & 11 & 5.9 \\
\hline $07 / 05 / 1984$ & $17: 49: 42$ & IT & 11 & 5.9 \\
\hline $07 / 05 / 1984$ & $17: 49: 42$ & IT & 11 & 5.9 \\
\hline $07 / 05 / 1984$ & $17: 49: 42$ & IT & 11 & 5.9 \\
\hline $07 / 05 / 1984$ & $17: 49: 42$ & IT & 11 & 5.9 \\
\hline $11 / 05 / 1984$ & $10: 41: 50$ & IT & 8 & 5.5 \\
\hline $11 / 05 / 1984$ & $10: 41: 50$ & IT & 8 & 5.5 \\
\hline $11 / 05 / 1984$ & $10: 41: 50$ & IT & 8 & 5.5 \\
\hline $11 / 05 / 1984$ & $10: 41: 50$ & IT & 8 & 5.5 \\
\hline $11 / 05 / 1984$ & $10: 41: 50$ & IT & 8 & 5.5 \\
\hline $11 / 05 / 1984$ & $10: 41: 50$ & IT & 8 & 5.5 \\
\hline $11 / 05 / 1984$ & $10: 41: 50$ & IT & 8 & 5.5 \\
\hline 09/07/1984 & $18: 57: 12$ & GR & 5 & 5.2 \\
\hline 09/07/1984 & $18: 57: 12$ & GR & 5 & 5.2 \\
\hline $24 / 08 / 1984$ & $06: 02: 26$ & IS & 18 & 5.3 \\
\hline $24 / 08 / 1984$ & $06: 02: 26$ & IS & 18 & 5.3 \\
\hline $30 / 04 / 1985$ & $18: 14: 13$ & GR & 13 & 5.6 \\
\hline $09 / 11 / 1985$ & $23: 30: 43$ & GR & 18 & 5.2 \\
\hline $09 / 11 / 1985$ & $23: 30: 43$ & GR & 18 & 5.2 \\
\hline 05/05/1986 & 03:35:38 & $\mathrm{TU}$ & 4 & 6.0 \\
\hline 06/06/1986 & $10: 39: 47$ & $\mathrm{TU}$ & 11 & 5.8 \\
\hline $13 / 09 / 1986$ & $17: 24: 34$ & GR & 1 & 5.9 \\
\hline $13 / 09 / 1986$ & $17: 24: 34$ & GR & 1 & 5.9 \\
\hline $27 / 02 / 1987$ & 23:34:52 & GR & 5 & 5.7 \\
\hline $25 / 05 / 1987$ & $11: 31: 56$ & IC & 8 & 6.0 \\
\hline $25 / 05 / 1987$ & $11: 31: 56$ & IC & 8 & 6.0 \\
\hline $25 / 05 / 1987$ & $11: 31: 56$ & IC & 8 & 6.0 \\
\hline $25 / 05 / 1987$ & $11: 31: 56$ & IC & 8 & 6.0 \\
\hline $10 / 06 / 1987$ & $14: 50: 12$ & GR & 30 & 5.3 \\
\hline 09/01/1988 & 01:02:47 & $\mathrm{AB}$ & 5 & 5.9 \\
\hline $18 / 05 / 1988$ & 05:17:42 & GR & 26 & 5.3 \\
\hline $18 / 05 / 1988$ & $05: 17: 42$ & GR & 26 & 5.3 \\
\hline $16 / 10 / 1988$ & $12: 34: 05$ & GR & 4 & 5.9 \\
\hline
\end{tabular}


Table 5: continued

\begin{tabular}{|c|c|c|c|c|}
\hline Date & Time (UTC) & Co. & $\begin{array}{r}h \\
(\mathrm{~km})\end{array}$ & $M_{w}$ \\
\hline $16 / 10 / 1988$ & $12: 34: 05$ & GR & 4 & 5.9 \\
\hline $16 / 10 / 1988$ & $12: 34: 05$ & GR & 4 & 5.9 \\
\hline $07 / 12 / 1988$ & $07: 41: 24$ & $\mathrm{AR}$ & 6 & 6.7 \\
\hline $07 / 06 / 1989$ & $19: 45: 54$ & GR & 25 & 5.2 \\
\hline $07 / 06 / 1989$ & $19: 45: 54$ & GR & 25 & 5.2 \\
\hline $29 / 10 / 1989$ & $19: 09: 13$ & $\mathrm{AL}$ & 6 & 5.9 \\
\hline $29 / 10 / 1989$ & 19:09:13 & $\mathrm{AL}$ & 6 & 5.9 \\
\hline $29 / 10 / 1989$ & 19:09:13 & $\mathrm{AL}$ & 6 & 5.9 \\
\hline 05/05/1990 & $07: 21: 17$ & IT & 8 & 5.8 \\
\hline 05/05/1990 & $07: 21: 17$ & IT & 8 & 5.8 \\
\hline $20 / 06 / 1990$ & 21:00:08 & IR & 19 & 7.4 \\
\hline $20 / 06 / 1990$ & 21:00:08 & IR & 19 & 7.4 \\
\hline $20 / 06 / 1990$ & $21: 00: 08$ & IR & 19 & 7.4 \\
\hline $20 / 06 / 1990$ & $21: 00: 08$ & IR & 19 & 7.4 \\
\hline $13 / 12 / 1990$ & $00: 24: 26$ & IT & 5 & 5.6 \\
\hline $13 / 12 / 1990$ & $00: 24: 26$ & IT & 5 & 5.6 \\
\hline $13 / 12 / 1990$ & $00: 24: 26$ & IT & 5 & 5.6 \\
\hline $16 / 12 / 1990$ & $15: 45: 51$ & AR & 28 & 5.4 \\
\hline $16 / 12 / 1990$ & $15: 45: 51$ & $\mathrm{AR}$ & 28 & 5.4 \\
\hline $16 / 12 / 1990$ & $15: 45: 51$ & $\mathrm{AR}$ & 28 & 5.4 \\
\hline $16 / 12 / 1990$ & $15: 45: 51$ & $\mathrm{AR}$ & 28 & 5.4 \\
\hline $16 / 12 / 1990$ & $15: 45: 51$ & $\mathrm{AR}$ & 28 & 5.4 \\
\hline $16 / 12 / 1990$ & $15: 45: 51$ & AR & 28 & 5.4 \\
\hline $16 / 12 / 1990$ & $15: 45: 51$ & AR & 28 & 5.4 \\
\hline $21 / 12 / 1990$ & $06: 57: 43$ & GR & 1 & 6.1 \\
\hline $21 / 12 / 1990$ & $06: 57: 43$ & GR & 1 & 6.1 \\
\hline $19 / 03 / 1991$ & $12: 09: 23$ & GR & 5 & 5.5 \\
\hline $03 / 05 / 1991$ & $20: 19: 39$ & $\mathrm{GE}$ & 15 & 5.6 \\
\hline 03/05/1991 & $20: 19: 39$ & $\mathrm{GE}$ & 15 & 5.6 \\
\hline 03/05/1991 & $20: 19: 39$ & $\mathrm{GE}$ & 15 & 5.6 \\
\hline 03/05/1991 & $20: 19: 39$ & $\mathrm{GE}$ & 15 & 5.6 \\
\hline $15 / 06 / 1991$ & $00: 59: 20$ & $\mathrm{GE}$ & 6 & 6.0 \\
\hline $15 / 06 / 1991$ & $00: 59: 20$ & $\mathrm{GE}$ & 6 & 6.0 \\
\hline $15 / 06 / 1991$ & $00: 59: 20$ & GE & 6 & 6.0 \\
\hline $15 / 06 / 1991$ & $00: 59: 20$ & GE & 6 & 6.0 \\
\hline $15 / 06 / 1991$ & $00: 59: 20$ & $\mathrm{GE}$ & 6 & 6.0 \\
\hline $26 / 06 / 1991$ & $11: 43: 32$ & GR & 4 & 5.3 \\
\hline $04 / 07 / 1991$ & $06: 26: 29$ & $\mathrm{GE}$ & 12 & 5.4 \\
\hline $06 / 10 / 1991$ & $01: 46: 47$ & $\mathrm{TU}$ & 2 & 5.1 \\
\hline $06 / 10 / 1991$ & 01:46:47 & $\mathrm{TU}$ & 2 & 5.1 \\
\hline $06 / 10 / 1991$ & 01:46:47 & $\mathrm{TU}$ & 2 & 5.1 \\
\hline $23 / 01 / 1992$ & $04: 24: 17$ & GR & 3 & 5.6 \\
\hline $23 / 01 / 1992$ & $04: 24: 17$ & GR & 3 & 5.6 \\
\hline $13 / 03 / 1992$ & $17: 18: 40$ & $\mathrm{TU}$ & 10 & 6.6 \\
\hline $13 / 03 / 1992$ & $17: 18: 40$ & $\mathrm{TU}$ & 10 & 6.6 \\
\hline $13 / 03 / 1992$ & $17: 18: 40$ & $\mathrm{TU}$ & 10 & 6.6 \\
\hline $15 / 03 / 1992$ & $16: 16: 16$ & $\mathrm{TU}$ & 10 & 5.2 \\
\hline $15 / 03 / 1992$ & $16: 16: 16$ & $\mathrm{TU}$ & 10 & 5.2 \\
\hline $06 / 11 / 1992$ & 19:08:09 & $\mathrm{TU}$ & 17 & 6.0 \\
\hline 18/11/1992 & $21: 10: 41$ & GR & 15 & 5.9 \\
\hline $18 / 11 / 1992$ & $21: 10: 41$ & GR & 15 & 5.9 \\
\hline 05/03/1993 & 06:55:06 & GR & 1 & 5.2 \\
\hline 05/03/1993 & 06:55:06 & GR & 1 & 5.2 \\
\hline $26 / 03 / 1993$ & $11: 58: 15$ & GR & 10 & 5.4 \\
\hline $26 / 03 / 1993$ & $11: 58: 15$ & GR & 10 & 5.4 \\
\hline $13 / 06 / 1993$ & 23:26:40 & GR & 5 & 5.3 \\
\hline $13 / 06 / 1993$ & $23: 26: 40$ & GR & 5 & 5.3 \\
\hline $14 / 07 / 1993$ & $12: 31: 50$ & GR & 13 & 5.6 \\
\hline $14 / 07 / 1993$ & $12: 31: 50$ & GR & 13 & 5.6 \\
\hline $14 / 07 / 1993$ & $12: 31: 50$ & GR & 13 & 5.6 \\
\hline $14 / 07 / 1993$ & $12: 31: 50$ & GR & 13 & 5.6 \\
\hline $14 / 07 / 1993$ & $12: 31: 50$ & GR & 13 & 5.6 \\
\hline $14 / 07 / 1993$ & $12: 31: 50$ & GR & 13 & 5.6 \\
\hline $14 / 07 / 1993$ & $12: 31: 50$ & GR & 13 & 5.6 \\
\hline $04 / 11 / 1993$ & $05: 18: 37$ & GR & 10 & 5.3 \\
\hline $04 / 11 / 1993$ & $05: 18: 37$ & GR & 10 & 5.3 \\
\hline $04 / 11 / 1993$ & $05: 18: 37$ & GR & 10 & 5.3 \\
\hline $23 / 12 / 1993$ & $14: 22: 34$ & SP & 18 & 5.2 \\
\hline $23 / 12 / 1993$ & $14: 22: 34$ & SP & 18 & 5.2 \\
\hline $23 / 12 / 1993$ & $14: 22: 34$ & SP & 18 & 5.2 \\
\hline $23 / 12 / 1993$ & $14: 22: 34$ & SP & 18 & 5.2 \\
\hline $23 / 12 / 1993$ & $14: 22: 34$ & SP & 18 & 5.2 \\
\hline $23 / 12 / 1993$ & $14: 22: 34$ & SP & 18 & 5.2 \\
\hline $25 / 02 / 1994$ & $02: 30: 50$ & GR & 5 & 5.4 \\
\hline $25 / 02 / 1994$ & $02: 30: 50$ & GR & 5 & 5.4 \\
\hline $25 / 02 / 1994$ & $02: 30: 50$ & GR & 5 & 5.4 \\
\hline $25 / 02 / 1994$ & $02: 30: 50$ & GR & 5 & 5.4 \\
\hline $25 / 02 / 1994$ & $02: 30: 50$ & GR & 5 & 5.4 \\
\hline 20/06/1994 & 09:09:03 & IR & 9 & 5.9 \\
\hline 20/06/1994 & 09:09:03 & IR & 9 & 5.9 \\
\hline 20/06/1994 & 09:09:03 & IR & 9 & 5.9 \\
\hline 20/06/1994 & 09:09:03 & IR & 9 & 5.9 \\
\hline 20/06/1994 & 09:09:03 & IR & 9 & 5.9 \\
\hline 20/06/1994 & 09:09:03 & IR & 9 & 5.9 \\
\hline 20/06/1994 & 09:09:03 & IR & 9 & 5.9 \\
\hline 29/11/1994 & $14: 30: 30$ & GR & 21 & 5.1 \\
\hline 29/11/1994 & $14: 30: 30$ & GR & 21 & 5.1 \\
\hline $29 / 11 / 1994$ & $14: 30: 30$ & GR & 21 & 5.1 \\
\hline $04 / 05 / 1995$ & $00: 34: 11$ & GR & 14 & 5.3 \\
\hline $04 / 05 / 1995$ & 00:34:11 & GR & 14 & 5.3 \\
\hline $04 / 05 / 1995$ & 00:34:11 & GR & 14 & 5.3 \\
\hline $13 / 05 / 1995$ & $08: 47: 15$ & GR & 14 & 6.5 \\
\hline $13 / 05 / 1995$ & $08: 47: 15$ & GR & 14 & 6.5 \\
\hline
\end{tabular}


Table 5: continued

\begin{tabular}{|c|c|c|c|c|}
\hline Date & Time (UTC) & Co. & $\begin{array}{r}h \\
(\mathrm{~km})\end{array}$ & $M_{w}$ \\
\hline $13 / 05 / 1995$ & $08: 47: 15$ & GR & 14 & 6.5 \\
\hline $13 / 05 / 1995$ & $08: 47: 15$ & GR & 14 & 6.5 \\
\hline $13 / 05 / 1995$ & $08: 47: 15$ & GR & 14 & 6.5 \\
\hline $13 / 05 / 1995$ & $08: 47: 15$ & GR & 14 & 6.5 \\
\hline $13 / 05 / 1995$ & $08: 47: 15$ & GR & 14 & 6.5 \\
\hline $15 / 05 / 1995$ & 04:13:57 & GR & 9 & 5.2 \\
\hline $15 / 05 / 1995$ & 04:13:57 & GR & 9 & 5.2 \\
\hline $15 / 05 / 1995$ & 04:13:57 & GR & 9 & 5.2 \\
\hline $19 / 05 / 1995$ & $06: 48: 49$ & GR & 7 & 5.2 \\
\hline $19 / 05 / 1995$ & 06:48:49 & GR & 7 & 5.2 \\
\hline $19 / 05 / 1995$ & 06:48:49 & GR & 7 & 5.2 \\
\hline $19 / 05 / 1995$ & 06:48:49 & GR & 7 & 5.2 \\
\hline $15 / 06 / 1995$ & $00: 15: 51$ & GR & 10 & 6.5 \\
\hline $15 / 06 / 1995$ & $00: 15: 51$ & GR & 10 & 6.5 \\
\hline $15 / 06 / 1995$ & $00: 15: 51$ & GR & 10 & 6.5 \\
\hline $15 / 06 / 1995$ & $00: 15: 51$ & GR & 10 & 6.5 \\
\hline $15 / 06 / 1995$ & $00: 15: 51$ & GR & 10 & 6.5 \\
\hline $15 / 06 / 1995$ & $00: 15: 51$ & GR & 10 & 6.5 \\
\hline $15 / 06 / 1995$ & $00: 15: 51$ & GR & 10 & 6.5 \\
\hline $15 / 06 / 1995$ & $00: 15: 51$ & GR & 10 & 6.5 \\
\hline $17 / 07 / 1995$ & $23: 18: 15$ & GR & 22 & 5.2 \\
\hline $01 / 10 / 1995$ & $15: 57: 13$ & $\mathrm{TU}$ & 10 & 6.4 \\
\hline 01/10/1995 & $15: 57: 13$ & $\mathrm{TU}$ & 10 & 6.4 \\
\hline $01 / 10 / 1995$ & $15: 57: 13$ & $\mathrm{TU}$ & 10 & 6.4 \\
\hline $01 / 10 / 1995$ & $15: 57: 13$ & $\mathrm{TU}$ & 10 & 6.4 \\
\hline $22 / 11 / 1995$ & $04: 15: 12$ & EG & 13 & 7.1 \\
\hline $23 / 11 / 1995$ & $18: 07: 13$ & EG & 24 & 5.7 \\
\hline $05 / 12 / 1995$ & $18: 49: 32$ & $\mathrm{TU}$ & 11 & 5.8 \\
\hline $02 / 04 / 1996$ & $07: 59: 26$ & GR & 15 & 5.4 \\
\hline $14 / 08 / 1996$ & 01:55:03 & $\mathrm{TU}$ & 10 & 5.7 \\
\hline $14 / 08 / 1996$ & 02:59:41 & $\mathrm{TU}$ & 10 & 5.6 \\
\hline $14 / 08 / 1996$ & 02:59:41 & $\mathrm{TU}$ & 10 & 5.6 \\
\hline $09 / 10 / 1996$ & $13: 10: 50$ & $\mathrm{CY}$ & 19 & 6.8 \\
\hline $24 / 12 / 1996$ & $22: 16: 26$ & SY & 29 & 5.5 \\
\hline $13 / 01 / 1997$ & $10: 19: 25$ & $\mathrm{CY}$ & 15 & 5.7 \\
\hline $13 / 01 / 1997$ & $10: 19: 25$ & $\mathrm{CY}$ & 15 & 5.7 \\
\hline $13 / 01 / 1997$ & $10: 19: 25$ & $\mathrm{CY}$ & 15 & 5.7 \\
\hline $22 / 01 / 1997$ & $17: 57: 20$ & $\mathrm{TU}$ & 15 & 5.7 \\
\hline $22 / 01 / 1997$ & $17: 57: 20$ & $\mathrm{TU}$ & 15 & 5.7 \\
\hline $22 / 01 / 1997$ & $17: 57: 20$ & $\mathrm{TU}$ & 15 & 5.7 \\
\hline $22 / 01 / 1997$ & $18: 24: 51$ & $\mathrm{TU}$ & 10 & 5.1 \\
\hline $22 / 01 / 1997$ & $18: 24: 51$ & $\mathrm{TU}$ & 10 & 5.1 \\
\hline $26 / 03 / 1997$ & $04: 22: 51$ & LE & 5 & 5.1 \\
\hline $26 / 04 / 1997$ & $22: 18: 34$ & GR & 7 & 5.0 \\
\hline 26/09/1997 & $00: 33: 16$ & IT & 7 & 5.7 \\
\hline 26/09/1997 & $00: 33: 16$ & IT & 7 & 5.7 \\
\hline 26/09/1997 & $00: 33: 16$ & IT & 7 & 5.7 \\
\hline 26/09/1997 & $00: 33: 16$ & IT & 7 & 5.7 \\
\hline $26 / 09 / 1997$ & $00: 33: 16$ & IT & 7 & 5.7 \\
\hline 26/09/1997 & $00: 33: 16$ & IT & 7 & 5.7 \\
\hline 26/09/1997 & $00: 33: 16$ & IT & 7 & 5.7 \\
\hline 26/09/1997 & $00: 33: 16$ & IT & 7 & 5.7 \\
\hline $26 / 09 / 1997$ & $00: 33: 16$ & IT & 7 & 5.7 \\
\hline $26 / 09 / 1997$ & $00: 33: 16$ & IT & 7 & 5.7 \\
\hline $26 / 09 / 1997$ & $00: 33: 16$ & IT & 7 & 5.7 \\
\hline $26 / 09 / 1997$ & $00: 33: 16$ & IT & 7 & 5.7 \\
\hline 26/09/1997 & 09:40:30 & IT & 6 & 6.0 \\
\hline 26/09/1997 & 09:40:30 & IT & 6 & 6.0 \\
\hline 26/09/1997 & 09:40:30 & IT & 6 & 6.0 \\
\hline $26 / 09 / 1997$ & 09:40:30 & IT & 6 & 6.0 \\
\hline $26 / 09 / 1997$ & 09:40:30 & IT & 6 & 6.0 \\
\hline 26/09/1997 & 09:40:30 & IT & 6 & 6.0 \\
\hline 26/09/1997 & 09:40:30 & IT & 6 & 6.0 \\
\hline 26/09/1997 & 09:40:30 & IT & 6 & 6.0 \\
\hline 26/09/1997 & 09:40:30 & IT & 6 & 6.0 \\
\hline $26 / 09 / 1997$ & $09: 40: 30$ & IT & 6 & 6.0 \\
\hline 26/09/1997 & 09:40:30 & IT & 6 & 6.0 \\
\hline 26/09/1997 & 09:40:30 & IT & 6 & 6.0 \\
\hline 26/09/1997 & 09:40:30 & IT & 6 & 6.0 \\
\hline 26/09/1997 & 09:40:30 & IT & 6 & 6.0 \\
\hline 26/09/1997 & 09:40:30 & IT & 6 & 6.0 \\
\hline 26/09/1997 & 09:40:30 & IT & 6 & 6.0 \\
\hline 03/10/1997 & $08: 55: 22$ & IT & 6 & 5.3 \\
\hline 03/10/1997 & $08: 55: 22$ & IT & 6 & 5.3 \\
\hline 03/10/1997 & $08: 55: 22$ & IT & 6 & 5.3 \\
\hline 03/10/1997 & $08: 55: 22$ & IT & 6 & 5.3 \\
\hline 03/10/1997 & $08: 55: 22$ & IT & 6 & 5.3 \\
\hline 03/10/1997 & $08: 55: 22$ & IT & 6 & 5.3 \\
\hline 03/10/1997 & $08: 55: 22$ & IT & 6 & 5.3 \\
\hline 03/10/1997 & $08: 55: 22$ & IT & 6 & 5.3 \\
\hline 03/10/1997 & $08: 55: 22$ & IT & 6 & 5.3 \\
\hline 06/10/1997 & $23: 24: 00$ & IT & 7 & 5.5 \\
\hline $06 / 10 / 1997$ & $23: 24: 00$ & IT & 7 & 5.5 \\
\hline 06/10/1997 & $23: 24: 00$ & IT & 7 & 5.5 \\
\hline 06/10/1997 & $23: 24: 00$ & IT & 7 & 5.5 \\
\hline $06 / 10 / 1997$ & 23:24:00 & IT & 7 & 5.5 \\
\hline $06 / 10 / 1997$ & $23: 24: 00$ & IT & 7 & 5.5 \\
\hline $06 / 10 / 1997$ & $23: 24: 00$ & IT & 7 & 5.5 \\
\hline 06/10/1997 & $23: 24: 00$ & IT & 7 & 5.5 \\
\hline 06/10/1997 & 23:24:00 & IT & 7 & 5.5 \\
\hline $06 / 10 / 1997$ & 23:24:00 & IT & 7 & 5.5 \\
\hline $06 / 10 / 1997$ & $23: 24: 00$ & IT & 7 & 5.5 \\
\hline $06 / 10 / 1997$ & $23: 24: 00$ & IT & 7 & 5.5 \\
\hline
\end{tabular}


Table 5: continued

\begin{tabular}{|c|c|c|c|c|}
\hline Date & Time (UTC) & Co. & $\begin{array}{r}h \\
(\mathrm{~km}) \\
\end{array}$ & $M_{w}$ \\
\hline $06 / 10 / 1997$ & $23: 24: 00$ & IT & 7 & 5.5 \\
\hline $12 / 10 / 1997$ & $11: 08: 36$ & IT & 6 & 5.2 \\
\hline $12 / 10 / 1997$ & 11:08:36 & IT & 6 & 5.2 \\
\hline $12 / 10 / 1997$ & 11:08:36 & IT & 6 & 5.2 \\
\hline $12 / 10 / 1997$ & 11:08:36 & IT & 6 & 5.2 \\
\hline $12 / 10 / 1997$ & 11:08:36 & IT & 6 & 5.2 \\
\hline $12 / 10 / 1997$ & 11:08:36 & IT & 6 & 5.2 \\
\hline $12 / 10 / 1997$ & 11:08:36 & IT & 6 & 5.2 \\
\hline $12 / 10 / 1997$ & $11: 08: 36$ & IT & 6 & 5.2 \\
\hline $12 / 10 / 1997$ & 11:08:36 & IT & 6 & 5.2 \\
\hline $12 / 10 / 1997$ & 11:08:36 & IT & 6 & 5.2 \\
\hline $12 / 10 / 1997$ & 11:08:36 & IT & 6 & 5.2 \\
\hline $05 / 11 / 1997$ & $21: 10: 28$ & GR & 24 & 5.6 \\
\hline $05 / 11 / 1997$ & $21: 10: 28$ & GR & 24 & 5.6 \\
\hline $18 / 11 / 1997$ & 13:07:41 & GR & 10 & 6.6 \\
\hline 18/11/1997 & 13:07:41 & GR & 10 & 6.6 \\
\hline 18/11/1997 & 13:07:41 & GR & 10 & 6.6 \\
\hline $18 / 11 / 1997$ & 13:13:46 & GR & 10 & 6.0 \\
\hline $18 / 11 / 1997$ & 13:13:46 & GR & 10 & 6.0 \\
\hline $21 / 03 / 1998$ & $16: 45: 10$ & IT & 10 & 5.0 \\
\hline $21 / 03 / 1998$ & $16: 45: 10$ & IT & 10 & 5.0 \\
\hline $21 / 03 / 1998$ & $16: 45: 10$ & IT & 10 & 5.0 \\
\hline $21 / 03 / 1998$ & $16: 45: 10$ & IT & 10 & 5.0 \\
\hline $21 / 03 / 1998$ & $16: 45: 10$ & IT & 10 & 5.0 \\
\hline $21 / 03 / 1998$ & $16: 45: 10$ & IT & 10 & 5.0 \\
\hline $21 / 03 / 1998$ & $16: 45: 10$ & IT & 10 & 5.0 \\
\hline $21 / 03 / 1998$ & $16: 45: 10$ & IT & 10 & 5.0 \\
\hline $03 / 04 / 1998$ & 07:26:00 & IT & 6 & 5.1 \\
\hline $03 / 04 / 1998$ & 07:26:00 & IT & 6 & 5.1 \\
\hline $03 / 04 / 1998$ & 07:26:00 & IT & 6 & 5.1 \\
\hline 03/04/1998 & 07:26:00 & IT & 6 & 5.1 \\
\hline 03/04/1998 & 07:26:00 & IT & 6 & 5.1 \\
\hline 03/04/1998 & 07:26:00 & IT & 6 & 5.1 \\
\hline 03/04/1998 & 07:26:00 & IT & 6 & 5.1 \\
\hline $03 / 04 / 1998$ & 07:26:00 & IT & 6 & 5.1 \\
\hline $03 / 04 / 1998$ & 07:26:00 & IT & 6 & 5.1 \\
\hline $03 / 04 / 1998$ & 07:26:00 & IT & 6 & 5.1 \\
\hline 03/04/1998 & 07:26:00 & IT & 6 & 5.1 \\
\hline 03/04/1998 & 07:26:00 & IT & 6 & 5.1 \\
\hline 03/04/1998 & 07:26:00 & IT & 6 & 5.1 \\
\hline 03/04/1998 & 07:26:00 & IT & 6 & 5.1 \\
\hline $12 / 04 / 1998$ & $10: 55: 33$ & SL & 8 & 5.6 \\
\hline $12 / 04 / 1998$ & $10: 55: 33$ & SL & 8 & 5.6 \\
\hline $12 / 04 / 1998$ & $10: 55: 33$ & SL & 8 & 5.6 \\
\hline $12 / 04 / 1998$ & $10: 55: 33$ & SL & 8 & 5.6 \\
\hline $12 / 04 / 1998$ & $10: 55: 33$ & SL & 8 & 5.6 \\
\hline $12 / 04 / 1998$ & $10: 55: 33$ & SL & 8 & 5.6 \\
\hline $12 / 04 / 1998$ & $10: 55: 33$ & SL & 8 & 5.6 \\
\hline $12 / 04 / 1998$ & $10: 55: 33$ & SL & 8 & 5.6 \\
\hline 04/06/1998 & $21: 36: 54$ & IC & & 5.4 \\
\hline $04 / 06 / 1998$ & $21: 36: 54$ & IC & & 5.4 \\
\hline $04 / 06 / 1998$ & $21: 36: 54$ & IC & & 5.4 \\
\hline $04 / 06 / 1998$ & $21: 36: 54$ & IC & & 5.4 \\
\hline $04 / 06 / 1998$ & $21: 36: 54$ & IC & & 5.4 \\
\hline $04 / 06 / 1998$ & $21: 36: 54$ & IC & & 5.4 \\
\hline 04/06/1998 & $21: 36: 54$ & IC & & 5.4 \\
\hline $04 / 06 / 1998$ & 21:36:54 & IC & & 5.4 \\
\hline $04 / 06 / 1998$ & $21: 36: 54$ & IC & & 5.4 \\
\hline $04 / 06 / 1998$ & $21: 36: 54$ & IC & & 5.4 \\
\hline 09/07/1998 & 05:19:07 & PO & 10 & 6.1 \\
\hline 09/07/1998 & 05:19:07 & PO & 10 & 6.1 \\
\hline $13 / 11 / 1998$ & $10: 38: 34$ & IC & & 5.1 \\
\hline 13/11/1998 & $10: 38: 34$ & IC & & 5.1 \\
\hline $13 / 11 / 1998$ & $10: 38: 34$ & IC & & 5.1 \\
\hline $13 / 11 / 1998$ & $10: 38: 34$ & IC & & 5.1 \\
\hline $13 / 11 / 1998$ & $10: 38: 34$ & IC & & 5.1 \\
\hline $13 / 11 / 1998$ & $10: 38: 34$ & IC & & 5.1 \\
\hline $13 / 11 / 1998$ & $10: 38: 34$ & IC & & 5.1 \\
\hline $13 / 11 / 1998$ & $10: 38: 34$ & IC & & 5.1 \\
\hline 17/08/1999 & 00:01:40 & $\mathrm{TU}$ & 17 & 7.6 \\
\hline $17 / 08 / 1999$ & 00:01:40 & $\mathrm{TU}$ & 17 & 7.6 \\
\hline $17 / 08 / 1999$ & 00:01:40 & $\mathrm{TU}$ & 17 & 7.6 \\
\hline $17 / 08 / 1999$ & 00:01:40 & $\mathrm{TU}$ & 17 & 7.6 \\
\hline $17 / 08 / 1999$ & 00:01:40 & $\mathrm{TU}$ & 17 & 7.6 \\
\hline 17/08/1999 & 00:01:40 & $\mathrm{TU}$ & 17 & 7.6 \\
\hline 17/08/1999 & 00:01:40 & $\mathrm{TU}$ & 17 & 7.6 \\
\hline 17/08/1999 & 00:01:40 & $\mathrm{TU}$ & 17 & 7.6 \\
\hline $17 / 08 / 1999$ & 00:01:40 & $\mathrm{TU}$ & 17 & 7.6 \\
\hline 17/08/1999 & 00:01:40 & $\mathrm{TU}$ & 17 & 7.6 \\
\hline 17/08/1999 & 00:01:40 & $\mathrm{TU}$ & 17 & 7.6 \\
\hline 17/08/1999 & 00:01:40 & $\mathrm{TU}$ & 17 & 7.6 \\
\hline $17 / 08 / 1999$ & 00:01:40 & $\mathrm{TU}$ & 17 & 7.6 \\
\hline $17 / 08 / 1999$ & 00:01:40 & $\mathrm{TU}$ & 17 & 7.6 \\
\hline $17 / 08 / 1999$ & 00:01:40 & $\mathrm{TU}$ & 17 & 7.6 \\
\hline $17 / 08 / 1999$ & 00:01:40 & $\mathrm{TU}$ & 17 & 7.6 \\
\hline 17/08/1999 & 00:01:40 & $\mathrm{TU}$ & 17 & 7.6 \\
\hline $17 / 08 / 1999$ & 00:01:40 & $\mathrm{TU}$ & 17 & 7.6 \\
\hline $17 / 08 / 1999$ & 00:01:40 & $\mathrm{TU}$ & 17 & 7.6 \\
\hline $17 / 08 / 1999$ & 00:01:40 & $\mathrm{TU}$ & 17 & 7.6 \\
\hline $19 / 08 / 1999$ & $15: 17: 45$ & $\mathrm{TU}$ & 12 & 5.1 \\
\hline 19/08/1999 & $15: 17: 45$ & $\mathrm{TU}$ & 12 & 5.1 \\
\hline 19/08/1999 & $15: 17: 45$ & $\mathrm{TU}$ & 12 & 5.1 \\
\hline $19 / 08 / 1999$ & $15: 17: 45$ & $\mathrm{TU}$ & 12 & 5.1 \\
\hline
\end{tabular}


Table 5: continued

\begin{tabular}{|c|c|c|c|c|}
\hline Date & Time (UTC) & Co. & $\begin{array}{r}h \\
(\mathrm{~km}) \\
\end{array}$ & $M_{w}$ \\
\hline $31 / 08 / 1999$ & $08: 10: 49$ & TU & 4 & 5.1 \\
\hline $31 / 08 / 1999$ & $08: 10: 49$ & $\mathrm{TU}$ & 4 & 5.1 \\
\hline $31 / 08 / 1999$ & 08:10:49 & $\mathrm{TU}$ & 4 & 5.1 \\
\hline $31 / 08 / 1999$ & $08: 10: 49$ & $\mathrm{TU}$ & 4 & 5.1 \\
\hline $31 / 08 / 1999$ & 08:10:49 & $\mathrm{TU}$ & 4 & 5.1 \\
\hline $31 / 08 / 1999$ & $08: 10: 49$ & $\mathrm{TU}$ & 4 & 5.1 \\
\hline $31 / 08 / 1999$ & $08: 10: 49$ & $\mathrm{TU}$ & 4 & 5.1 \\
\hline $31 / 08 / 1999$ & $08: 10: 49$ & $\mathrm{TU}$ & 4 & 5.1 \\
\hline $31 / 08 / 1999$ & 08:10:49 & $\mathrm{TU}$ & 4 & 5.1 \\
\hline $31 / 08 / 1999$ & 08:10:49 & $\mathrm{TU}$ & 4 & 5.1 \\
\hline $31 / 08 / 1999$ & 08:10:49 & $\mathrm{TU}$ & 4 & 5.1 \\
\hline $31 / 08 / 1999$ & 08:10:49 & $\mathrm{TU}$ & 4 & 5.1 \\
\hline $31 / 08 / 1999$ & $08: 10: 49$ & $\mathrm{TU}$ & 4 & 5.1 \\
\hline $31 / 08 / 1999$ & $08: 10: 49$ & $\mathrm{TU}$ & 4 & 5.1 \\
\hline $31 / 08 / 1999$ & $08: 10: 49$ & $\mathrm{TU}$ & 4 & 5.1 \\
\hline 07/09/1999 & $11: 56: 51$ & GR & 17 & 6.0 \\
\hline 07/09/1999 & $11: 56: 51$ & GR & 17 & 6.0 \\
\hline 07/09/1999 & $11: 56: 51$ & GR & 17 & 6.0 \\
\hline 07/09/1999 & $11: 56: 51$ & GR & 17 & 6.0 \\
\hline 07/09/1999 & $11: 56: 51$ & GR & 17 & 6.0 \\
\hline 07/09/1999 & $11: 56: 51$ & GR & 17 & 6.0 \\
\hline 07/09/1999 & $11: 56: 51$ & GR & 17 & 6.0 \\
\hline 07/09/1999 & $11: 56: 51$ & GR & 17 & 6.0 \\
\hline 07/09/1999 & $11: 56: 51$ & GR & 17 & 6.0 \\
\hline 07/09/1999 & $11: 56: 51$ & GR & 17 & 6.0 \\
\hline 07/09/1999 & $11: 56: 51$ & GR & 17 & 6.0 \\
\hline 07/09/1999 & $11: 56: 51$ & GR & 17 & 6.0 \\
\hline $13 / 09 / 1999$ & $11: 55: 30$ & $\mathrm{TU}$ & 14 & 5.8 \\
\hline $13 / 09 / 1999$ & $11: 55: 30$ & $\mathrm{TU}$ & 14 & 5.8 \\
\hline $13 / 09 / 1999$ & $11: 55: 30$ & $\mathrm{TU}$ & 14 & 5.8 \\
\hline $13 / 09 / 1999$ & $11: 55: 30$ & $\mathrm{TU}$ & 14 & 5.8 \\
\hline $13 / 09 / 1999$ & $11: 55: 30$ & $\mathrm{TU}$ & 14 & 5.8 \\
\hline $13 / 09 / 1999$ & $11: 55: 30$ & $\mathrm{TU}$ & 14 & 5.8 \\
\hline $13 / 09 / 1999$ & $11: 55: 30$ & $\mathrm{TU}$ & 14 & 5.8 \\
\hline $13 / 09 / 1999$ & $11: 55: 30$ & $\mathrm{TU}$ & 14 & 5.8 \\
\hline $13 / 09 / 1999$ & $11: 55: 30$ & $\mathrm{TU}$ & 14 & 5.8 \\
\hline $13 / 09 / 1999$ & $11: 55: 30$ & $\mathrm{TU}$ & 14 & 5.8 \\
\hline $13 / 09 / 1999$ & $11: 55: 30$ & $\mathrm{TU}$ & 14 & 5.8 \\
\hline $13 / 09 / 1999$ & $11: 55: 30$ & $\mathrm{TU}$ & 14 & 5.8 \\
\hline $13 / 09 / 1999$ & $11: 55: 30$ & $\mathrm{TU}$ & 14 & 5.8 \\
\hline $13 / 09 / 1999$ & $11: 55: 30$ & $\mathrm{TU}$ & 14 & 5.8 \\
\hline $13 / 09 / 1999$ & $11: 55: 30$ & $\mathrm{TU}$ & 14 & 5.8 \\
\hline $13 / 09 / 1999$ & $11: 55: 30$ & $\mathrm{TU}$ & 14 & 5.8 \\
\hline $13 / 09 / 1999$ & $11: 55: 30$ & $\mathrm{TU}$ & 14 & 5.8 \\
\hline $13 / 09 / 1999$ & $11: 55: 30$ & $\mathrm{TU}$ & 14 & 5.8 \\
\hline $13 / 09 / 1999$ & $11: 55: 30$ & $\mathrm{TU}$ & 14 & 5.8 \\
\hline $13 / 09 / 1999$ & $11: 55: 30$ & $\mathrm{TU}$ & 14 & 5.8 \\
\hline $13 / 09 / 1999$ & $11: 55: 30$ & $\mathrm{TU}$ & 14 & 5.8 \\
\hline $13 / 09 / 1999$ & $11: 55: 30$ & $\mathrm{TU}$ & 14 & 5.8 \\
\hline $13 / 09 / 1999$ & $11: 55: 30$ & $\mathrm{TU}$ & 14 & 5.8 \\
\hline $13 / 09 / 1999$ & $11: 55: 30$ & $\mathrm{TU}$ & 14 & 5.8 \\
\hline $13 / 09 / 1999$ & $11: 55: 30$ & $\mathrm{TU}$ & 14 & 5.8 \\
\hline $13 / 09 / 1999$ & $11: 55: 30$ & $\mathrm{TU}$ & 14 & 5.8 \\
\hline $11 / 11 / 1999$ & $14: 41: 23$ & $\mathrm{TU}$ & 8 & 5.6 \\
\hline $11 / 11 / 1999$ & $14: 41: 23$ & $\mathrm{TU}$ & 8 & 5.6 \\
\hline 11/11/1999 & $14: 41: 23$ & $\mathrm{TU}$ & 8 & 5.6 \\
\hline $11 / 11 / 1999$ & $14: 41: 23$ & $\mathrm{TU}$ & 8 & 5.6 \\
\hline $11 / 11 / 1999$ & $14: 41: 23$ & $\mathrm{TU}$ & 8 & 5.6 \\
\hline $11 / 11 / 1999$ & $14: 41: 23$ & $\mathrm{TU}$ & 8 & 5.6 \\
\hline $11 / 11 / 1999$ & $14: 41: 23$ & $\mathrm{TU}$ & 8 & 5.6 \\
\hline $11 / 11 / 1999$ & $14: 41: 23$ & $\mathrm{TU}$ & 8 & 5.6 \\
\hline $11 / 11 / 1999$ & $14: 41: 23$ & $\mathrm{TU}$ & 8 & 5.6 \\
\hline 11/11/1999 & $14: 41: 23$ & $\mathrm{TU}$ & 8 & 5.6 \\
\hline $11 / 11 / 1999$ & $14: 41: 23$ & $\mathrm{TU}$ & 8 & 5.6 \\
\hline $11 / 11 / 1999$ & $14: 41: 23$ & $\mathrm{TU}$ & 8 & 5.6 \\
\hline $12 / 11 / 1999$ & $16: 57: 20$ & $\mathrm{TU}$ & 14 & 7.2 \\
\hline $12 / 11 / 1999$ & $16: 57: 20$ & $\mathrm{TU}$ & 14 & 7.2 \\
\hline $12 / 11 / 1999$ & $16: 57: 20$ & $\mathrm{TU}$ & 14 & 7.2 \\
\hline $12 / 11 / 1999$ & $16: 57: 20$ & $\mathrm{TU}$ & 14 & 7.2 \\
\hline $12 / 11 / 1999$ & $16: 57: 20$ & $\mathrm{TU}$ & 14 & 7.2 \\
\hline $12 / 11 / 1999$ & $16: 57: 20$ & $\mathrm{TU}$ & 14 & 7.2 \\
\hline $12 / 11 / 1999$ & $16: 57: 20$ & $\mathrm{TU}$ & 14 & 7.2 \\
\hline $12 / 11 / 1999$ & $16: 57: 20$ & $\mathrm{TU}$ & 14 & 7.2 \\
\hline $12 / 11 / 1999$ & $16: 57: 20$ & $\mathrm{TU}$ & 14 & 7.2 \\
\hline $12 / 11 / 1999$ & $16: 57: 20$ & $\mathrm{TU}$ & 14 & 7.2 \\
\hline $12 / 11 / 1999$ & $16: 57: 20$ & $\mathrm{TU}$ & 14 & 7.2 \\
\hline $12 / 11 / 1999$ & $16: 57: 20$ & $\mathrm{TU}$ & 14 & 7.2 \\
\hline $12 / 11 / 1999$ & $16: 57: 20$ & $\mathrm{TU}$ & 14 & 7.2 \\
\hline $12 / 11 / 1999$ & $16: 57: 20$ & $\mathrm{TU}$ & 14 & 7.2 \\
\hline $12 / 11 / 1999$ & $16: 57: 20$ & $\mathrm{TU}$ & 14 & 7.2 \\
\hline $14 / 02 / 2000$ & $06: 56: 35$ & $\mathrm{TU}$ & 10 & 5.2 \\
\hline $14 / 02 / 2000$ & $06: 56: 35$ & $\mathrm{TU}$ & 10 & 5.2 \\
\hline $14 / 02 / 2000$ & $06: 56: 35$ & $\mathrm{TU}$ & 10 & 5.2 \\
\hline $14 / 02 / 2000$ & $06: 56: 35$ & $\mathrm{TU}$ & 10 & 5.2 \\
\hline $17 / 06 / 2000$ & $15: 40: 41$ & IC & 15 & 6.5 \\
\hline $17 / 06 / 2000$ & $15: 40: 41$ & IC & 15 & 6.5 \\
\hline $17 / 06 / 2000$ & $15: 40: 41$ & IC & 15 & 6.5 \\
\hline $17 / 06 / 2000$ & $15: 40: 41$ & IC & 15 & 6.5 \\
\hline $17 / 06 / 2000$ & $15: 40: 41$ & IC & 15 & 6.5 \\
\hline $17 / 06 / 2000$ & $15: 40: 41$ & IC & 15 & 6.5 \\
\hline $17 / 06 / 2000$ & $15: 40: 41$ & IC & 15 & 6.5 \\
\hline $17 / 06 / 2000$ & $15: 40: 41$ & IC & 15 & 6.5 \\
\hline $17 / 06 / 2000$ & $15: 40: 41$ & IC & 15 & 6.5 \\
\hline
\end{tabular}


Table 5: continued

\begin{tabular}{|c|c|c|c|c|c|c|c|c|c|}
\hline Date & Time (UTC) & Co. & $\begin{array}{r}h \\
(\mathrm{~km})\end{array}$ & $M_{w}$ & Mech. & Station & Co. & Site & $\begin{array}{r}d \\
(\mathrm{~km})\end{array}$ \\
\hline $17 / 06 / 2000$ & $15: 40: 41$ & IC & 15 & 6.5 & $\mathrm{~S}$ & Selfoss-City Hall & IC & $\mathrm{R}$ & 31 \\
\hline $17 / 06 / 2000$ & $15: 40: 41$ & IC & 15 & 6.5 & $\mathrm{~s}$ & Irafoss-Hydroelectric Power Station & IC & $\mathrm{R}$ & 32 \\
\hline $17 / 06 / 2000$ & $15: 40: 41$ & IC & 15 & 6.5 & $\mathrm{~s}$ & Ljosafoss-Hydroelectric Power Station & IC & $\mathrm{R}$ & 32 \\
\hline $17 / 06 / 2000$ & $15: 40: 41$ & IC & 15 & 6.5 & $\mathrm{~s}$ & Sultartanga-Hydroelectric Power Station & IC & $\mathrm{R}$ & 38 \\
\hline $17 / 06 / 2000$ & $15: 40: 41$ & IC & 15 & 6.5 & $\mathrm{~s}$ & Hveragerdi-Retirement House & IC & $\mathrm{R}$ & 40 \\
\hline $17 / 06 / 2000$ & $15: 40: 41$ & IC & 15 & 6.5 & $\mathrm{~s}$ & Hveragerdi-Church & IC & $\mathrm{R}$ & 40 \\
\hline $17 / 06 / 2000$ & $15: 40: 41$ & IC & 15 & 6.5 & $\mathrm{~s}$ & Sultartangastifla & IC & $\mathrm{R}$ & 41 \\
\hline $17 / 06 / 2000$ & $15: 40: 41$ & IC & 15 & 6.5 & $\mathrm{~s}$ & Thorlakshofn & IC & A & 50 \\
\hline $17 / 06 / 2000$ & $15: 40: 41$ & IC & 15 & 6.5 & $\mathrm{~s}$ & Hrauneyjafoss-Hydroelectric Power Station & IC & $\mathrm{R}$ & 56 \\
\hline $17 / 06 / 2000$ & $15: 40: 41$ & IC & 15 & 6.5 & $\mathrm{~s}$ & Sigolduvirkjun-Hydroelectric Power Station & IC & $\mathrm{R}$ & 61 \\
\hline $17 / 06 / 2000$ & $15: 40: 41$ & IC & 15 & 6.5 & $\mathrm{~s}$ & Sigoldustifla & IC & A & 62 \\
\hline $17 / 06 / 2000$ & $15: 40: 41$ & IC & 15 & 6.5 & $\mathrm{~s}$ & Reykjavik-Heidmork (Jadar) & IC & $\mathrm{R}$ & 68 \\
\hline $17 / 06 / 2000$ & $15: 40: 41$ & IC & 15 & 6.5 & $\mathrm{~s}$ & Reykjavik-Foldaskoli & IC & $\mathrm{R}$ & 70 \\
\hline $17 / 06 / 2000$ & $15: 40: 41$ & IC & 15 & 6.5 & $\mathrm{~s}$ & Reykjavik-Hus Verslunarinnar & IC & $\mathrm{R}$ & 76 \\
\hline $17 / 06 / 2000$ & $15: 40: 41$ & IC & 15 & 6.5 & $\mathrm{~s}$ & Reykjavik-University (VR-II) & IC & $\mathrm{R}$ & 78 \\
\hline $21 / 06 / 2000$ & $00: 51: 48$ & IC & & 6.4 & $\mathrm{~s}$ & Thjorsarbru & IC & $\mathrm{R}$ & 2 \\
\hline $21 / 06 / 2000$ & $00: 51: 48$ & IC & & 6.4 & $\mathrm{~s}$ & Thjorsartun & IC & $\mathrm{R}$ & 3 \\
\hline $21 / 06 / 2000$ & $00: 51: 48$ & IC & & 6.4 & $\mathrm{~s}$ & Solheimar & IC & A & 4 \\
\hline $21 / 06 / 2000$ & $00: 51: 48$ & IC & & 6.4 & $\mathrm{~s}$ & Kaldarholt & IC & A & 12 \\
\hline $21 / 06 / 2000$ & $00: 51: 48$ & IC & & 6.4 & $\mathrm{~s}$ & Selfoss-Hospital & IC & $\mathrm{R}$ & 14 \\
\hline $21 / 06 / 2000$ & 00:51:48 & IC & & 6.4 & $\mathrm{~s}$ & Selfoss-City Hall & IC & $\mathrm{R}$ & 14 \\
\hline $21 / 06 / 2000$ & 00:51:48 & IC & & 6.4 & $\mathrm{~s}$ & Irafoss-Hydroelectric Power Station & IC & $\mathrm{R}$ & 14 \\
\hline $21 / 06 / 2000$ & $00: 51: 48$ & IC & & 6.4 & $\mathrm{~s}$ & Ljosafoss-Hydroelectric Power Station & IC & $\mathrm{R}$ & 15 \\
\hline $21 / 06 / 2000$ & $00: 51: 48$ & IC & & 6.4 & $\mathrm{~s}$ & Hella & IC & A & 16 \\
\hline $21 / 06 / 2000$ & $00: 51: 48$ & IC & & 6.4 & $\mathrm{~s}$ & Flagbjarnarholt & IC & $\mathrm{R}$ & 22 \\
\hline $21 / 06 / 2000$ & $00: 51: 48$ & IC & & 6.4 & $\mathrm{~s}$ & Hveragerdi-Retirement House & IC & $\mathrm{R}$ & 23 \\
\hline $21 / 06 / 2000$ & 00:51:48 & IC & & 6.4 & $\mathrm{~s}$ & Hveragerdi-Church & IC & $\mathrm{R}$ & 23 \\
\hline $21 / 06 / 2000$ & 00:51:48 & IC & & 6.4 & $\mathrm{~s}$ & Minni-Nupur & IC & $\mathrm{R}$ & 27 \\
\hline $21 / 06 / 2000$ & 00:51:48 & IC & & 6.4 & $\mathrm{~s}$ & Thorlakshofn & IC & A & 33 \\
\hline $21 / 06 / 2000$ & $00: 51: 48$ & IC & & 6.4 & $\mathrm{~s}$ & Burfell-Hydroelectric Power Station & IC & $\mathrm{R}$ & 43 \\
\hline $21 / 06 / 2000$ & $00: 51: 48$ & IC & & 6.4 & $\mathrm{~s}$ & Reykjavik-Heidmork (Jadar) & IC & $\mathrm{R}$ & 51 \\
\hline $21 / 06 / 2000$ & 00:51:48 & IC & & 6.4 & $\mathrm{~s}$ & Reykjavik-Foldaskoli & IC & $\mathrm{R}$ & 53 \\
\hline $21 / 06 / 2000$ & 00:51:48 & IC & & 6.4 & $\mathrm{~s}$ & Sultartanga-Hydroelectric Power Station & IC & $\mathrm{R}$ & 55 \\
\hline $21 / 06 / 2000$ & 00:51:48 & IC & & 6.4 & $\mathrm{~s}$ & Sultartangastifla & IC & $\mathrm{R}$ & 57 \\
\hline $21 / 06 / 2000$ & 00:51:48 & IC & & 6.4 & $\mathrm{~s}$ & Reykjavik-Hus Verslunarinnar & IC & $\mathrm{R}$ & 58 \\
\hline $21 / 06 / 2000$ & $00: 51: 48$ & IC & & 6.4 & $\mathrm{~s}$ & Hrauneyjafoss-Hydroelectric Power Station & IC & $\mathrm{R}$ & 73 \\
\hline $21 / 06 / 2000$ & 00:51:48 & IC & & 6.4 & $\mathrm{~s}$ & Sigolduvirkjun-Hydroelectric Power Station & IC & $\mathrm{R}$ & 78 \\
\hline $21 / 06 / 2000$ & 00:51:48 & IC & & 6.4 & $\mathrm{~s}$ & Sigoldustifla & IC & A & 79 \\
\hline $01 / 08 / 2000$ & 04:35:46 & PO & 13 & 5.1 & $\mathrm{~s}$ & Horta & $\mathrm{PO}$ & $\mathrm{s}$ & 39 \\
\hline $23 / 08 / 2000$ & $13: 41: 28$ & $\mathrm{TU}$ & 15 & 5.5 & $\mathrm{~S}$ & Düzce-Meteoroloji Mudurlugu & TU & $\mathrm{s}$ & 41 \\
\hline $25 / 06 / 2001$ & $13: 28: 46$ & $\mathrm{TU}$ & 5 & 5.4 & $\mathrm{O}$ & Andirin-Tufanpassa Ilkokulu & $\mathrm{TU}$ & $\mathrm{R}$ & 40 \\
\hline $25 / 06 / 2001$ & $13: 28: 46$ & $\mathrm{TU}$ & 5 & 5.4 & $\mathrm{O}$ & Kahramanmaras-Bayindirlik Mudurlugu & $\mathrm{TU}$ & A & 72 \\
\hline $16 / 09 / 2001$ & 02:00:46 & GR & 7 & 5.4 & $\mathrm{~N}$ & Kernitsa & GR & A & 99 \\
\hline 03/02/2002 & 07:11:28 & $\mathrm{TU}$ & 5 & 6.5 & $\mathrm{~N}$ & Afyon-Bayindirlik ve Iskan Mudurlugu & TU & $\mathrm{S}$ & 66 \\
\hline 03/02/2002 & 09:26:43 & $\mathrm{TU}$ & 10 & 5.8 & $\mathrm{~N}$ & Afyon-Bayindirlik ve Iskan Mudurlugu & TU & $\mathrm{s}$ & 35 \\
\hline $22 / 06 / 2002$ & $02: 58: 21$ & IR & 10 & 6.5 & $\mathrm{~T}$ & Avaj (Bakhshdari) & IR & $\mathrm{R}$ & 28 \\
\hline $22 / 06 / 2002$ & $02: 58: 21$ & IR & 10 & 6.5 & $\mathrm{~T}$ & Abhar & IR & $\mathrm{s}$ & 53 \\
\hline $27 / 01 / 2003$ & $05: 26: 23$ & $\mathrm{TU}$ & 10 & 6.0 & $\mathrm{~s}$ & Tercan-Meteoroji Mudurlugu & $\mathrm{TU}$ & A & 53 \\
\hline $27 / 01 / 2003$ & $05: 26: 23$ & $\mathrm{TU}$ & 10 & 6.0 & $\mathrm{~s}$ & Bingol-Bayindirlik Murlugu & $\mathrm{TU}$ & $\mathrm{R}$ & 87 \\
\hline $10 / 04 / 2003$ & 00:40:14 & TU & 10 & 5.7 & $\mathrm{O}$ & Bornova-Eylul Universite Ziraat Fakultesi & $\mathrm{TU}$ & $\mathrm{s}$ & 42 \\
\hline $01 / 05 / 2003$ & 00:27:04 & TU & 10 & 6.3 & $\mathrm{~s}$ & Bingol-Bayindirlik Murlugu & $\mathrm{TU}$ & $\mathrm{R}$ & 14 \\
\hline
\end{tabular}

